\title{
Molecular and cellular pathways associated with chromosome Ip deletions during colon carcinogenesis
}

\author{
Claire M Payne \\ Cheray Crowley-Skillicorn \\ Carol Bernstein \\ Hana Holubec \\ Harris Bernstein \\ Department of Cell Biology \\ and Anatomy, College of Medicine, \\ University of Arizona Tucson, AZ, USA
}

Correspondence: Claire M Payne Department of Cell Biology and Anatomy, College of Medicine, University of Arizona, Tucson, Arizona 85724-5044

Email bmdiagnostics@cox.net
This article was published in the following Dove Press journal:

Clinical and Experimental Gastroenterology

3 May 201I

Number of times this article has been viewed

\begin{abstract}
Chromosomal instability is a major pathway of sporadic colon carcinogenesis. Chromosome arm 1p appears to be one of the "hot spots" in the non-neoplastic mucosa that, when deleted, is associated with the initiation of carcinogenesis. Chromosome arm 1p contains genes associated with DNA repair, spindle checkpoint function, apoptosis, multiple microRNAs, the Wnt signaling pathway, tumor suppression, antioxidant activities, and defense against environmental toxins. Loss of $1 p$ is dangerous since it would likely contribute to genomic instability leading to tumorigenesis. The $1 \mathrm{p}$ deletion-associated colon carcinogenesis pathways are reviewed at the molecular and cellular levels. Sporadic colon cancer is strongly linked to a high-fat/low-vegetable/low-micronutrient, Western-style diet. We also consider how selected dietary-related compounds (eg, excess hydrophobic bile acids, and low levels of folic acid, niacin, plant-derived antioxidants, and other modulatory compounds) might affect processes leading to chromosomal deletions, and to the molecular and cellular pathways specifically altered by chromosome 1p loss.
\end{abstract}

Keywords: chromosome 1p, colon carcinogenesis, molecular pathways, cellular pathways

\section{Introduction}

Chromosomal instability is a major feature of sporadic colon carcinogenesis. ${ }^{1-11}$ Eighty-five percent of colorectal cancers are aneuploid, the remaining $15 \%$ being diploid. ${ }^{5}$ Chromosome $1 \mathrm{p}$ deletions in colon tumors have been reported by laboratories from at least 15 countries around the world. ${ }^{12-49}$ Chromosome $1 \mathrm{p}$ deletions occur at an early stage of colon carcinogenesis, ${ }^{21,24,26-28,30,31,33,37,39,41-45}$ and are strongly linked to karyotypic evolution during colon cancer development. ${ }^{43}$

Many reports in the literature indicate that the macroscopically normal mucosa proximal or distal to a colon cancer exhibit aneuploidy (loss or gain of chromosomes or parts of chromosomes). Relevant to this review, Cianciulla et $\mathrm{al}^{44}$ reported that deletions of chromosome $1 \mathrm{p}$ were simultaneously found in both the distant normal-appearing mucosa of $76 \%$ of patients who also harbored $1 \mathrm{p}$ deletions in their cancer. These findings indicate that the loss of chromosome 1p may be one of the "hot spots" among the numerous defects in the non-neoplastic mucosa associated with the possible initiation of colon carcinogenesis. ${ }^{50-70}$

The pioneering work of Paraskeva et $\mathrm{al}^{71-75}$ indicated the likely involvement of chromosome $1 \mathrm{p}$ loss in in vitro immortalization ${ }^{72,74}$ and in the progression of adenomas to carcinomas. ${ }^{75}$ The functional importance of loss of distal $1 \mathrm{p}$ in colon tumorigenesis was demonstrated in 1993 by Tanaka et $\mathrm{al}^{76}$ who introduced 
chromosomal band 1p36 into colon carcinoma cells and found that their tumorigenicity was suppressed.

Chromosome $1 \mathrm{p}$ deletions can affect distinct pathways of sporadic colon carcinogenesis, including both chromosomal instability and chromosomal instability-negative pathways. The underlying mechanisms associated with the loss of chromosome $1 \mathrm{p}$ that may contribute to genomic instabilty and drive colon carcinogenesis are loss of genes associated with DNA repair, spindle checkpoint function, apoptosis, multiple microRNAs (miRNAs), the Wnt signaling pathway, tumor suppression, antioxidant activities, and defense against environmental toxins. ${ }^{77,78}$ Since centromeric instability and resulting telomeric fusions have been proposed as a mechanism for the loss of chromosome $1 \mathrm{p},{ }^{79}$ the loss of genes located on chromosome $1 \mathrm{p}$ that function to ensure centromeric stability and telomere integrity, in turn, can exacerbate chromosomal instability throughout the genome. These $1 \mathrm{p}$ deletionassociated pathways that may lead to colon carcinogenesis will be reviewed at the molecular and cellular levels, and dietary factors that affect these pathways (eg, excess hydrophobic bile acids, and low levels of folic acid, niacin, plantderived antioxidants, and other modulatory compounds) will be explored. It is likely that certain dietary factors prevent, initiate, or exacerbate genomic instability in colon epithelial cells and thus have importance for colon carcinogenesis.

\section{Mechanisms of carcinogenesis associated with the loss of key genes on chromosome I p}

Chromosome 1, the longest human chromosome, is genedense with 3141 genes. ${ }^{80}$ The genes located on chromosome 1 were identified with the assistance of the Weizmann Institute of Science websites:

GeneLoc (www.genecards.weizmann.ac.il/geneloc/index. shtml) and GeneCards - The Human Gene Compendium (www.genecards.org). Genes located on the $p$ arm of chromosome 1 that are associated with protection against oxidative stress, DNA damage, mitotic perturbations, excessive cellular proliferation, development of apoptosis resistance, aberrant colonic cell differentiation, and environmental toxicity have been tabulated and the function of the gene products described (Tables 1-8). Since many of these genes have tumor suppressive capabilities, the simultaneous loss caused by a $1 \mathrm{p}$ deletion could initiate the formation of neoplastic clones and enhance tumorigenesis through Darwinian selection. ${ }^{8}$

\section{Mechanisms protective against genomic instability}

Cells with DNA damage, spindle damage, and dysfunctional telomeres signal DNA damage responses. ${ }^{81-84}$ These DNA damage responses include the activation of numerous checkpoints that arrest the damaged cells in the G1, S, G2, or M-phase of the cell cycle, depending upon the nature of the damage or dysfunction and the stage of the cell cycle of the target cell. DNA-damage checkpoints are activated following direct damage to DNA..$^{85-91}$ Spindle assembly checkpoints are activated following damage to the mitotic machinery, ${ }^{85,92-98}$ or as a result of DNA damage during mitosis. ${ }^{99}$ Telomere checkpoints are activated by defective telomeres. ${ }^{100-106}$ These checkpoints prevent the damaged cell from completing DNA replication and mitosis until all damage is repaired (Figure 1), and thus prevent 1) mutations that could be formed by replicating a damaged DNA template, 2) aneuploidy that could result from chromosome mis-segregation, and 3) telomere fusions that result in anaphase bridges, broken chromosomes, and translocations as a consequence of the well-known breakage-fusion-bridge cycles. ${ }^{107-114}$

However, cells with excessive direct DNA damage, ${ }^{115-122}$ massive chromosome loss or chromosomal imbalances, ${ }^{123}$ prolonged activation or inhibition of the spindle checkpoint pathways, ${ }^{122-127}$ or excessively shortened or dysfunctional telomeres, ${ }^{128-140}$ initiate a cascade of molecular events that ultimately leads to either caspase-dependent cell death, ${ }^{141-143}$ caspase-independent cell death, ${ }^{144}$ or a special form of apoptosis referred to as mitotic catastrophe ${ }^{145-148}$ (Figure 2). (Brightfield micrographs are shown in Figure 3 illustrating the cellular alterations that accompany apoptosis [Figure 3A], mitotic perturbation [Figure 3B], mitotic catastrophe [Figure 3C], and micronuclei formation [associated with aneuploidy] [Figure 3D]). The cell-destructive and cellprotective pathways are downstream of a common signal transduction network that responds to DNA damage. ${ }^{149}$ The repair/survival and non-repair/cell death pathways are probably activated simultaneously. ${ }^{149}$ The repair, checkpoint, and cell death response to DNA damage are, however, well co-ordinated, ${ }^{150}$ the interplay of positive and negative regulatory loops resulting in a delayed death response to DNA damage. ${ }^{149}$

\section{DNA repair and the DNA damage response (DDR) (Table I)}

The genes on chromosome $1 \mathrm{p}$ associated with DNA repair or the DNA damage response (DDR) include CLSN, DCLRE1B (APOLLO), DDI2, GADD45 $\alpha$, MSH4, MUTYH, 
Table I DNA repair and DNA damage response genes

\begin{tabular}{ll}
\hline Gene & Function \\
\hline CLSN & Claspin homolog (Xenopus laevis); upstream regulator of checkpoint kinase I (ChkI) and triggers checkpoint arrest of \\
& the cell in response to inhibition of DNA replication or to DNA damage induced by ionizing and UV radiation; binds \\
& specifically to BRCAI and ChkI and facilitates the ATR-dependent phosphorylation of both proteins; ChkI is required to \\
& maintain Claspin stability; ring-shaped DNA-binding protein with high affinity for branched DNA structures and associates \\
& with S-phase chromatin following formation of the pre-replication complex; acts as a sensor which monitors the integrity \\
& of DNA replication forks.
\end{tabular}

DCLREIB DNA cross-link repair IB (PSO2 homolog, S. cerevisiae); aliases: APOLLO, SNMIB; one of several evolutionarily conserved genes involved in the repair of interstrand cross-links which prevent strand separation, thereby blocking transcription, replication, and segregation of DNA; functions in the HSP70-mediated DNA damage response; APOLLO is stabilized when bound to the telomere-binding protein TRF2, and protects human telomeres in S phase; reduced levels result in an increased number of telomere-induced DNA damage foci and telomeric fusions in S-phase, suggesting that APOLLO contributes to a processing step associated with the replication of chromosome ends; interacts with astrin (microtubule binding protein) and is required for the prophase cell cycle checkpoint in response to spindle stress.

DDI2 DNA-damage inducible I homolog 2 (S. cerevisiae); protein has aspartic-type endopeptidase activity; very little is known as to the function of this gene product in the DNA damage response.

GADD $45 \alpha \quad$ Growth arrest and DNA-damage-inducible 45 alpha; multifunctional protein; responds to environmental stresses by mediating activation of the $\mathrm{p} 38 / \mathrm{JNK}$ pathway via MTKI/MEKK4 kinase; the DNA damage-induced transcription of this gene is mediated by $\mathrm{p} 53$-dependent and -independent mechanisms; exhibits checkpoint function in response to oxidative DNA damage; responsive to $\mathrm{p} 53$ and modifies DNA accessibility on damaged chromatin; involved in base excision repair; stimulates DNA excision repair and inhibits entry of cells into $S$ phase; level of expression modulated by glutathione peroxidase-I and quercetin; deficiency associated with multidrug resistance; interacts with Aurora-A and inhibits its kinase activity; mediator of CD437-induced apoptosis; demethylation of 5' CpG island in GADD45 $\alpha$ leads to apoptosis; increased expression arrests the cell cycle at the G2/M phase; GADD45 $\alpha$-mediated apoptosis is activated by DNA mismatch repair; induces Bim dissociation from the cytoskeleton and translocation to mitochondria; regulates beta-catenin distribution and maintains cell-cell adhesion.

MSH4 MutS homolog 4 (E. coli); multifunctional protein; physically interacts with MSH5, MLHI, MLH3, RAD5I, DMCI, and von Hippel-Lindau tumor suppressor-binding protein I during meiosis; required for reciprocal recombination and proper segregation of homologous chromosomes at meiosis; ATP binding by MSH4-MSH5 results in the formation of a sliding clamp that dissociates from the Holliday Junction crossover region embracing 2 duplex DNA arms; evidence is lacking at present for functional involvement of MSH4 and MSH5 in mismatch repair; in addition to meiosis, MSH4 and MSH5 are thought to play roles in mitotic DNA double strand break repair and the DNA damage response in human cells.

MUTYH MutY homolog (E. coli); DNA glycosylase involved in oxidative DNA damage repair; the enzyme excises adenine bases from the DNA backbone where adenine is inappropriately paired with guanine, cytosine, or 8-oxo-deoxyguanosine (a major DNA lesion caused by oxidative stress); mutations in this gene result in heritable predisposition to colon and stomach cancer; the protein is localized to the nucleus and the mitochondria; excessive activity of MUTYH in response to oxidative DNA damage results in cell death. See text and Figure 4 for an in-depth discussion of the functions of MUTYH in base excision repair and cell death.

RAD54L RAD54-like (S. cerevisiae); aliases: HR54, hRAD54, RAD54A. DNA repair and recombination protein RAD54-like; protein product is a double-stranded DNA-dependent ATPase belonging to the DEAD-like helicase superfamily (Swi2/Snf2 protein family), and shares similarity with Saccharomyces cerevisiae Rad54, a protein involved in the repair of DNA double-strand breaks through homologous recombination; belongs to the RAD52 epistasis group that additionally includes RAD50, RAD5I, RAD52, RAD55, RAD57, RAD59, MREII, and Nbs I/XRS2; the binding of Rad54 to double-stranded DNA utilizes the energy from ATP hydrolysis to induce topological changes in DNA, believed to facilitate homologous DNA pairing and stimulate DNA recombination in the Rad52 DNA repair pathway; essential for strand invasion of the homologous donor sequence and may involve disruption or movement of nucleosomes (chromatin remodeling activity) that might block joint molecule formation and/or branch migration; dissociates Rad5 I from nucleoprotein filaments formed on single-stranded DNA; Rad54 oligomers (dimer to particles $>40 \mathrm{~nm}$ in diameter) possess a unique ability to cross-bridge or bind double-stranded DNA molecules positioned in close proximity. The combination of the cross-bridging and double-strand DNA translocation activities of Rad54 stimulates the formation of DNA networks, leading to rapid and efficient DNA strand exchange by Rad5I; also plays an essential role in telomere length maintenance and telomere capping in mammalian cells through the Rad5I recombination pathway.

TP73 Tumor protein 73 ; member of the $\mathrm{p} 53$ family of transcription factors involved in cellular responses to stress; the family members include $p 53, p 63$, and p73 which have high sequence similarity to each other allowing $p 63$ and $p 73$ to transactivate $\mathrm{p} 53$-responsive genes causing cell cycle arrest and apoptosis; regulated by tyrosine kinase c-Abl in the apoptotic response to DNA damage; induces apoptosis via PUMA transactivation and Bax mitochondrial translocation; inactivated by human papillomavirus $\mathrm{E} 6$ proteins; has a role in mitotic exit and caspase-independent cell death; regulates DRAM-independent autophagy that does not contribute to programmed cell death; has a role in E2FI-induced apoptosis; may be a tumor suppressor protein. 
Table 2 Mitosis-related and spindle checkpoint genes

\begin{tabular}{ll}
\hline Gene & Protein function \\
\hline APITDI & Apoptosis-inducing, TAF9-like domain I; centromere protein and component of the CENPA-CAD complex found at the \\
distal nucleosome; this complex is recruited to centromeres where it is involved in the assembly of kinetochore proteins, \\
mitotic progression and chromosome segregation; has a role in apoptosis.
\end{tabular}

AURKAIPI Aurora kinase A interacting protein I; functions as a negative regulator of AURKA by degrading AURKA through several mechanisms involving the proteasomal pathway and ubiquitin-independent pathways involving antizyme I; the inhibition of Aurora A has the effect of canceling the mitotic delay that occurs as a result of perturbation of cellular microtubules.

CCDC28B

CCNL2 Coiled-coil domain containing 28B; localizes to centrosomes and basal bodies.

Cyclin L2; a novel RNA polymerase II-associated cyclin located in nuclear speckles; transcriptional regulator involved in regulating the pre-mRNA splicing process; contains a RS region (arginine-serine dipeptide repeat) within the C-terminal domain which is the hallmark of the SR family of splicing factors; co-localizes with splicing factors; pro-apoptotic protein which modulates the expression of a critical apoptotic factor, leading to apoptosis.

CDC2LI Cell division cycle 2-like I (PITSLRE proteins); aliases: CDKI IB, p58CDC2LI, galactosyl transferase-associated protein kinase p58/GTA; a member of the p34Cdc2 protein kinase family known to be essential for eukaryotic cell cycle control; has multiple roles in cell cycle progression, cytokinesis, and apoptosis; during Fas or tumor necrosis factor-induced apoptosis, CDKII pIIO isoforms are cleaved by caspases.

CDC2L2 Cell division cycle 2-like 2 (PITSLRE proteins); aliases: CDKI IA, PITSLRE protein kinase beta; this gene encodes a member of the $\mathrm{P} 34 \mathrm{Cdc} 2$ protein kinase family and is in close proximity to CDC2LI, a nearly identical gene in the same chromosomal region; has multiple roles in cell cycle progression, cytokinesis (maintains sister chromatid cohesion) and apoptosis.

CDC7 Cell division cycle 7 homolog (S. cerevisiae); kinase activity of CDC7 is critical for the GI/S transition of the cell cycle; functions in replication stress and mediates Claspin phosphorylation in DNA replication checkpoint control.

CDCI4A CDCI4 cell division cycle 14 homolog A (S. cerevisiae); alias: dual specificity protein phosphatase CDCI4A; required for centrosome separation, chromosome segregation and subsequent cytokinesis during cell division; phosphorylates the APC (anaphase-promoting complex) subunit FZRI/CDHI, thereby promoting APC-FZRI-dependent degradation of mitotic cyclins and subsequent exit from mitosis; interacts with and dephosphorylates tumor suppressor protein $\mathrm{p} 53$, thereby regulating $\mathrm{P} 53$ function; interacts with KIF20A to localize CDCI4 to the midzone of the mitotic spindle.

CDC20 Cell division cycle 20 homolog (S. cerevisiae); acts as a regulatory protein by interacting with several proteins at multiple points in the cell cycle; required for 2 microtubule-dependent processes, nuclear movement prior to anaphase and chromosome separation; required for full ubiquitin ligase activity of the APC; regulated by MAD2LI resulting in an inactive ternary complex (MAD2LI-CDC20-APC) in metaphase; in anaphase the binary complex (CDC20-APC) is active in degrading its targeted substrates.

CDC42 Cell division cycle 42; 25 kDa GTP binding protein; small GTPase of the Rho-subfamily which regulates multiple signaling pathways including cell cycle progression GI to S; controls spindle orientation of adherent cells; antagonistic cross-talk between Rac and Cdc42 GTPases regulates generation of reactive oxygen species; Cdc42 is a substrate for caspases and influences Fas-induced apoptosis.

CDCA8 Cell division cycle associated 8; alias: BOREALIN; component of a chromosomal passenger complex (CPC) required for stability of the bipolar mitotic spindle; The CPC consists of survivin, CDCA8, INCENP, and Aurora-B; the CPC functions at the centromere to ensure correct chromosome alignment and segregation; CDCA8 is required for chromatin-induced microtubule stabilization and spindle assembly; CDCA8 may be required to direct the CPC to centromeric DNA; major effector of the TTK kinase in the control of "attachment-error-correction" and chromosome alignment.

CDKN2C Cyclin-dependent kinase inhibitor 2C; alias: p-I8-INK4C; this protein is a member of the INK family of cyclin-dependent kinase inhibitors; interacts strongly with CDK6 and weakly with CDK4 and prevents the activation of the CDK kinases; inhibits cell growth and proliferation in the presence of retinoblastoma protein I (RBI) and acts as a tumor suppressor.

CROCC Ciliary rootlet coiled-coil protein; aliases: rootletin, TaxI-binding protein 2, ROLT; major structural component of the ciliary rootlet; forms centriole-associated filaments and contributes to centrosome cohesion before mitosis; recombinant rootletin forms detergent-insoluble filaments radiating from the centrioles; the homopolymeric rootletin protofilaments bundle into variably shaped thick filaments; interacts with C-NapI and may function in centrosome cohesion by acting as a physical linker between the pair of centrioles/basal bodies; ciliary rootlet interacts with kinesin light chains and may provide a scaffold for kinesin-I vesicular cargos; rootletin is phosphorylated by Nek2 kinase and is displaced from the centrosomes at the onset of mitosis, resulting in the binding of beta-catenin to rootletin-independent sites on centrosomes (an event that is required for centrosome separation); overexpression of rootletin in cells results in the formation of extensive fibers resulting in multinucleation, micronucleation and irregularity of nuclear shape and size, indicative of defects in chromosome separation. E2F transcription factor 2: member of the E2F family of transcription factors; transcription activator that binds DNA cooperatively with DP (differentiation regulated transcription factor proteins) through the E2 recognition site, $5^{\prime}$-TTTC[CG]CGC-3', found in the promoter region of a number of genes whose products are involved in cell cycle regulation 
Table 2 (Continued)

Gene Protein function

or in DNA replication; the E2F family plays a crucial role in the control of the cell cycle and action of tumor suppressor proteins (eg, pl4 (ARF); binds specifically to unphosphorylated retinoblastoma protein PRB in G0/GI, leading to the repression of E2F target genes; subsequent phosphorylation of $\mathrm{PRB}$ by cyclin-dependent kinases in late $\mathrm{GI}$ inactivates $\mathrm{PRB}$, liberating free $\mathrm{E} 2 \mathrm{~F}$, which then functions to activate the expression of target genes required for S-phase entry and cell cycle progression; although E2FI-3 transcription factors were classified as positive regulators of the cell cycle (E2F activators), they also cause transcriptional repression, indicating that their specific effects may be cell type-specific; represses the expression of survivin, a dual mediator of apoptosis resistance and cell cycle progression; can function as a tumor suppressor in epithelial tissues, perhaps by limiting proliferation in response to Myc; hemizygosity of the E2F2 locus is sufficient to increase tumor incidence in the Myc-transgenic mouse model of tumorigenesis in the skin and oral cavity.

HDACI Histone deacetylase I: in addition to effects on gene expression, histone deacetylase activity plays an important role in regulating the assembly of kinetochores, the activation of the mitotic checkpoint and the process of cytokinesis; decreased activity or aberrant control of HDAC activity can result in altered kinetochore assembly by disrupting pericentromeric heterochromatin, failure of appropriate chromosome segregation, and defects in the mitotic spindle checkpoint, resulting in mitotic slippage and chromosome instability; HDACs I, 2, and 4 are closely related $\mathrm{Zn}^{++}$-dependent enzymes; $\mathrm{HDACl}$ is part of a complex that binds to the promoter of TBP-2 (thioredoxin binding protein-2), resulting in repression of TBP-2 transcription, increasing the activity of thioredoxin and protecting cells against oxidative stress.

KIFIB Kinesin family member IB; motor protein that transports mitochondria and synaptic vesicle precursors; involved in the movement of chromosomes during mitosis; functions as a haploinsufficient tumor suppressor by inducing apoptotic cell death; acts downstream of EgIN3 to induce apoptosis.

KIF2C Kinesin family member 2C; aliases: MCAK (mitotic centromere-associated kinesin); Aurora B regulates MCAK at the mitotic centromere; phosphorylated by STKI 2 and regulates the association of centromeres and kinetochores; promotes the ATP-dependent removal of tubulin dimers from microtubules in association with the process of microtubule depolymerization and turnover; functions in chromosome segregation during mitosis; contains the microtubule tip localization signal (MtLS) motif; phosphorylated after DNA damage, probably by ATM or ATR.

KIFI7 Kinesin family member 17; proteins of the kinesin family are microtubule-dependent molecular motors that transport organelles within cells and move chromosomes during cell division.

MAD2L2 Mitotic arrest deficient-like 2 (yeast)-Like 2; component of the mitotic spindle assembly checkpoint that, like MAD2, may prevent the onset of anaphase until all chromosomes are properly aligned at the metaphase plate; suppression of MAD2L2 confers sensitivity to a range of DNA-damaging agents, especially a DNA cross-linker, such as cisplatin; in MAD2L2-depleted cells there is a significant decrease in the cisplatin-induced sister chromatid exchange rate, a marker for homologous recombination-mediated post-replication repair; Unlike MAD2, MAD2L2 has not been shown to have a dual-role mitotic/pro-apoptotic function; interacts with the small GTPase RAN, which may play a role in the control of the spindle checkpoint during mitosis and the regulation of nucleocytoplasmic trafficking during interphase.

PLK3 Polo-like kinase 3; aliases: FNK, PRK; multifunctional serine/threonine protein kinase involved in stress response pathways; required for entry into $S$ phase; regulates the $M$ phase of the cell cycle; activated by genotoxic stress, through a Chk3mediated priming phosphorylation followed by an ATM-mediated full activation; functions as a centrosome localization signal, overexpression of which causes mitotic arrest, cytokinesis defects, and apoptosis; involved in checkpoint-mediated cell cycle arrest to ensure genetic stability; links DNA damage to cell cycle arrest and apoptosis, in part through the p53 pathway; may also be part of the signaling network that controls cellular adhesion.

$\mathrm{PSRCI} \quad$ Proline/serine-rich coiled-coil I; alias: DDA3; functions as a microtubule destabilizing protein that controls spindle dynamics and mitotic progression by recruiting and regulating microtubule depolymerases; the $\mathrm{N}$-terminal domain of PSRCI regulates the spindle association of the microtubule depolymerase Kif2a and controls the mitotic function of PSRCI; regulated by p53 and may participate in p53-mediated growth suppression; direct transcriptional target of p53 and p73.

$\mathrm{RCCl}$ Regulator of chromosome condensation I; a protein with a 7-bladed propeller structure that is involved in the regulation of onset of chromosome condensation in S phase; binds to chromatin and promotes the exchange of Ran-bound GDP by GTP; phosphorylation of RCCl by cdc2 kinase in mitosis is essential for producing a high RanGTP concentration on chromosomes and for chromatin-induced mitotic spindle formation; perturbation of the chromosomal binding of RCCI, Mad2 and survivin causes spindle assembly defects and mitotic catastrophe; the RCCI/Ran complex, in conjunction with other proteins, acts as a component of a signal transmission pathway that detects unreplicated DNA.

RCC2 Regulator of chromosome condensation 2; alias: telophase disk protein of $60 \mathrm{kDa}$ (TD-60); has an essential role in the prometaphase to metaphase progression and required for the completion of mitosis and signaling cytokinesis; may function as a guanine nucleotide exchange factor for the small GTPase RACI; interacts with microtubules; appears in the nucleus at G2, then concentrates at the inner centromere region of chromosomes during prophase, then redistributes to the midzone of the mitotic spindle during anaphase where it covers the entire equatorial diameter from cortex to cortex; phosphorylated upon DNA damage, probably by ATM and ATR.

SASS6 Spindle assembly 6 Homolog (C. elegans); necessary for centrosome duplication and functions during procentriole formation to ensure that each centriole seeds the formation of a single procentriole per cell cycle; part of a ternary complex of SASS6, CENPJ, and CEP350. 
Table 3 Apoptosis-related genes

\begin{tabular}{|c|c|}
\hline Gene & Protein function \\
\hline BCL2LI5 & $\begin{array}{l}\text { Bcl-2-like protein } 15 \text { has a pro-apoptotic function; alias Bfk; human bfk mRNA is found in cerebellum, colon, small intestine, } \\
\text { testis, and uterus, but the protein is predominantly expressed in tissues of the gastrointestinal tract; in the transition from normal } \\
\text { human colonic mucosal tissue to tumors, } 80 \% \text { of colon tumors show a substantially reduced expression of Bfk; gene expression } \\
\text { appears to be regulated by female sex hormones. }\end{array}$ \\
\hline BCLIO & $\begin{array}{l}\text { B-cell lymphoma I0; wild-type bclI0 is a pro-apoptotic protein that suppresses cellular transformation, whereas mutant forms } \\
\text { lose this activity and display gain-of-function transforming activity; the bclI0 protein contains an amino-terminal CARD (caspase } \\
\text { recruitment domain) found in many apoptotic-related molecules; the BCLI0 gene often exhibits a frameshift mutation resulting } \\
\text { in truncation distal to the CARD; has a high mutation frequency in hepatocellular carcinoma ( } 57 \% \text { of cases); the frequency } \\
\text { of mutation in other cancers is as follows: lymphoma ( } 45 \%) \text {, colon cancers with the microsatellite mutator phenotype (I3\%), } \\
\text { mesothelioma, male germ cell tumors, adenocarcinoma cell lines (I } 2 \%) \text {, gastric cancers with the microsatellite mutator phenotype } \\
\text { (I0\%); the presence of the bcll } 0 \text { protein highly correlates with the expression of phosphorylated p65 NF-kappaB in peripheral } \\
\text { T-cell lymphomas and is associated with a better clinical outcome than bcll } 0 \text {-negative tumors. }\end{array}$ \\
\hline CASP9 & $\begin{array}{l}\text { Caspase- } 9 \text { (cysteine-aspartic acid protease, family member 9) precursor; aliases: APAF-3 (apoptotic protease-activating factor 3), } \\
\text { apoptosis-related cysteine peptidase, MCH6, ICE-LAP6, ICE-like apoptotic protease 6; caspase-9 and APAFI bind to each } \\
\text { other via their respective NH2-terminal CED-3 homologous domains in the presence of cytochrome C and ATP to form the } \\
\text { apoptosome, a high-molecular-weight complex; the caspase- } 9 \text { precursor then becomes activated, which in turn activates the } \\
\text { downstream caspases, caspase-3, and caspase-2, in response to genotoxic stress. }\end{array}$ \\
\hline DFFA & $\begin{array}{l}\text { DNA fragmentation factor, } 45 \mathrm{kD} \text {, alpha polypeptide; alias ICAD (inhibitor of caspase-activated DNase, DFFB); DFF is a } \\
\text { heterodimeric protein consisting of } 45 \mathrm{kD} \text { (DFFA) and } 40 \mathrm{kD} \text { (DFFB) subunits; DFF becomes activated when DFFA is cleaved by } \\
\text { caspase } 3 \text { and dissociates from DFFB (DFFB is the active component of DFF involved in both DNA fragmentation and chromatin } \\
\text { condensation during the process of apoptosis [see below]). }\end{array}$ \\
\hline DFFB & $\begin{array}{l}\text { DNA fragmentation factor, } 40 \mathrm{kD} \text {, beta polypeptide (caspase-activated DNase; alias CPAN; enzyme activity is inhibited by } \\
\text { DFFA; its } \mathrm{Mg}^{++} \text {-dependent endnuclease activity degrades DNA and induces DNA fragmentation; the fragmented DNA results } \\
\text { in chromatin condensation during apoptosis, and is responsible for the typical crescents and margination of chromatin that are } \\
\text { characteristic morphological features of the nucleus during apoptosis. }\end{array}$ \\
\hline THAP3 & $\begin{array}{l}\text { THAP domain containing, apoptosis-associated protein } 3 \text {; the THAP-family } \mathrm{C}(2) \mathrm{CH} \text { zinc-coordinating DNA-binding proteins } \\
\text { function in diverse eukaryotic cellular processes, including transposition, transcriptional repression, stem-cell pluripotency, } \\
\text { angiogenesis, neurological function, and apoptosis; the specific mechanism by which THAP3 contributes to apoptosis is unknown. }\end{array}$ \\
\hline TNFRSF25 & $\begin{array}{l}\text { Tumor necrosis factor receptor superfamily, member 25; aliases: death receptor 3; DR3; translocating chain-association } \\
\text { membrane protein; apoptosis inducing receptor; APO3; lymphocyte-associated receptor of death; LARD; apoptosis-mediating } \\
\text { receptor TRAMP; a death domain-containing receptor related to TNFR-I and CD95 (Apo-I/Fas); receptor for TNFSFI2/ } \\
\text { APO3L/TWEAK; interacts with the adaptor TRADD; DR3 signal transduction is mediated by a complex of intracellular signaling } \\
\text { molecules including TRADD, TRAF2, FADD, and FLICE. }\end{array}$ \\
\hline
\end{tabular}

RAD54L, and TP73. The functions of these gene products are described in Table 1. The pathways that lead to the prevention of genomic instability are diagrammatically shown in Figure 4. DNA damage elicits a well orchestrated and highly interactive series of events called the DDR, which causes cells to undergo growth arrest so that DNA damage can be adequately repaired. Although p 53 mutation or loss of heterozygosity ( $\mathrm{LOH})$ is a late event in colon carcinogenesis, ${ }^{151}$ the loss of $\mathrm{p} 73$ (found on chromosome 1p) through chromosomal deletion events may act early in colon carcinogenesis. P73 is an important isoform of the p53 family, since it performs many of the transcriptional functions of $\mathrm{p} 53$, and may even target the same genes as p53 during the DDR. In addition, TP73 has distinct transcriptional targets and harmonizes with $\mathrm{p} 53$ and $\mathrm{p} 63$ to maintain genomic stability. ${ }^{152-158}$ In addition to its role in growth arrest after DNA damage to allow DNA repair to take place, $\mathrm{p} 73$ plays an active role in spindle dynamics, mitotic exit and chromosomal stability.
The PSRC1 (proline/serine-rich coiled-coil 1) gene found on chromosome $1 \mathrm{p}$ (see Table 2 ) encodes a protein which is a direct transcriptional target of both $\mathrm{p} 53$ and $\mathrm{p} 73 .{ }^{159} \mathrm{PSRC} 1$ functions as a microtubule destabilizing protein that controls spindle dynamics and mitotic progression by recruiting and regulating microtubule depolymerases. ${ }^{160}$ Through its transcriptional activity, p73 is important for the M-to-G1 transition during mitosis. ${ }^{161}$ Functional knock-out of $\mathrm{p} 73$ gene expression by small interfering RNAs alters mitotic progression, resulting in an increase of ana-telophase cells, the accumulation of aberrant late mitotic figures, and the appearance of abnormalities in the subsequent interphase. ${ }^{161}$ This novel pathway involves the p73-mediated transcription of Kip2/ p57, a cyclin-dependent kinase inhibitor, and the coordination of mitotic exit and transition to G1. ${ }^{161,162}$ Like p53, p73 has been confirmed to be a tumor suppressor. ${ }^{163-167}$ Therefore, a loss of p 73 should have a major impact in the development of genomic instability during carcinogenesis. 
Table 4 MicroRNAs (miRNAs) and components of the miRNA processing complex

\begin{tabular}{|c|c|}
\hline MicroRNA & Function \\
\hline $30 c-1$ & A genetic variant of $30 \mathrm{c}-\mathrm{I}$ is associated with familial breast cancer in noncarriers of BRCAI/2 mutations. \\
\hline $30 \mathrm{e}$ & A functional variant of pre-miRNA-30e is strongly associated with schizophrenia. \\
\hline $34 a$ & $\begin{array}{l}\text { Major pro-apoptotic miRNA that is regulated by } \mathrm{p} 53 \text {; induced by treatment of pancreatic } \beta \text { cells with IL-I } \beta \text { and } \\
\text { TNF- } \alpha \text {, and responsible, in part, for cytokine-triggered cell death; expression frequently lost in pancreatic ductal } \\
\text { adenocarcinoma cells. }\end{array}$ \\
\hline $101-1$ & $\begin{array}{l}\text { MiR-I0I is downregulated in stage II MSS and MSI colon cancers compared to normal mucosa, hepatocellular } \\
\text { carcinoma, prostate cancer and transitional cell carcinoma of the bladder; miR-I0I inhibits cell proliferation, represses } \\
\text { the expression of the Polycomb group protein EZH2, and induces apoptosis. }\end{array}$ \\
\hline 137 & $\begin{array}{l}\text { MiR-I37 exhibits decreased levels of expression in colon tumors compared to normal mucosa; frequently upregulated } \\
\text { in rectal cancer in response to capecitabine chemoradiotherapy; changes level in reaction to xenobiotic challenge; } \\
\text { targets MITF (micropthalmia-associated transcription factor) in melanoma cell lines. }\end{array}$ \\
\hline 186 & $\begin{array}{l}\text { Expression of miR-186 significantly reduces the abundance of FOXOI, a tumor suppressor, in endometrial cancer, } \\
\text { resulting in deregulated cell cycle control and impaired apoptotic responses; downregulates expression of the } \\
\text { pro-apoptotic purinergic P2X7 receptor; dysregulated in human myocardial infarction. }\end{array}$ \\
\hline 197 & Target miRNAs not experimentally verified. \\
\hline $200 \mathrm{a}$ & $\begin{array}{l}\text { Involved in the regulation of the Wnt/ } \beta \text {-catenin signaling pathway; miRNAs-200a, }-200 \mathrm{~b} \text {, and }-429 \text { are all encoded } \\
\text { on a } 7.5 \mathrm{~kb} \text { polycistronic primary miRNA transcript. }\end{array}$ \\
\hline $200 \mathrm{~b}$ & $\begin{array}{l}\text { Involved in the regulation of the Wnt/ } \beta \text {-catenin signaling pathway; miRNAs-200a, }-200 \mathrm{~b} \text {, and }-429 \text { are all encoded } \\
\text { on a } 7.5 \mathrm{~kb} \text { polycistronic primary miRNA transcript. }\end{array}$ \\
\hline $320 \mathrm{~b}-\mathrm{I}$ & $\begin{array}{l}\text { MiR-320 shows highest expression in the proliferative compartment of the crypts; the decrease in miR-320 in stage } \\
\text { II colon cancers is predictive of a metastatic recurrence independent of age, differentiation grade, and histologic } \\
\text { subtype; targets the transferrin receptor I and inhibits proliferation; expression of miRNA-320 in myocardial } \\
\text { microvascular endothelial cells (MMEC) impairs angiogenesis by decreasing proliferation and migration of MMEC; } \\
\text { overexpression of miR-320 in mouse hearts increases apoptosis and infarction; targets heat-shock } 20 \text { mRNA; } \\
\text { potentially targets the mRNA of the p } 85 \text { subunit of phosphatidylinositol 3-kinase; exhibits a 50-fold increase in } \\
\text { insulin-resistant } 3 \text { T3-LI adipocytes; affects cell cycle progression of bronchial epithelial cells exposed to benzo[a] } \\
\text { pyrene. }\end{array}$ \\
\hline 429 & $\begin{array}{l}\text { Involved in the regulation of the Wnt/ } \beta \text {-catenin signaling pathway; miRNAs- } 200 \mathrm{a},-200 \mathrm{~b} \text {, and }-429 \text { are all encoded on a } \\
7.5 \mathrm{~kb} \text { polycistronic primary miRNA transcript; regulates the differential expression of miR200. }\end{array}$ \\
\hline $55 \mathrm{la}$ & Target mRNAs not experimentally verified. \\
\hline 552 & $\begin{array}{l}\text { MiR-552 exhibits decreased levels of expression in proficient mismatch-repair colon tumors relative to deficient } \\
\text { mismatch-repair tumors; target mRNAs not identified. }\end{array}$ \\
\hline 553 & Target mRNAs not identified. \\
\hline 760 & Regulated by $17 \beta$-estradiol and may affect a number of transcripts belonging to estrogen-responsive gene clusters. \\
\hline 942 & Target mRNAs not experimentally verified. \\
\hline 1256 & Target mRNAs not experimentally verified. \\
\hline 1262 & Targets the HLA-G mRNA. \\
\hline 1290 & Target mRNAs not experimentally verified. \\
\hline $1302-2$ & $\begin{array}{l}\text { Controlled by the multifunctional Y-Box protein I (YB-I); upregulated more than I.5-fold in drug-sensitive gastric } \\
\text { carcinoma cells. }\end{array}$ \\
\hline \multicolumn{2}{|c|}{ MiRNA processing } \\
\hline Agol & $\begin{array}{l}\text { Argonaute I; aliases: protein argonaute I, EIF2CI (eukaryotic translation initiation factor } 2 \mathrm{CI} \text { ), putative RNA-binding } \\
\text { protein Q99, GERP95 (Golgi endoplasmic reticulum protein 95); encodes a member of the Argonaute family of } \\
\text { proteins which binds to miRNAs and plays a role in gene silencing through RNA interference; may interact with dicer I; } \\
\text { highly basic protein which contains a PAZ domain and a PIWI domain; found in a tandem cluster of closely related } \\
\text { argonaute proteins, Ago3 and Ago4 on chromosome Ip; lacks endonuclease activity and does not appear to cleave } \\
\text { target mRNAs. }\end{array}$ \\
\hline Ago3 & $\begin{array}{l}\text { Argonaute 3; aliases: protein argonaute } 3 \text {, EIF2C3 (eukaryotic translation initiation factor } 2 \mathrm{C} 3 \text { ); encodes a member } \\
\text { of the Argonaute family of proteins which binds to miRNAs and plays a role in gene silencing through RNA } \\
\text { interference; highly basic protein which contains a PAZ domain and a PIWI domain; found in a tandem cluster of closely } \\
\text { related argonaute proteins, Agol and Ago } 4 \text { on chromosome Ip; lacks endonuclease activity and does not appear } \\
\text { to cleave target mRNAs. }\end{array}$ \\
\hline Ago4 & $\begin{array}{l}\text { Argonaute 4; aliases: protein argonaute 4, EIF2C4 (eukaryotic translation initiation factor 2C4); encodes a member } \\
\text { of the Argonaute family of proteins which binds to miRNAs and plays a role in gene silencing through RNA } \\
\text { interference; may interact with dicer I; highly basic protein which contains a PAZ domain and a PIWI domain; found in } \\
\text { a tandem cluster of closely related argonaute proteins, Agol and Ago3 on chromosome Ip; lacks endonuclease activity } \\
\text { and does not appear to cleave target mRNAs. }\end{array}$ \\
\hline
\end{tabular}


Table 5 Genes associated with the Wnt signaling pathway

\begin{tabular}{|c|c|}
\hline Gene & Protein function \\
\hline CTNNBIPI & $\begin{array}{l}\text { Catenin, beta interacting protein I: aliases: ICAT (inhibitor of beta-catenin-interacting protein ICAT), inhibitor of beta-catenin and } \\
\text { Tcf-4; 9-kDa negative protein regulator of the Wnt signaling pathway; prevents interaction between beta-catenin and Tcf- } 4 \text { family } \\
\text { members, thereby repressing beta-catenin-Tcf-4-mediated transactivation; in intestinal tissue, ICAT is upregulated in the mature, } \\
\text { non-dividing enterocyte lining the villi, and is absent in the beta-catenin/TCF signaling region of the crypts; does not protect the } \\
\text { soluble pool of beta-catenin from degradation by the APC (adenomatous popyposis coli); has a pro-apoptotic function in certain } \\
\text { situations (see text). }\end{array}$ \\
\hline DVLI & $\begin{array}{l}\text { Dishevelled-I; aliases: DVL, segment polarity protein dishevelled DVL-I; the human homolog of the Drosophila dishevelled gene } \\
\text { (dsh) encodes a cytoplasmic phosphoprotein that regulates cell proliferation, acting as a transducer molecule for developmental } \\
\text { processes; dishevelled family proteins are cytoplasmic mediators of the Wnt/beta-catenin signaling pathway linked to cancer with Dvl } \\
\text { considered to be a middle molecule in the pathway; Dvl, Axin and GSK form a ternary complex bridged by Axin, and Fratl can be } \\
\text { recruited into this complex by Dvl; the Dvl-binding domain of either Frat I or Axin is able to inhibit Wnt-I-induced LEF-I activation, } \\
\text { suggesting that the interactions between Dvl and Axin and between Dvl and Frat may be important for the Wnt/beta-catenin signaling } \\
\text { pathway; Wnt-I appears to promote the disintegration of the quaternary Frat I-Dvl-GSK-Axin complex, resulting in the dissociation } \\
\text { of GSK from Axin and the formation of the Dvl/Frat-I complex that leads to the activation of the Wnt signaling pathway. }\end{array}$ \\
\hline WNT2B & $\begin{array}{l}\text { Wingless-type MMTV integration site family, 2B; aliases: WNTI3, XWNT2, protein Wnt-2b; member of the WNT family of highly } \\
\text { conserved, secreted signaling factors that regulate cell growth and differentiation; ligand for members of the frizzled family of } \\
\text { seven transmembrane receptors with an extracellular WNT-binding domain and a cytoplasmic dishevelled-binding domain; may be } \\
\text { a signaling molecule that affects the development of discrete regions of tissues; is likely to signal over only a few cell diameters; } \\
\text { WNT2B is one of the canonical WNTs transducing signals through Frizzled and LRP5/LRP6 receptors to beta-catenin-TCF/LEF } \\
\text { signaling pathway; functions as a stem cell factor during embryogenesis and during carcinogenesis. }\end{array}$ \\
\hline WNT4 & $\begin{array}{l}\text { Wingless-type MMTV integration site family, 4; aliases: WNT-4, SERKAL; member of the WNT family of highly conserved, secreted } \\
\text { signaling factors that regulate cell growth and differentiation; ligand for members of the frizzled family of seven transmembrane } \\
\text { receptors; is likely to signal over only a few cell diameters; activates the canonical beta-catenin-mediated Wnt pathway and binds } \\
\text { Frizzled-6 receptor; WNT4 promoter harbors } 2 \text { p63/p73 response elements which contributes to an increase in WNT gene } \\
\text { expression; WNT4 gene expression can be negatively regulated by Notch I activation through p2IWAFI/CipI. }\end{array}$ \\
\hline
\end{tabular}

Since base excision repair (BER) removes damage that would otherwise be mutagenic in mammalian cells, ${ }^{168-170}$ BER is one of the most important DNA repair pathways in the gastrointestinal tract. BER ameliorates environmentally induced DNA damage in addition to the alkylation, oxidation, and deamination events that occur during normal metabolic processes. ${ }^{171,172} \mathrm{~A}$ critical enzyme in the base excision repair pathway is MUTYH (MutY homolog or A/G-specific adenine DNA glycosylase), whose germline mutation is a known cause of MAP (MutYH-associated polyposis), a recently described autosomal recessive colorectal adenoma predisposition syndrome with a very high risk of colorectal cancer. ${ }^{173} M y h$ deficiency enhances intestinal tumorigenesis in multiple intestinal neoplasia $\left(A p c^{M i n /}\right)$ mice. ${ }^{174}$ Interestingly, $M y h$ deficiency in mice has a larger effect on tumor initiation than on progression in the small bowel. ${ }^{174}$ Since $1 p$ deletions are observed in the human non-neoplastic mucosa of patients with colon cancer, ${ }^{44}$ it is possible that Myh-deficient field defects may initiate the process of colon carcinogenesis in humans as it does in the mouse model. Since MUTYH-null mouse embryonic stem cells exhibit a mutator phenotype, ${ }^{175}$ the loss of MUTYH can affect multiple pathways associated with colon carcinogenesis. The role of MUTYH in the repair of oxidative DNA damage begins with the formation of 8-oxo-guanine (8-oxoG) (see Figure 4), which then causes a mispairing of the oxidized guanine base with adenine upon DNA replication. Mismatch repair processes are activated and MUTYH excises adenine leaving an apurinic (AP) site resulting, after AP endonuclease action, in a DNA single strand (ss) break. ${ }^{176-180}$ The activity of MUTYH, in conjunction with other glycosylases and the spontaneous generation of AP sites, may be quite extensive, since about 9000 AP sites/cell occur daily. ${ }^{168}$ The AP site is then correctly repaired by the sequential action of several enzymes which catalyze template-directed insertion of one or a few nucleotides at the previously damaged site. ${ }^{172}$

In addition to their role in DNA repair or the DDR, MUTYH and $\mathrm{p} 73$ play important roles in the death of cells that experience either excessive oxidative DNA damage or chromosomal instability. The MUTYH-mediated cell death pathway is described in the next section followed by a section on the p73-mediated cell death pathway, which utilizes part of the MUTYH pathway in its mediation of cell death in response to excessive mitotic perturbation.

\section{MUTYH/PARP/AIF pathway of cell death}

MUTYH-mediated cell death has, as a central player, the activation of PARP-1 [poly(ADP-ribose) polymerase-1] (Figure 5). 
Table 6 Tumor suppressor genes

\section{Gene and genomic locus (ensembl cytogenetic band)}

CHD5 (Ip36.3I)

DEARI (IP35.I)

APITDI (Ip36.22)

PRDM2 (IP36.2I)

$\operatorname{SDHB}(1 \mathrm{p} 36.13)$

PRDXI (IP34.I)

PTCH2 (IP34.I)

\section{Functions}

Chromodomain helicase DNA binding protein 5; aliases: ATP-dependent helicase CHD5; belongs to a group of SWI/SNF proteins called CHD proteins, which contain a SWI/SNF-like helicase/ATPase domain, as well as a DNA-binding domain and a chromodomain that directly modifies chromatin structure; chromatin is maintained in a transcriptionally active state by CHD5 which can affect the expression levels of many genes at once and can affect the quick progression of a tumor; appears to be involved in early tumorigenic processes and controls proliferation, apoptosis, and senescence via the p $16^{\text {Inka }}$ and $19^{\text {Arf }}$ pathway; overexpression of CHD5 increases apoptosis through a p I9Arf/p53 pathway; mice heterozygous for CHD5 are prone to spontaneous tumor formation; expression is downregulated through methylation, which may explain the higher level of colon cancer incidence in African Americans (78\% with methylated CHD5) compared with Iranians (47\% with methylated CHD5). Ductal epithelium-associated RING chromosome I; alias: TRIM62 (tripartite motif-containing 62); member of the RING-B-box-coiled-coil (RBCC)/TRIM subfamily of RING finger proteins which regulate tissue architecture; first member of the TRIM family that localizes to the cell-cell junction; down regulation in normal mammary epithelial cells results in formation of aberrant acinar structures with a loss of normal cell polarity and decreased rates of apoptosis.

Apoptosis-inducing, TAF9-like domain I; see Table 2 for general description; contains a predicted domain with similarity to the human TATA box-binding protein-associated factor, TAFII3I, which is required for $\mathrm{p} 53$ mediated transcriptional activation; since loss of function for APITDI is a mechanism by which tumor cells can overcome the cell growth-regulating and apoptosis-inducing properties of $\mathrm{p} 53$, it is considered to have tumorsuppressive properties.

PR domain containing 2, with ZNF domain; aliases: RIZI, Zinc finger protein RIZ, HUMHOXYI, MTB-ZF, KMT8, retinoblastoma protein-interacting zinc finger protein, Lysine $\mathrm{N}$-methyltransferase, MTE-binding protein, GATA-3-binding protein G3B, PR domain zinc finger protein 2; this tumor suppressor is a member of the nuclear histone/protein methyltransferase superfamily involved in chromatin-mediated gene expression; encodes a zinc finger protein that can bind to the retinoblastoma protein, estrogen receptor, and the macrophage-specific TPA-responsive element (MTE) of the heme oxygenase I (HO-I) gene; the PR domain is responsible for its tumor suppressing activity; the S-adenosyl-L-methionine-dependent histone methyltransferase activity of PRDM2 specifically methylates "Lys-9" of histone H3; regulates normal cell division and function using a "Yin-Yang" fashion; overexpression induces a $G_{2}-M$ cell cycle arrest and/or apoptosis (cell death independent of Rb and $\mathrm{p} 53$ ); expression and activity are reduced in many cancers; loss of activity results in decreased apoptosis and differentiation and enhanced proliferation; common target of frameshift mutation in microsatellite-unstable cancers; gene expression epigenetically silenced through promoter hypermethylation; upregulated by a methyl-balanced diet accompanied by the repression of the oncogene, c-jun.

Succinate dehydrogenase complex, subunit B, iron sulfur (IP); SDHI, Ip (iron-sulfur protein), GL4, succinic dehydrogenase [ubiquinone] iron-sulfur subunit, mitochondrial; one of 4 nuclear-encoded subunits of complex II of the mitochondrial respiratory chain, specifically involved in the oxidation of succinate and the transfer of electrons from FADH to CoQ (ubiquinone); this iron-sulfur subunit is highly conserved and contains three cysteine-rich clusters which comprise the iron-sulfur centers of the enzyme; responsible for specifically transferring electrons from succinate to CoQ; decreased activity results in altered mitochondrial metabolism, the activation of pseudohypoxia and a shift to glycolytic respiration; SDHB-silenced cells can result in $>400$ genes either 6-fold or more upregulated or downregulated (dysregulated genes involve those involved in proliferation, adhesion, and the hypoxia pathway); DDHB-silenced cells display characteristic features of the tumor phenotype (eg, greater capacity to adhere to extracellular matrix components, including fibronectin and laminin) suggesting a possible mechanism of tumor initiation and enhanced tumorigenesis.

Peroxiredoxin I; see Table 7 for description; PrdxI knockout mice generate malignancies in intestines, lymphomas, and sarcomas; prdxI-I- mouse cells show a shift in intracellular ROS from the cytoplasm to the nucleus with increased oxidative DNA damage; prdxI-deficient mouse cells show increased sensitivity to oxidative DNA damage; lower expression of PRDXI found in tumors of the oral cavity and correlates with larger tumor size, lymph node metastasis, and clinically advanced stages. PRDXI acts as a tumor suppressor in esophageal cells and induces apoptosis after activation by histone deacetylase inhibitors; interacts with a region of the c-Myc transcriptional regulatory (Myc box II) domain that is essential for transformation, and selectively alters its biological function and target gene expression; inhibits c-Abl kinase activity by interacting with its $\mathrm{SH} 3$ domain. Patched homolog 2 (Drosophila); aliases: patched (Drosophila) homolog 2, PTC2, protein patched homolog 2; gene encodes a transmembrane receptor of the patched gene family; functions as a tumor suppressor by inhibiting another transmembrane protein SMO (smoothened), which functions in the hedgehog signaling pathway; receptor for Sonic Hedgehog, a secreted molecule implicated in the formation of embryonic structures and in tunorigenesis. 
Table 6 (Continued)

\begin{tabular}{|c|c|}
\hline $\begin{array}{l}\text { Gene and genomic locus } \\
\text { (ensembl cytogenetic band) }\end{array}$ & Functions \\
\hline CAMTAI (Ip36.3I) & $\begin{array}{l}\text { Calmodulin binding transcription activator I; cell cycle regulatory gene; in cases with Ip LOH, its expression is } \\
\text { reduced by half, suggesting a functional effect caused by haploinsufficiency. }\end{array}$ \\
\hline AJAPI (Ip36.32) & $\begin{array}{l}\text { Adherens junctions associated protein I; aliases: SHREWI, Mot8, transmembrane protein SHREWI; membrane } \\
\text { protein that targets to the basolateral membrane of polarized epithelial cells through cytoplasmic sorting motifs } \\
\text { that include three tyrosines and a dileucine; interacts with E-cadherin-catenin complexes of adherens junctions; } \\
\text { functions to inhibit cell adhesion and migration. }\end{array}$ \\
\hline UBE4B (Ip36.22) & $\begin{array}{l}\text { Ubiquitination factor E4B (UFD2 homolog, yeast); UBOX3, ubiquitin-fusion degradation protein } 2 \text {, } \\
\text { homozygously deleted in neuroblastoma-I; binds to the ubiquitin moieties of preformed conjugates and } \\
\text { catalyzes ubiquitin chain assembly in conjunction with the EI, E2, and E3 classes of ubiquitin-activating enzymes; } \\
\text { activity linked to cell survival under stress conditions; involved in protecting the cell from environmental stress; } \\
\text { cleaved by caspase } 6 \text { and granzyme B during apoptosis. }\end{array}$ \\
\hline NBLI (Ip36.|3) & $\begin{array}{l}\text { Neuroblastoma, suppression of tumorigenicity I; aliases: zinc finger protein DAN, DANDI, Dan domain family } \\
\text { member, NO3; founding member of the evolutionarily conserved CAN (cerberus and DAN) family of proteins } \\
\text { which contain a domain resembling the CTCK (C-terminal cystine knot-like) motif found in a number of signaling } \\
\text { molecules; secreted protein which acts as BMP (bone morphogenetic protein) antagonist by binding BMPs and } \\
\text { preventing them from interacting with their receptors; plays an important role in growth and development; } \\
\text { contains a putative p53/p73-binding site in the } 5 \text {-upstream region of the gene; acts as an inhibitor of cell } \\
\text { cycle progression; may play an important role in preventing cells from entering the final stage (GI/S) of the } \\
\text { transformation process; functional association exists between NBLI and p73 during cisplatin-induced cell death. }\end{array}$ \\
\hline PLA2S-II (Ip36.I3) & $\begin{array}{l}\text { The secretory type II phospholipase A2; aliases: MOMI (modifier of MIN-I), group IIA phospholipase A2, non- } \\
\text { pancreatic secretory phospholipase A2, phosphatidylcholine 2-acylhydrolase } 2 \mathrm{~A} \text {; catalyzes the hydrolysis of the } \\
\text { sn-2 fatty acid acyl ester bond of phosphoglycerides, releasing free fatty acids and lysophospholipids, liberating } \\
\text { arachidonic acid (AA) and prostaglandin D2, a metabolite of AA; participates in the regulation of phospholipid } \\
\text { metabolism in biomembranes and the maintenance of membrane asymmetry; other known functions are } \\
\text { related to microbial defense mechanisms (bactericidal activity) and the inflammatory response; human homolog } \\
\text { of the MOM (modifier of min [APC]) gene, which suppresses polyp number during intestinal tumorigenesis in } \\
\text { the min mouse model, possibly by altering the cellular microenvironment within the intestinal crypt or inducing } \\
\text { AA metabolite-mediated apoptosis in pre-neoplastic or neoplastic cells. }\end{array}$ \\
\hline ST7L (Ip |3.2) & $\begin{array}{l}\text { Suppression of tumorigenesis } 7 \text { like; aliases: related to the tumor suppressor gene, ST7, found at the } \\
\text { chromosome 7q3I genomic locus; ST7L gene is clustered in a tail-to-tail manner with the WNT2B gene on } \\
\text { chromosome Ip (analogous to the clustering of ST7 with the WNT2 gene on chromosome 7q; the related } \\
\text { gene, ST7, induces changes in genes involving the re-modeling of the extracellular matrix, such as SPARC, } \\
\text { IGFBP5 and several matrix metalloproteinases; may act as a tumor suppressor by modification of the tumor } \\
\text { microenvironment. }\end{array}$ \\
\hline RAD54L (Ip34.I) & RAD54-like (S. cerevisiae); see Table I and text for description. \\
\hline $\mathrm{E} 2 \mathrm{~F} 2(\mathrm{Ip} 36.12)$ & E2F transcription factor 2; see Table 2 for description. \\
\hline TNFRSF25 (Ip36.3I) & Tumor necrosis factor receptor superfamily, member 25; see Table 3 for description. \\
\hline PLK3 (I 34.1$)$ & Polo-like kinase 3; see Table 2 for description. \\
\hline GADD45 $\alpha(|\mathrm{p} 3| .3)$ & Growth arrest and DNA-damage-inducible 45 alpha; see Table I for description. \\
\hline CTNNBIPI (Ip36.22) & Alias ICAT; see Table 5 for description. \\
\hline MUTYH (Ip34.I) & MutY homolog (E. coli); see Table I and text for description. \\
\hline CDKN2C (Ip32.3) & Cyclin-dependent kinase inhibitor 2C; see Table 2 for description. \\
\hline DFFA (Ip36.22) DFFB (Ip36.32) & DNA fragmentation factor; see Table 3 and text for description. \\
\hline KIFIB (Ip36.22) & Kinesin family member IB; see Table 2 and text for description. \\
\hline TP73 (Ip36.32) & $\begin{array}{l}\text { Tumor protein 73; DNA damage response protein and pro-apoptotic tumor suppressor; see Table I and text } \\
\text { for description. }\end{array}$ \\
\hline MiR-34a (Ip36.22) & miRNA-34a; see Table 4 and text for description. \\
\hline MiR-IOI-I (Ip3I.3) & miRNA-IOI-I; see Table 4 and text for description. \\
\hline
\end{tabular}

Excessive DNA ss breaks caused by the action of MUTYH and $\mathrm{AP}$ endonuclease in the nucleus results in the activation of PARP-1, which attaches polymers of ADP-ribose to proteins, thereby opening up the chromatin to allow access of DNA repair proteins. ${ }^{181,182}$ PARP initially serves as a survival protein facilitating the rapid repair of DNA strand breaks, and also prevents DNA degradation, in part, by inhibiting the activity of deoxyribonucleases through the process of poly(ADP) ribosylation. ${ }^{183}$ Since the synthesis of ADP-ribose polymers consumes nicotinamide adenine dinucleotide $\left(\mathrm{NAD}^{+}\right){ }^{184}$ and $\mathrm{NAD}^{+}$is largely found in mitochondria where it participates in the production of ATP (bottom right side of Figure 5), sustained 
Table 7 Genes associated with antioxidant function

\begin{tabular}{|c|c|}
\hline Gene & Protein function \\
\hline GCLM & $\begin{array}{l}\text { Glutamate-cysteine ligase, modifier subunit; aliases: gamma-glutamylcysteine synthetase, GSC light chain; the first rate limiting } \\
\text { enzyme of glutathione synthesis; the enzyme consists of a heavy catalytic subunit and a light ( } 30.8 \mathrm{kDa}) \text { regulatory subunit. }\end{array}$ \\
\hline GPX7 & $\begin{array}{l}\text { Glutathione peroxidase } 7 \text {; non-selenocysteine containing phospholipid hydroperoxide glutathione peroxidase; alleviates oxidative } \\
\text { stress generated from polyunsaturated fatty acids. }\end{array}$ \\
\hline PRDXI & $\begin{array}{l}\text { Peroxiredoxin I; aliases: thioredoxin peroxidase 2, thioredoxin-dependent peroxide reductase } 2 \text {, TDPX2, natural killer cell- } \\
\text { enhancing factor A, PAG, PAGB; member of the peroxiredoxin family of antioxidant enzymes which reduce hydrogen peroxide } \\
\text { and alkyl hydroperoxides; the enzyme reduces peroxides using reducing equivalents provided through the thioredoxin system, not } \\
\text { through glutaredoxin; plays an important role in eliminating peroxides generated during metabolism; participates in the signaling } \\
\text { pathways of growth factors and tumor necrosis factor-alpha by regulating the intracellular concentrations of hydrogen peroxide; } \\
\text { overoxidized peroxiredoxins (eg, cysteines oxidized to cysteine sulfinic or sulfonic acids) are regenerated by p53-regulated } \\
\text { sestrins (homologs of a bacterial AhpC which reduces bacterial peroxiredoxins), thus re-establishing the antioxidant firewall. }\end{array}$ \\
\hline TXNDCI 2 & $\begin{array}{l}\text { Thioredoxin domain containing I2; aliases: endoplasmic reticulum protein ERPI9, ERPI9, hTLPI9, protein disulfide isomerase } \\
\text { family A (member I6), endoplasmic reticulum thioredoxin superfamily member, } 18 \mathrm{kDa} \text {; members of this superfamily possess } \\
\text { a thioredoxin fold with a consensus active-site sequence }(\mathrm{CxxC}) \text { and have roles in redox regulation, defense against oxidative } \\
\text { stress, refolding of disulfide-containing proteins, and regulation of transcription factors; induced at the transcriptional level by } \\
\text { the unfolded protein response (UPR), a signaling pathway that responds to the accumulation of misfolded proteins; possesses } \\
\text { significant protein thiol-disulfide oxidase activity; inhibits the induction of apoptosis by agents that cause ER stress, including } \\
\text { brefeldin A, tunicamycin, and dithiothreitol; smallest member of the protein disulfide isomerase (PDI) family of proteins to contain } \\
\text { a Cys-Xxx-Xxx-Cys active site motif; like the catalytic domains of PDls; TXNDCI } 2 \text { adopts a thioredoxin fold with a thioredoxin- } \\
\text { like active site located at the N-terminus of a long kinked helix that spans the length of the protein. }\end{array}$ \\
\hline
\end{tabular}

PARP activation will consume energy reserves, resulting in cell death, usually through the process of necrosis. ${ }^{185-188} \mathrm{~A}$ marked deficiency in energy reserves may cause the ATP-dependent $\mathrm{Na}^{+} / \mathrm{K}^{+}$transport proteins, which maintain ionic balance, to fail, resulting in cell swelling and lysis of the cell, ${ }^{189}$ one of the hallmarks of necrosis. ${ }^{190}$

In addition to the above energy catastrophe caused by excessive PARP activity in the nucleus, persistent singlestranded gaps in newly replicated DNA initiated by the action of MUTYH in mitochondria can result in the fragmentation and depletion of mitochondrial DNA (mtDNA) ${ }^{191,192}$ accompanied by the loss of mitochondrial function culminating in cell death $^{191,193}$ (bottom right side of Figure 5). Dysfunctional mitochondria can release $\mathrm{Ca}^{++}$into the cytosol which can activate calpains, causing Bax activation, lysosomal rupture, and the release of cathepsins into the cytosol ${ }^{191,194}$ resulting in a caspase-independent mode of cell death. Calpain activation can also result in Bax activation, followed by Bax oligomerization and mitochondrial damage, resulting in the loss of the mitochondrial membrane potential.

There is another unique mechanism that can lead to PARP-mediated cell death after excessive MUTYH activity, in addition to the fragmentation of mtDNA, energy catastrophe and calpain/lysosomal rupture/cathepsin pathways of mitochondrial failure described above. The main product of PARP-1 activity is the generation of polymers of ADP-ribose (PAR). Although these polymers are usually covalently bound to proteins, free PAR polymers are themselves toxic ${ }^{195-197}$ and function as a death signal. ${ }^{197-199}$
The PAR polymers bind to mitochondria and induce the release of tAIF (truncated apoptosis-inducing factor) from the mitochondria into the cytosol ${ }^{199}$ (lower left side of Figure 5). tAIF is then translocated to the nucleus where it binds to DNA, ${ }^{200-202}$ causes DNA condensation ${ }^{203}$ and recruits DNA degrading factors (eg, endogenous endo- and exo-nucleases) resulting in DNA degradation ${ }^{198,204}$ (upper left side of Figure 5). This series of events is part of an intricate program of caspase-independent cell death, ${ }^{203-213}$ and is currently an active area of research.

Several mechanisms have been proposed to explain how tAIF is released from the mitochondria into the cytosol. ${ }^{210,214}$ Prior to truncation, AIF is embedded in the inner mitochondrial membrane, ${ }^{215}$ and the release of AIF requires its cleavage ${ }^{215,216}$ from a $62 \mathrm{kDa}$ AIF mitochondrial form to a truncated $57 \mathrm{kDa}$ soluble AIF form (tAIF). ${ }^{217,218}$ Calpain-I, which is activated by $\mathrm{Ca}^{++},{ }^{219}$ and $\mathrm{Ca}^{++}$-independent cathepsins $\mathrm{B}, \mathrm{L}$, and $\mathrm{S}^{218,220}$ can cleave intramitochondrial AIF. ${ }^{221-223}$ The calpains and cathepsins can truncate AIF in the same position at Gly102/Leu103. ${ }^{218}$ Calpain-I, however, appears to be the critical enzyme regulating AIF processing in which the AIF pathway is important for cell death. ${ }^{219}$ Oxidative modifcation of AIF markedly increases the susceptibility of AIF to calpain-I-mediated processing, most probably through the exposure of a normally hidden calpain cleavage site. ${ }^{219}$ Since the PAR polymer is a highly negatively charged molecule, it could depolarize mitochondria leading to opening of the mitochondrial membrane permeability transition pore (MPTP) followed by the release of tAIF. ${ }^{197,199}$ PAR polymers 
Table 8 Genes associated with protection against environmental and metabolic toxicity

\begin{tabular}{ll}
\hline Gene & Protein function \\
\hline AADACL3 & $\begin{array}{l}\text { Arylacetamide deacetylase-like 3; the enzymatic activity of the family of arylacetamide deacetylases carry out } \\
\text { the deacetylation of carcinogenic arylacetamides such as 4-acetylaminobiphenyl, 2-acetylaminofluorene, and } \\
\text { 2-acetylaminaphthalene. }\end{array}$ \\
AArylacetamide deacetylase-like 4; the enzymatic activity of the family of arylacetamide deacetylases carry out \\
the deacetylation of carcinogenic arylacetamides such as 4-acetylaminobiphenyl, 2-acetylaminofluorene, and \\
2-acetylaminaphthalene.
\end{tabular}

AKRIAI Aldo-keto reductase family I, member AI; aliases ALDRI, ARM, dihydrodiol dehydrogenase 3; member of the aldo/ keto reductase superfamily; catalyzes the NADPH-dependent reduction of a variety of biogenic/xenobiotic aromatic and aliphatic aldehydes to their corresponding alcohols; oxidizes proximate carcinogen trans-dihydrodiols to o-quinones. Aldo-keto reductase family 7, member A2; aliases: succinic semialdehyde reductase, SSA reductase, AFARI; catalyzes the NADPH-dependent reduction of succinic semialdehyde to gamma-hydroxybutyrate; can reduce the dialdehyde protein-binding form of aflatoxin $\mathrm{BI}$ (AFBI) to the non-binding AFBI dialcohol.

AKR7A3 Aldo-keto reductase family 7, member A3; aliases: AFAR2, AFBI aldehyde reductase 2; involved in the detoxification of aldehydes and ketones; can reduce the dialdehyde protein-binding form of aflatoxin $\mathrm{BI}$ (AFBI) to the non-binding AFBI dialcohol.

AKR7L Aldo-keto reductase family 7-like; aliases: AFAR3, AFBI aldehyde reductase 3; involved in the detoxification of aldehydes and ketones; can reduce the dialdehyde protein-binding form of aflatoxin $\mathrm{BI}$ (AFBI) to the non-binding AFBI dialcohol; this family member encodes a selenoprotein, which contains a selenocysteine residue; the selenocysteine is encoded by the UGA codon that normally signals translational termination.

CYP2J2 Cytochrome P450, family 2, subfamily J, polypeptide 2; aliases: microsomal monooxygenase, flavoprotein-linked monooxygenase, arachidonic acid epoxygenase; the cytochrome P450 superfamily of enzymes catalyze many reactions involved in drug metabolism and synthesis of cholesterol, steroids and other lipids; this protein localizes to the endoplasmic reticulum and is the predominant enzyme responsible for epoxidation of endogenous arachidonic acid pools in cardiac tissue; also functions in the gastrointestinal tract; epoxygenase-derived eicosanoids have antiinflammatory properties. Cytochrome P450, family 4, subfamily Z, polypeptide I; catalyzes the in-chain hydroxylation of lauric acid and myristic acid; single-pass type II membrane protein found in the endoplasmic reticulum.

CYP4A II Cytochrome P450, family 4, subfamily A, polypeptide II; aliases: fatty acid omega-hydrolase, lauric acid omegahydrolase, alkane-I monooxygenase, 20-hydroxyeicosatetraenoic acid synthase; this CYP450 member localizes to the endoplasmic reticulum and catalyzes the omega- and omega-I-hydroxylation of medium-chain fatty acids such as laurate, myristate and palmitate; oxidizes arachidonic acid to 20-hydroxyeicosatetraenoic acid (20-HETE). Cytochrome P450, family 4, subfamily A, polypeptide 22; aliases: fatty acid omega-hydroxylase, lauric acid omegahydrolase; this CYP450 member localizes to the endoplasmic reticulum and catalyzes the omega- and (omega-I)hydroxylation of medium-chain fatty acids such as laurate and palmitate; shows no activity toward arachidonic acid and prostaglandin Al.

CYP4BI Cytochrome P450, family 4, subfamily B, polypeptide I; aliases: microsomal monooxygenase, P-450HP; this enzyme is located in the endoplasmic reticulum and oxidizes a variety of structurally unrelated compounds, including steroids, fatty acids and xenobiotics; involved in an NADPH-dependent electron transport pathway; can be induced to high levels in the liver and other tissues by various foreign compounds, including drugs, pesticides, and carcinogens.

CYP4XI Cytochrome P450, family 4, subfamily X, polypeptide I; aliases: CYPIVXI, MGC4005 I; located in the endoplasmic reticulum and may be involved in neurovascular function in the brain.

GSTMI Glutathione S-transferase Mu I; aliases: glutathione S-alkyltransferase MI, S-(hydroxyalkyl)glutathione lyase MI, HB subunit 4; glutathione transferases may serve as an antioxidant system preventing degenerative cellular processes; the genes encoding the mu class of enzymes are organized in a gene cluster on chromosome IpI 3.3 and are known to be highly polymorphic; this enzyme conjugates glutathione to a wide number of endogenous and exogenous toxins and carcinogens; null mutations of class mu genes have been linked with an increase in a number of cancers, most likely caused by an increased susceptibility to environmental toxins and carcinogens; specific genetic polymorphisms are associated with susceptibility to colorectal cancer.

GSTM2 Glutathione S-transferase Mu 2; aliases: glutathione S-alkyltransferase M2, S-(hydroxyalkyl)glutathione lyase M2; this enzyme conjugates glutathione to a wide number of endogenous and exogenous toxins and carcinogens; alleviates benzo[a]pyrene-diolepoxide-DNA damage.

GSTM3 Glutathione S-transferase Mu 3; aliases: glutathione S-alkyltransferase M3, S-(hydroxyalkyl)glutathione lyase M3; this enzyme conjugates glutathione to a wide number of endogenous and exogenous toxins and carcinogens; GSTMI and GSTM3 allele variants are a risk-modulating factor in colorectal cancer patients.

GSTM4 Glutathione S-transferase Mu 4; aliases: glutathione S-alkyltransferase M4, S-(hydroxyalkyl)glutathione lyase M4; this enzyme conjugates glutathione to a wide number of endogenous and exogenous toxins and carcinogens; active on I-chloro-2,4-dinitrobenzene. 
Table 8 (Continued)

\begin{tabular}{|c|c|}
\hline Gene & Protein function \\
\hline GSTM5 & $\begin{array}{l}\text { Glutathione S-transferase Mu 5; aliases: glutathione S-alkyltransferase M5, S-(hydroxyalkyl)glutathione lyase M5; this } \\
\text { enzyme conjugates glutathione to a wide number of endogenous and exogenous toxins and carcinogens. }\end{array}$ \\
\hline MTFI & $\begin{array}{l}\text { Metal response element binding transcription factor I; transcription factor that induces the expression of } \\
\text { metallothioneins and other genes involved in metal homeostasis in response to heavy metals such as cadmium, zinc, } \\
\text { copper and silver; is a nucleocytoplasmic shuttling protein that accumulates in the nucleus upon heavy metal exposure } \\
\text { and binds to promoters containing a metal-responsive element; nucleocytoplasmic shuttling of MTFI is regulated by } \\
\text { diverse signals. }\end{array}$ \\
\hline MTF2 & $\begin{array}{l}\text { Metal response element binding transcription factor 2; alias: polycomb-like protein 2; binds to the metal-regulating } \\
\text { element of the metallothionein-IA gene promoter, which is zinc-dependent. }\end{array}$ \\
\hline
\end{tabular}

of increasing complexity and molecular weight are more toxic than simple PAR polymers of low molecular weight. ${ }^{197}$ The PAR polymer could also bind to PAR polymer binding proteins associated with mitochondria, which then release AIF. ${ }^{199,224-226}$ This results in AIF cleavage producing a tAIF, which is soluble and enters the cytosol. The release of tAIF may also be caused by a significant but not excessive

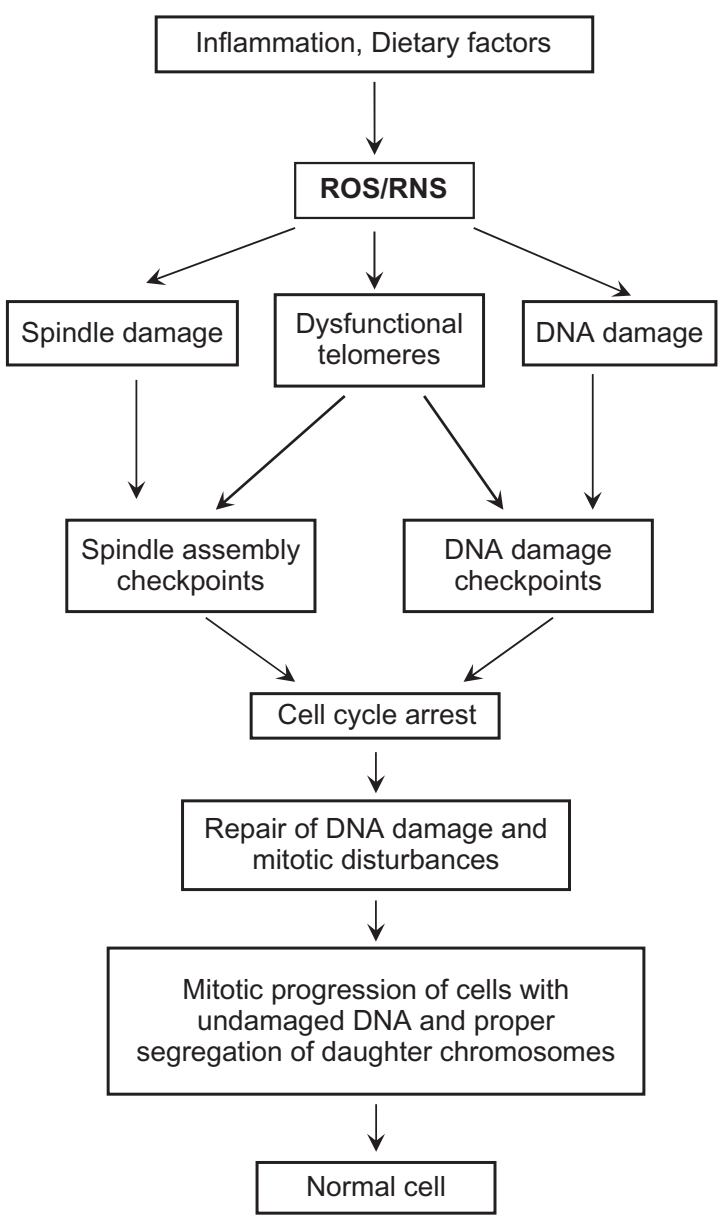

Figure I The damaging effects of dietary factors and inflammatory conditions on the colonic epithelium. Damage to DNA, the mitotic spindle, and to telomeres is mediated through the generation of ROS (reactive oxygen species) and/or RNS (reactive nitrogen species). This damage results in the activation of spindle and DNA damage checkpoints, which delay mitosis until repairs are made. decrease in $\mathrm{NAD}^{+}$(as a result of PARP activity), ATP, and the mitochondrial membrane potential, resulting in the opening of the MPTP (mitochondrial permeability transition pore). ${ }^{186,196,211}$ The release of tAIF may also be caused by other caspase-independent pathways involving molecules that are often found in the downstream execution phase of apoptosis, such as tBid (truncated Bid), ${ }^{227-229}$ Bax oligomers (formed after

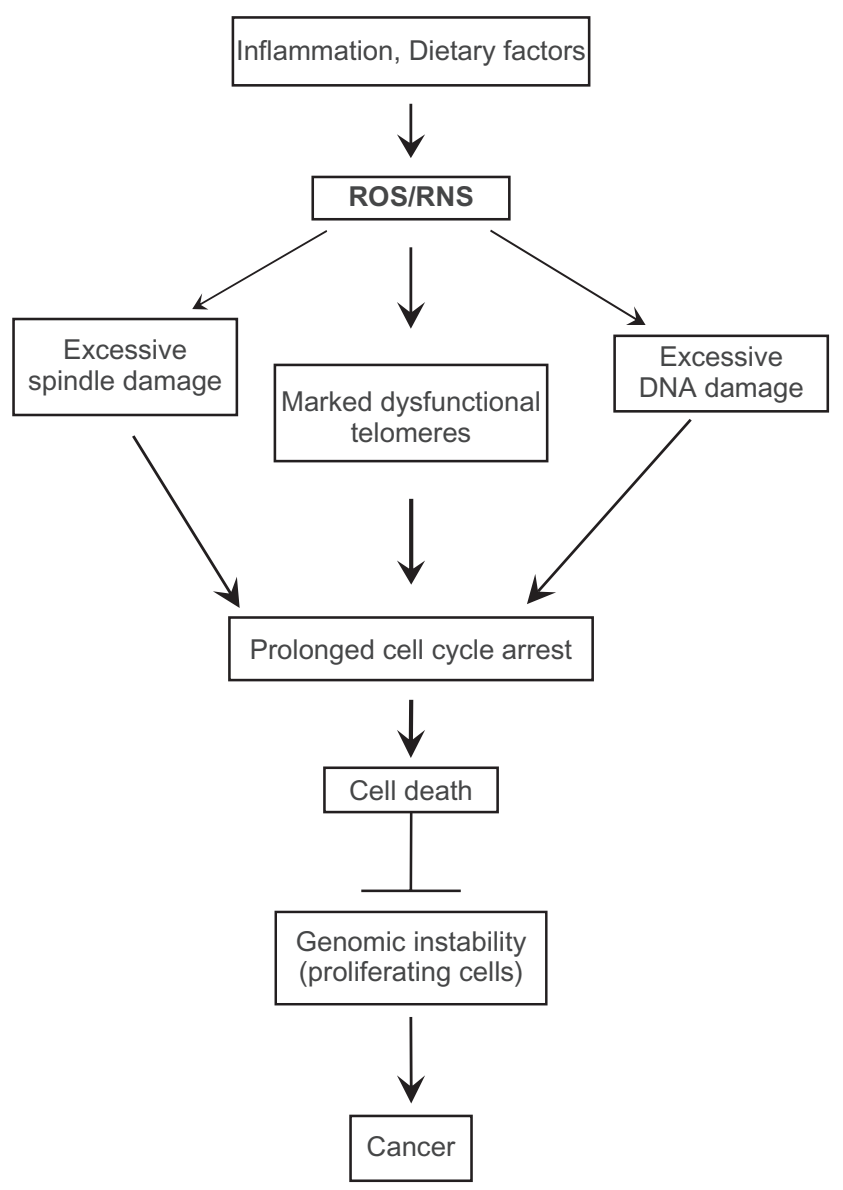

Figure 2 Excessive spindle damage, dysfunctional telomeres, or DNA damage can result in a prolonged cell cycle arrest which activates pro-cell death pathways. This activation of pro-cell death pathways leads to removal of cells with unrepaired damage to the mitotic spindle, the chromosome ends, and DNA and prevents the potential propagation of cells with many types of genomic instability.

Abbreviations: ROS, reactive oxygen species; RNS, reactive nitrogen species. 


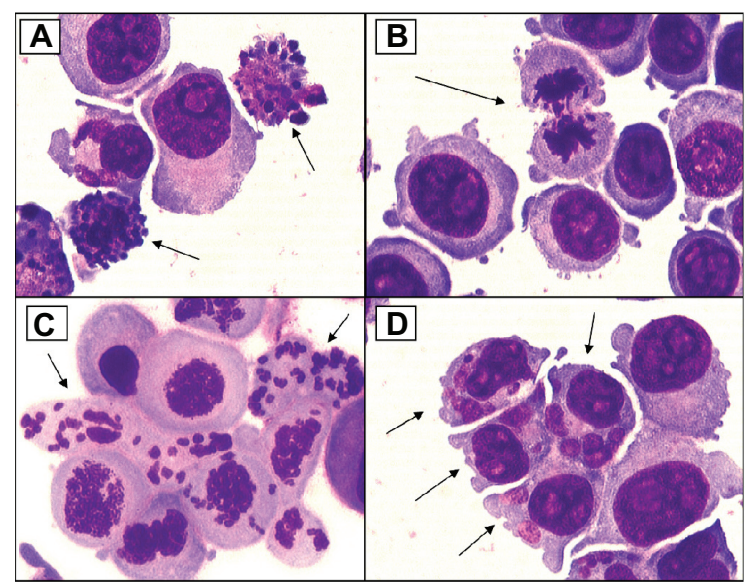

Figure 3 Examples of cellular alterations that accompany apoptosis (A), mitotic perturbation during anaphase (B), mitotic catastrophe with complete chromosome/ spindle disruption (C), and abundant micronuclei formation associated with aneuploidy (D). Panels A, B, and D are examples of HCT-II6 cells treated with $10 \mu \mathrm{M}$ camptothecin. Panel $\mathrm{C}$ represents cells treated with $5 \mu \mathrm{M}$ phenstatin (drug obtained through courtesy of Dr GR. Pettit, Arizona State University) (cytospin preparations of Giemsa-stained cells; $\times 100$ oil objective lens)

activation of Bax by $\mathrm{Ca}^{++}$-dependent calpains), ${ }^{211,217} \mathrm{Bak}^{230}$ and Bim-EL. ${ }^{231,232}$ The activation of PARP also activates other stress-response pathways such as the RIP/TRAF2/ JNK pathway, ${ }^{233-235}$ which may be responsible, in part, for generation of $\mathrm{tBid}^{228}$ and the phosphorylation of Bim-EL. The phosphorylation of Bim-EL releases Bim-EL from sequestration by the microtubular dynein motor complex, ${ }^{236}$ allowing it to bind to bcl-2, ${ }^{231}$ thereby enhancing the cell death process.

Mechanisms that interfere with tAIF release include the 1) degradation of the PAR polymer by PARG (PAR glycohydrolase), ${ }^{237} 2$ ) inhibition of tAIF translocation to the nucleus by Bcl-2, Bcl-xl, HSP70, or Iduna, and 3) interference of transcription of the AIF gene by BNIP3. ${ }^{238}$ PARG, Bcl-2, Bcl-xl, HSP70, Iduna, and BNIP3 have been shown to be upregulated during carcinogenesis, consistent with the development of tumor cell resistance to cell death. In addition, pro-cell death molecules involved in this MUTYH/PARP/ AIF pathway, such as AIF, Bid, Bax, Bak, and Bim-EL, have been reported to be downregulated during carcinogenesis. Thus, overall, MUTYH likely has an important role in the death of cells exposed to excessive reactive oxygen species/ reactive nitrogen species (ROS/RNS)-induced DNA damage, and interference with the MUTYH cell death pathway is associated with carcinogenesis.

\section{P73 and caspase-dependent cell death}

Like p53, p73 is responsible for the induction of apoptosis in response to excessive DNA damage that cannot be repaired. ${ }^{239}$ P73 has the ability to upregulate the transcription of numerous classic apoptosis-related genes such as caspases 3, 6, and 8, Bcl-2 family members, and death receptors (Figure 6). In order for p73 to function as a transcription factor, it must be phosphorylated. The c-Abl kinase, activated by DNA damage, phosphorylates and activates p73 on tyrosine $99 .{ }^{240}$ The stress-induced mitogen-activated protein kinase, p38 MAPK, phosphorylates and activates $\mathrm{p} 73$ on threonine residues. ${ }^{239}$ The degradation of $\mathrm{p} 73$ by the E3 ubiquitin-like protein, Itch, is prevented by the Yes-associated protein, YAP. E2F1, p53, and c-jun (located on chromosome 1p; Figures 4 and 6) may also have a role in p73 activation in different cell types. ${ }^{241,242}$ One mechanism by which p73 induces apoptosis includes the transcription of PUMA (p53 upregulated modulator of apoptosis), which in turn causes Bax translocation to the mitochondria with the release of cytochrome $c{ }^{243}$ A second mechanism involves the transcription of scotin, which causes endoplasmic reticulum (ER) stress and subsequent apoptosis. ${ }^{244,245}$ Unlike p53, a direct role of p73 in the apoptotic process (eg, mitochondrial translocation and perturbation) has not been verified. The role of $\mathrm{p} 73$ in the regulation of the miRNA processing complex will be discussed in the section "MiRNAs and miRNA processing". As noted above, loss of p73 through chromosome 1p deletion occurs early in colon carcinogenesis, contrary to the loss of p53 which is a late event.

\section{Mitosis-related and spindle checkpoint function (Table 2)}

There are 24 genes on chromosome $1 \mathrm{p}$ whose gene products affect many different aspects of the mitotic process, and include kinases, phosphatases, centromere proteins, centrosome proteins, cyclins, regulatory mitotic proteins, motor spindle proteins, regulators of chromosomal condensation, a mitosis-related transcription factor, a deacetylase, and a major spindle checkpoint protein (Table 2). The large number of mitosis-related genes that are lost if there is a chromosome $1 \mathrm{p}$ deletion could potentially be responsible for colon cancer initiation and progression, since cancer epidemiology studies show that abnormal expression of mitosis-related genes is frequent in different tumor types. ${ }^{246,247}$ Mitotic checkpoints, and specifically the spindle assembly checkpoint, are major targets for tumor-associated alterations. ${ }^{247}$ The mitotic spindle assembly checkpoint is essential for ensuring that all chromosomes are properly aligned on the metaphase plate, with every chromosome 


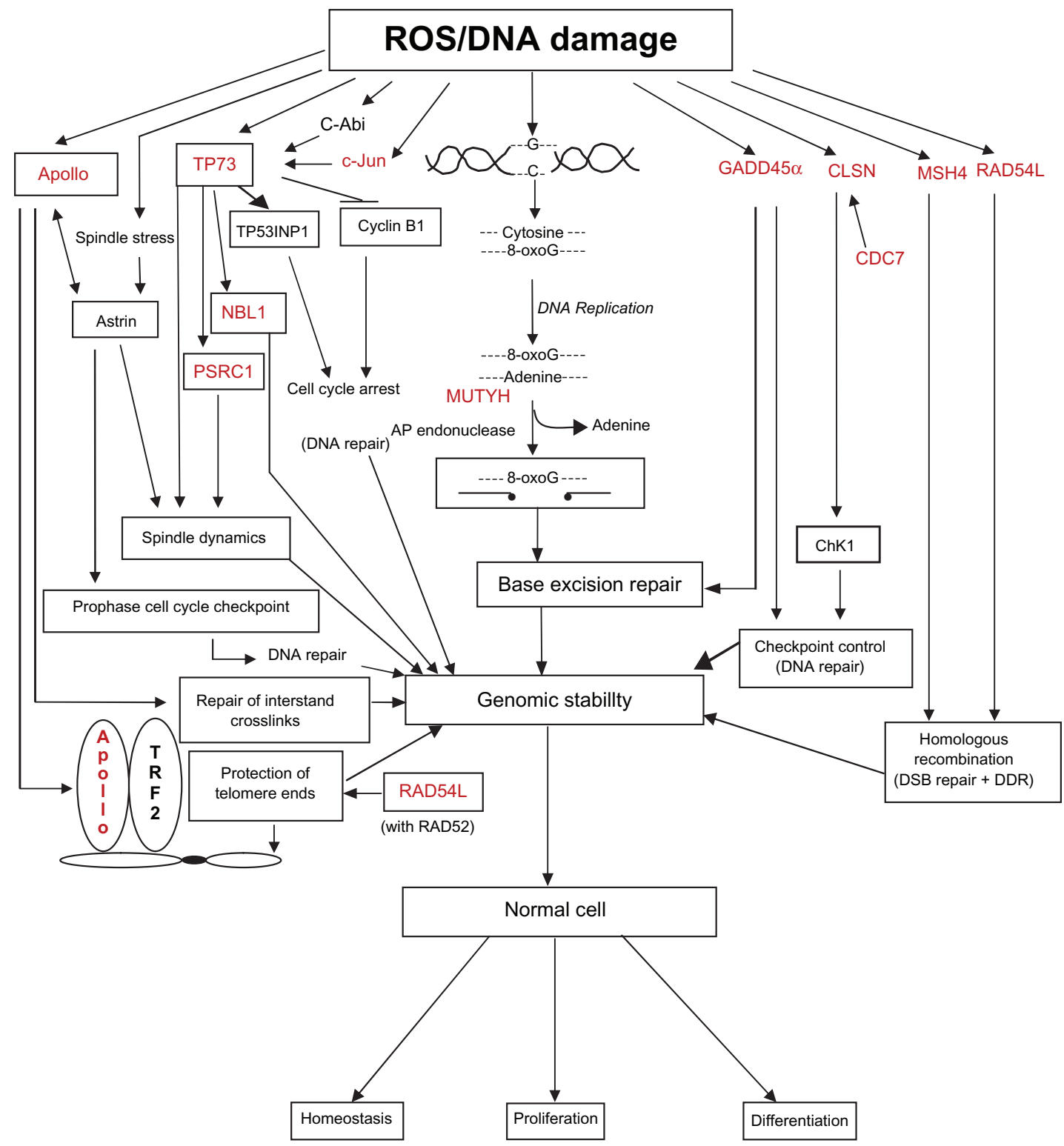

Figure 4 DNA damage causes several downstream molecular and cellular events. The DNA damage response involves several DNA repair proteins and transcription factors that allow the cell cycle to be arrested at several points to enhance genomic stability. All of the genes associated with these damage response pathways that are also found on chromosome Ip are highlighted in red, and reference to the appropriate tables (contain functions of gene products) in the text is provided below. The large number of molecular and cellular events affected by the loss of chromosome Ip is apparent.

Notes: Genes: CLSN, DCLRE (APOLLO), GADD45 $\alpha$, MSH4, MUTYH, TP73, RAD54L (Table I); CDC7 (phosphorylates claspin in response to DNA damage), PSRCI (DDA3) (Table 2); NBLI (Table 6). Additional protein functions in diagram not discussed in text: astrin (microtubule binding protein involved in the functional and dynamic regulation of mitotic spindles); CHKI (checkpoint homolog of S. pombe; serine/threonine-protein kinase required for cell cycle arrest in response to DNA damage or presence of unreplicated DNA); cyclin BI [regulatory protein involved in mitosis; complexes with p34 (cdc2) to form the maturation-promoting factor, MPF; expressed predominantly during G2/M]; TP53INPI (tumor protein p53-inducible nuclear protein I; in response to DNA damage, it promotes p53 phosphorylation on "Ser-46" and promotes cell cycle arrest; promotes apoptosis if DNA damage is excessive); TRF2 (telomeric repeat binding factor 2; component of the shelterin complex that binds the telomere double-stranded - TTAGGG - repeat and protects telomere ends).

Abbreviations: DDR, DNA damage response; ROS, reactive oxygen species; RNS, reactive nitrogen species.

attached to a spindle microtubule by its kinetochore to prevent aneuploidy. ${ }^{97}$ If these processes fail to occur and the cell undergoes a prolonged mitotic arrest (Figure 2), the cell may be eliminated through caspase-dependent or caspase-independent cell death mechanisms ${ }^{147}$ to ensure genomic stability (Figure 7).
Oxidative stress is a major factor that can induce disturbances in spindle organization, ${ }^{248,249}$ induce centrosome amplification, cause proteolysis of the anaphase inhibitor securin and mitotic cyclins, ${ }^{250}$ affect components of the anaphase-promoting complex, ${ }^{251}$ and override the spindle checkpoint, ${ }^{250}$ thereby affecting chromosomal stability. 


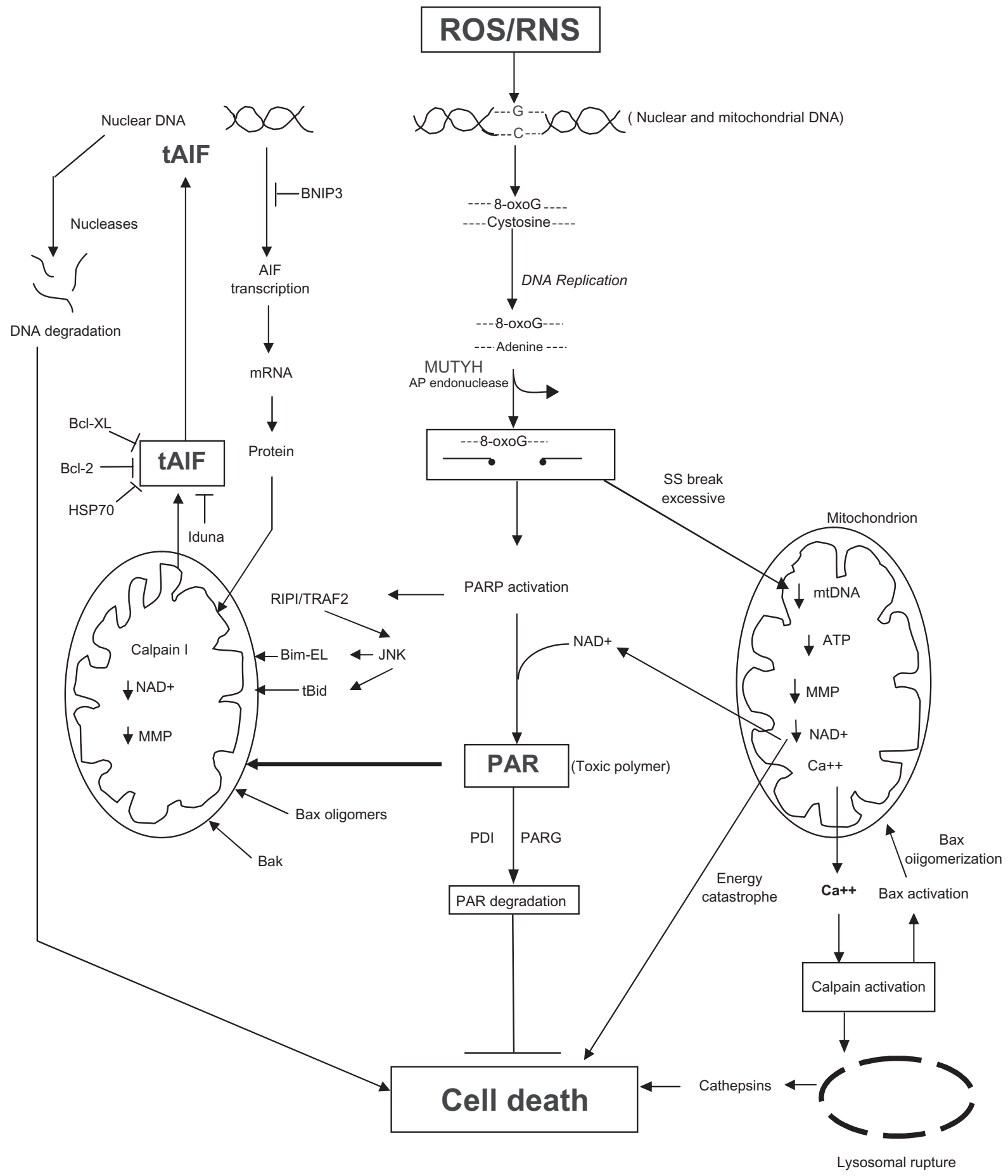

Figure 5 The mechanisms by which excessive activity of MUTYH and AP endonucleases can lead to cell death through the activation of PARP and the generation of toxic poly(ADP)ribose (PAR) polymers and mitochondrial DNA (mtDNA) damage (see text for detailed description).

Abbreviations: ROS, reactive oxygen species; RNS, reactive nitrogen species.

During the process of mitosis, direct oxidative damage to chromosomes resulting in double-strand breaks, or oxidative damage to telomeres can activate p53 (Figure 7) or p73 (Figure 6), major DNA damage response proteins that elicit apoptosis through multiple caspase-dependent mechanisms. In addition, caspase-independent mitotic cell death can also occur during a mitotic catastrophe (Figure 3C, Figure 7), which is a prestage to distinct modes of cell death that may be caspase-dependent or caspase-independent. ${ }^{148}$

The length of time that a spindle is destabilized may determine the mode and timing of cell death after mitotic exit. ${ }^{123,124,126}$ It has been suggested that prolonged mitotic 


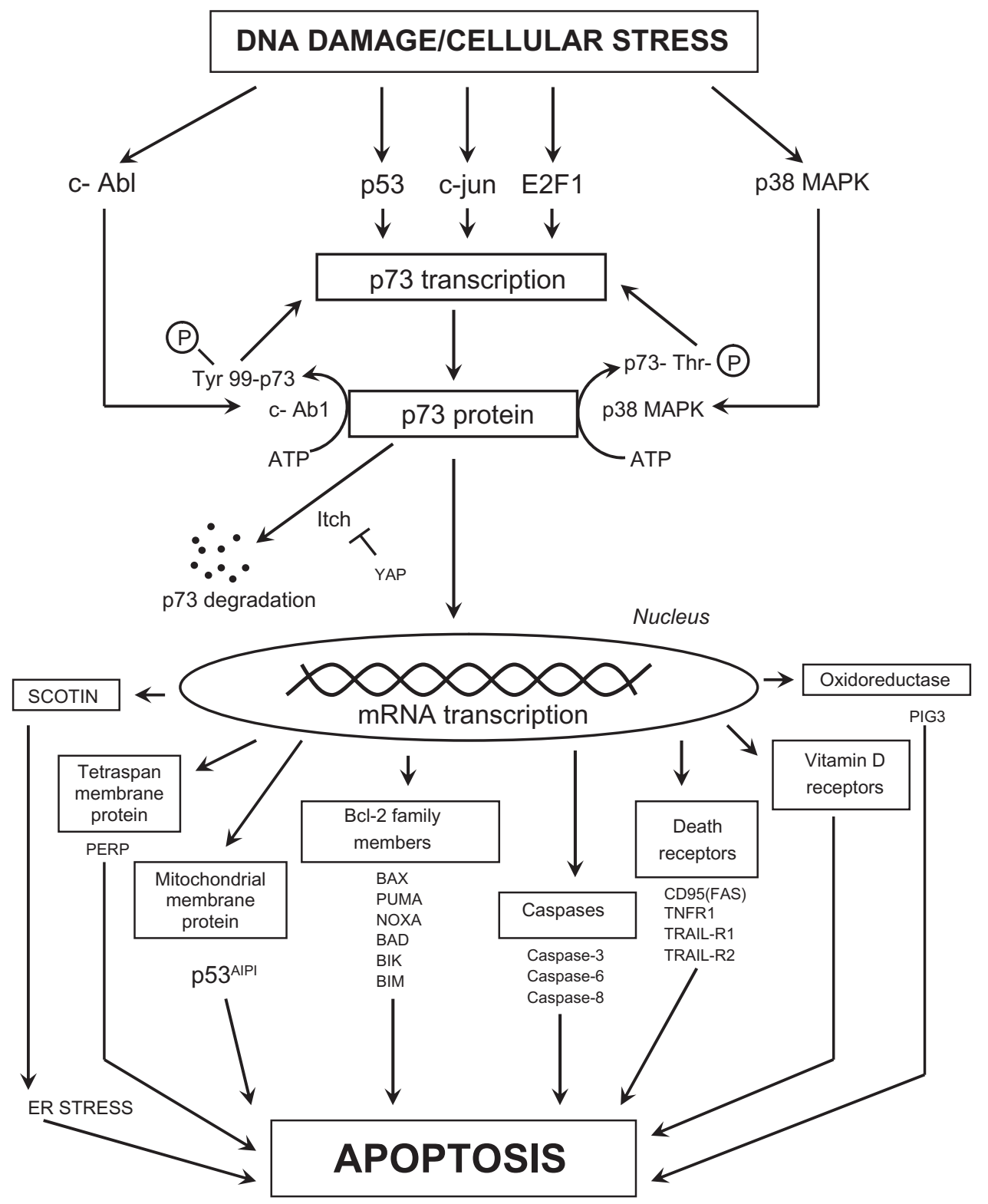

Figure 6 The possible mechanisms by which p 73 transcription and activation can lead to cell death through classic apoptotic mechanisms. Definitions of proteins not included in the main text: PERP (p53 apoptosis effector related to PMP22; tetraspan membrane protein and component of intercellular desmosome junctions); p53AIPI (p53 apoptosisinducing protein I; promoter activated by acetylated p73); FAS (CD95) (member 6 of the TNF receptor superfamily which contains a death domain); TNFRI (member IA of the TNF receptor superfamily); TRAIL-RI (member IOA of the TNF receptor superfamily); TRAIL-R2 (member IOB of the TNF receptor superfamily; death receptor 5); PIG3 ( $\mathrm{p} 53$-induced gene 3 protein; quinone oxidoreductase involved in the generation of ROS and cell death).

Abbreviation: $E R$ endoplasmic reticulum.

delay can lead to the decay of anti-apoptotic messenger RNAs (mRNAs) ${ }^{252,253}$ and/or the gradual accumulation of pro-apoptotic signals. ${ }^{252,254}$ Of the 24 mitosis-related genes (Table 2), the products of 7 genes have dual-role mitosis/ pro-apoptotic functions. These dual-role mitosis/pro-apoptotic genes include APITD1, CCNL2, CDC2L2, CDC42, E2F2, KIF1B, and PLK3 (Table 2). Cells may become genomically unstable if they evade mitotic checkpoints through a process referred to as mitotic slippage, mitotic arrest slippage, or mitotic checkpoint slippage ${ }^{255-263}$ (Figure 7). With mitotic slippage, the cell exits mitosis prematurely, carrying broken chromosomes, abnormal numbers of chromosomes, and unrepaired DNA damage into the daughter cells. In addition to loss of pro-apoptotic proteins, it has been reported that the gradual loss of the checkpoint effector, cyclin B, releases the mitotic arrest induced by spindle disruptive agents, despite the continued presence of spindle damage and upstream checkpoint proteins. ${ }^{14,258,260}$ In order for a DNA-damaged cell to survive after mitotic slippage, it must evade both apoptosis in the subsequent G1 phase of the cell 


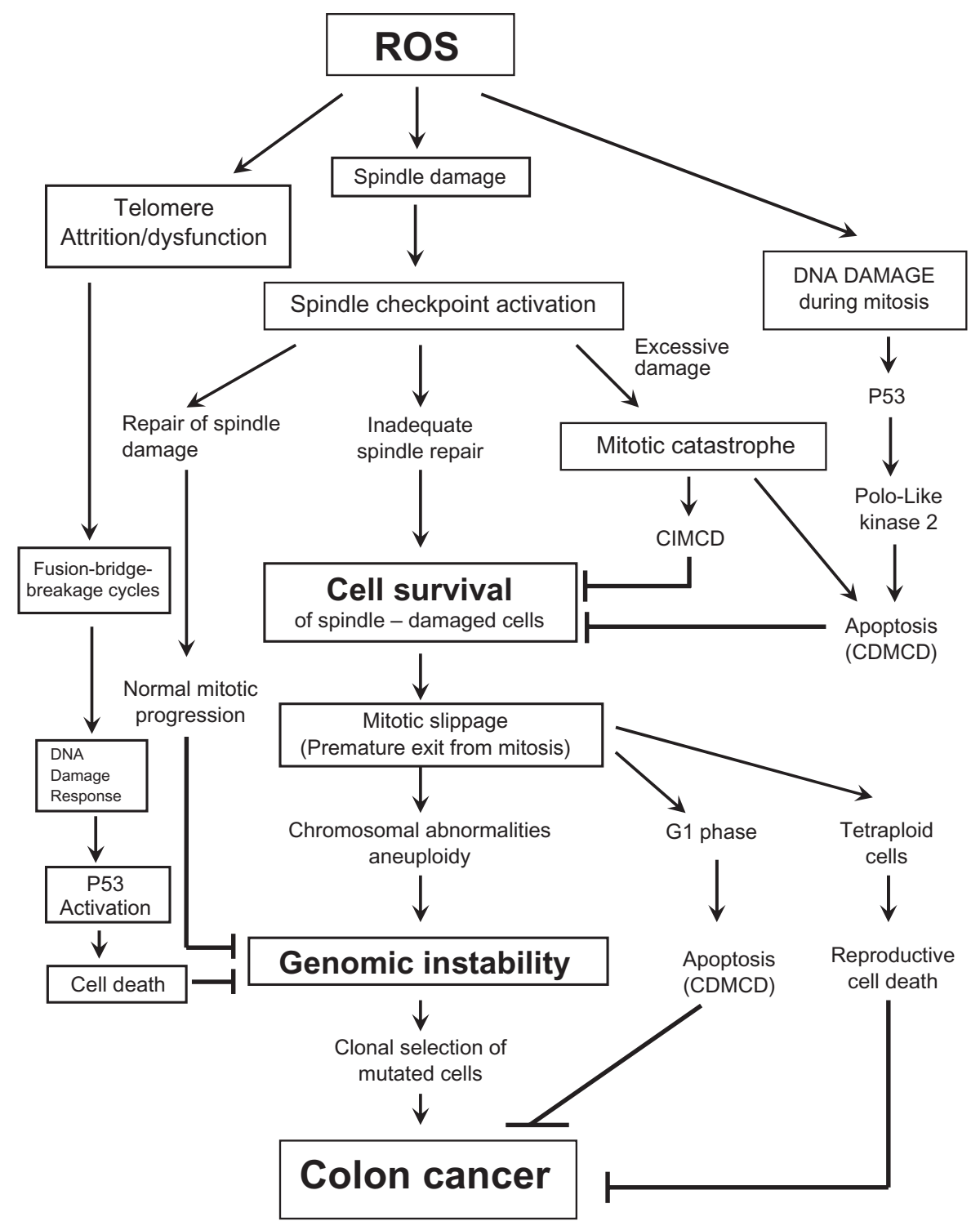

Figure 7 The different cellular fate following spindle, telomere and DNA damage during mitosis. Cells with excessive genomic damage can undergo caspase-dependent cell death (CDMCD) or caspase-independent mitotic cell death (CIMCD). DNA-damaged cells may, however, exit from mitosis by defying cell death pathways through a process referred to as mitotic slippage. These preneoplastic cells with DNA damage and chromosomal abnormalities can then be clonally expanded to produce a tumor and eventually develop into a malignancy through continued cycles of damage to the genome.

Abbreviation: ROS, reactive oxygen species.

cycle $^{124}$ (Figure 7) and reproductive cell death that can follow centrosome amplification and the generation of tetraploid cells $^{264}$ (Figure 7).

Thus, a decrease in pro-apoptotic mitotic/cell cyclerelated genes located on chromosome 1p (APITD1, CCNL2, CDC2L2, CDC42, E2F2, KIF1B, PLK3) (Table 2) may result in resistance to cell death, a critical event that drives tumorigenesis. ${ }^{52,54,265-267}$

\section{Apoptosis-related genes (Table 3)}

Seven genes associated with apoptosis are located on chromosome 1p. Bcl-10 and Bcl2L15 are Bcl-2 family members, THAP3 is a zinc-coordinating DNA-binding protein, DNA fragmentation factor A (DFFA) and B (DFFB) are the two subunits of DFF, caspase-9 is a major initiator caspase in the apoptotic proteolytic cascade, and TNFRSF25 is a death domain-containing receptor related to TNFR-1 and CD95 (Apo-1/Fas). The deletion of 3 of these genes would have important implications for carcinogenesis through the increase in apoptosis resistance, and will be discussed in some detail.

DFF is a heterodimeric protein composed of a catalytically active $40 \mathrm{kD}$ subunit, DFFB (CAD [caspase-activated DNase]), and an inhibitory $45 \mathrm{kD}$ subunit, DFFA (ICAD 
[inhibitor of CAD]). ${ }^{268,269}$ When bound to DFFB, DFFA inhibits the nuclease activity of DFFB. ${ }^{268,269}$ During apoptosis, caspase-3 cleaves DFFA at amino acids 117 and 224 and dissociates it from DFFB, thereby releasing the inhibition of DFFB. ${ }^{270}$ DFFB activity results in chromatin condensation $^{271}$ and the formation of the typical crescents and margination of chromatin that are characteristic of classic apoptotic cells at the ultrastructural level. ${ }^{190,266,272-276}$ Characteristic ultrastructural features of apoptotic cells treated with a ROS-generating and DNA-damaging agent are shown in Figure 8. At the molecular level, the action of DFF on DNA results in the initial cleavage of DNA

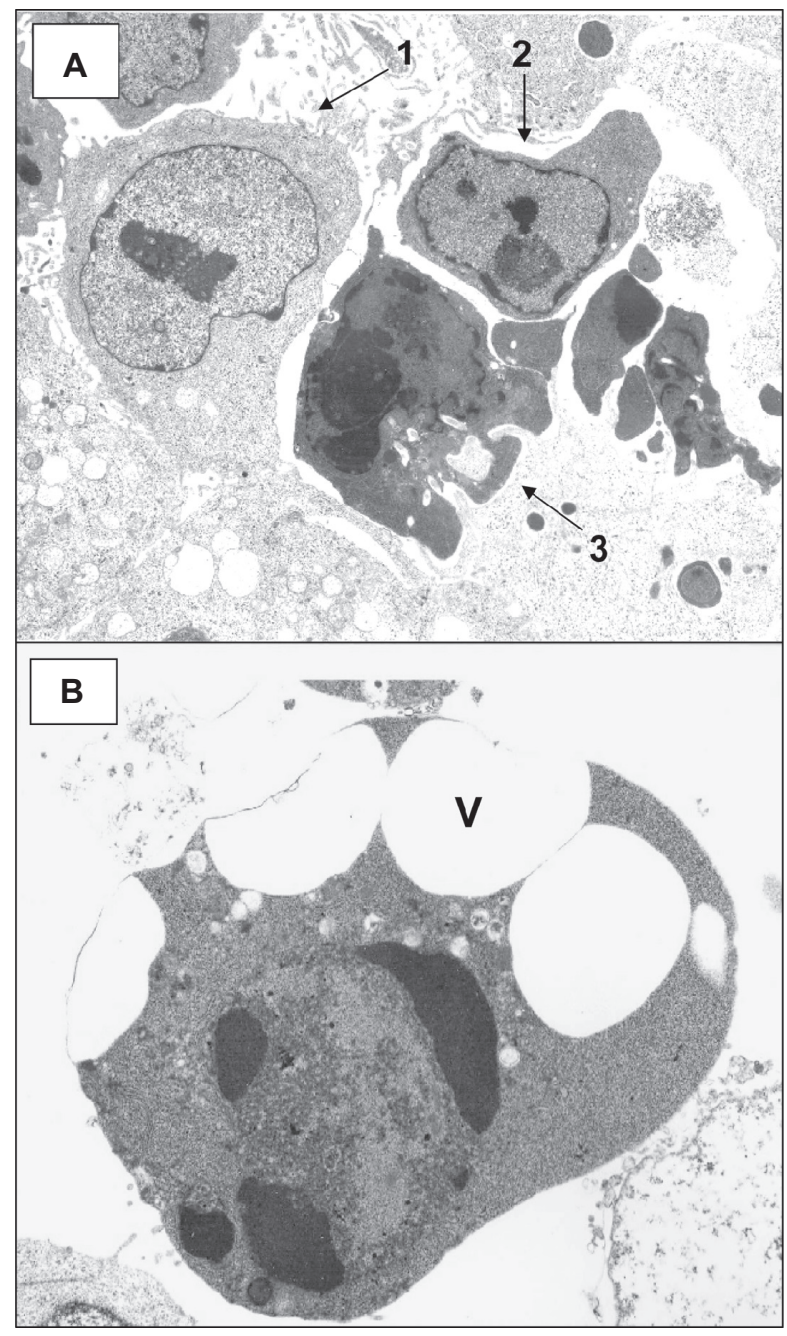

Figure 8 Transmission electron micrographs of HCT-II6 cells reacted with $0.5 \mathrm{mM}$ sodium deoxycholate for 2 hours. A) Normal cell (arrow I) with prominent nucleolus and dispersed chromatin; arrow 2 points to a cell in early apoptosis, showing margination of chromatin, a nucleolus showing nucleolar segregation, and an increase in electron density compared with the normal cell; arrow 3 points to a cell in a late stage of apoptosis showing condensed chromatin, a marked increase in electron density compared with the cell above, and apoptotic body formation. B) Apoptotic cell in a late stage of apoptosis showing condensed chromatin (including crescent formation), an increase in electron density, and cytoplasmic vacuole (V) formation. (Uranyl acetate, lead citrate stains.) into 50 - to $300-\mathrm{kb}$ long fragments, ${ }^{277,278}$ representing the dismemberment of the higher order organization of chromatin into chromosomal loop domains, and the fragmentation of DNA into oligonucleosomal sized fragments that form a "ladder" on agarose gel electrophoresis. ${ }^{279}$ The importance of DFF in suppressing tumorigenesis ${ }^{280}$ was demonstrated by Yan et $\mathrm{al}^{281}$ using DFF40-null mice. DFF-deficient cells exhibit significant increases in mutation, chromosomal instability, and survival compared with wild-type control cells. $^{281}$ This is probably a result of the inhibition of cell death of DNA-damaged cells resulting from the failure to undergo DNA fragmentation. ${ }^{282,283}$ DFF is reported to avoid chromosome instability in a p53-independent manner. ${ }^{284}$ Irradiation of cells with a caspase-resistant form of DFFA led to increased clonogenic survival of cells with increased chromosomal aberrations and aneuploidy. ${ }^{284}$ The ability of DFF to maintain chromsosomal stability appears to be the result of the DNA fragmentation-induced death of cells with excessive DNA damage. ${ }^{284}$ Although DFFB has intrinsic DNAse activity, both DFFA and DFFB are required to generate DNase activity, ${ }^{140,269}$ and must be co-expressed. ${ }^{280}$ DFFA has been postulated to stabilize the synthesis of DFFB, ${ }^{270,271}$ or mediate the correct folding and chromatin localization of DFFB. ${ }^{271}$ The absence of DFF results in an increased frequency of cell transformation and enhanced susceptibility to radiation-induced carcinogenesis, indicating that DFF is a tumor suppressor. ${ }^{280}$ Recently, it has been reported that the expression of DFFA protein, but not DFFA mRNA, is regulated by a specific miRNA, miR-145, suggesting a mechanism of translational regulation. ${ }^{285}$ The regulation of DFFB by miRNA has not been investigated, and, so far, none of the miRNAs found on chromosome 1p (Table 4) have been determined to have DFFA or DFFB as target mRNAs for translational regulation.

Caspase-9 is a member of the family of cysteine-aspartic acid-specific proteases (caspases), and is also referred to as Apaf-3 (apoptotic protease-activating factor 3). In the presence of cytochrome $c$ and dATP, Apaf-1 binds to procaspase- 928 via a CARD (caspase activation recruitment domain), ${ }^{287}$ forming a complex referred to as the apoptosome. ${ }^{286,288,289}$ The cellular oxidative state can affect apoptosome formation by promoting an interaction between caspase- 9 and Apaf-1 via disulfide formation. ${ }^{290}$ In the apoptosome, caspase- 9 is activated to process other downstream caspases, including caspase- 3 and caspase-2. ${ }^{291}$ Caspase-9 plays an important role in apoptosis induced by genotoxic stress. ${ }^{292,293}$ The caspase9-induced apoptotic pathway can result from mitochondrial membrane depolarization, formation of the apoptosome, 
and the activation of multiple caspases, including caspase-3 and caspase-2. ${ }^{294}$ Loss of caspase-9 is therefore important to carcinogenesis, since it can result in apoptosis resistance and the propagation of DNA-damaged cells. ${ }^{295}$ If caspase- 9 is lost, caspase- 3 cannot be activated, and thus cannot cleave many substrates including DFFA, an essential endonuclease in apoptosis (see previous page). Similarly, if caspase-9 is lost, caspase-2 may not be activated. Caspase-2 plays a specific role in genotoxic stress-induced apoptosis in some cell types. ${ }^{296,297}$ (However, there is another pathway for activation of caspase-2. Activation of p53 by DNA damage can result in the p53-mediated transcription of the death domain protein PIDD [p53-induced protein with a death domain], which, together with RAIDD or RIP1, can form a multiprotein complex called the PIDDosome ${ }^{298-300}$ which then activates caspase- $2^{298}$ ). DNA damage can also activate caspase-2 through the activation of $\mathrm{c}-\mathrm{Abl}{ }^{301} \mathrm{C}-\mathrm{Abl}$ binds directly to caspase-9, phosphorylates it on Tyr-153, which then results in the autocleavage and activation of caspase- 9 resulting in the apoptosis of excessively DNA-damaged cells. ${ }^{301}$ Caspase- 9 also mediates apoptosis caused by ER stress. ${ }^{302}$ ER stress first activates caspase-12, ${ }^{302}$ which is located on the outer membrane of the ER; ${ }^{303}$ caspase 12 then activates caspase- 9 through a cytochrome $c$-independent mechanism. ${ }^{302}$ In some cells, ER stress can result in caspase- 8 activation, formation of $\mathrm{tBid}$, mitochondrial damage, release of cytochrome $c$ and the activation of caspase- 9 through the formation of the apoptosome. ${ }^{304}$ Therefore, ER stress can activate caspase- 9 through both mitochondrial-independent and-dependent mechanisms.

\section{MiRNAs and miRNA processing (Table 4)}

miRNAs are evolutionarily conserved, endogenous, small (21 to 24 nucleotides) non-coding RNAs cleaved from 70 to 100 nucleotide hairpin-shaped precursors that reduce translation and stability of target mRNAs through RISC (RNA interference effector complex)-mediated mRNA degradation and translational suppression via sequencerecognition interactions with the $3^{\prime}$ untranslated region of their targeted mRNAs. ${ }^{305-315}$ The diverse cellular functions affected by miRNAs $s^{306,316,317}$ is underscored by the prediction that thousands of genes are potential miRNA targets. ${ }^{318-320}$ At least 800 different miRNAs predicted by computational scanning in the human genome have been documented (http://microrna.sanger.ac.uk). Individual miRNAs have the potential to downregulate large numbers of target mRNAs with seed region complementary sites in their $3^{\prime}$ untranslated regions..$^{321-323}$ It has been speculated that miRNAs could regulate $\sim 30 \%$ of the human genome. ${ }^{306}$ MiRNAs function in proliferation, cell cycle control, the prevention of replicative stress, differentiation, and apoptosis. ${ }^{324-333}$ More than half of the known human miRNAs are located at fragile sites, as well as at sites of $\mathrm{LOH}$, amplification, and common breakpoint regions, which are particular genomic regions that are prone to alteration in cancer cells. ${ }^{327}$ The overexpression or underexpression of miRNAs as a result of chromosomal additions or deletions, respectively, in individual cells can have dramatic effect on hundreds to thousands of target genes. It is, therefore, not surprising that aberrant expression of miRNAs is associated with cancerous tissues, ${ }^{334-340}$ and that characteristic miRNA expression profiles are features of certain human cancers. ${ }^{341-350}$ Impaired miRNA processing enhances cellular transformation and tumorigenesis, ${ }^{351,352}$ and certain miRNAs are even classified as tumor suppressors and oncogenes. ${ }^{353-355}$ Alterations in a series of specific miRNAs have been associated with the age of onset of colon cancer, the growth of colon cancer cells, and certain stages of colon carcinogenesis. ${ }^{344,356-369}$ Human colon cancer profiles from 80 colon tumors and 28 samples of normal mucosa show differential miRNA expression depending on mismatch repair status and are characteristic of undifferentiated proliferative states. ${ }^{367}$ Examination of the genomic regions containing differentially expressed miRNAs revealed that they were also differentially methylated in colon cancer at a far greater rate than would be expected by chance. ${ }^{367}$ MiRNA profiles could accurately predict microsatellite status in a set of 39 colon cancer studied by Lanza and colleagues. ${ }^{370}$ This is probably a reflection of the presence or near absence of chromosomal instabilty in the respective microsatellite stable vs unstable cancers. ${ }^{371}$

There are 20 miRNAs and 3 components of the miRNA processing complex (Argonaute proteins 1,3,4) encoded on chromosome $1 \mathrm{p}$ (Table 4). One of the 20 miRNAs, miR-34a, is known to be regulated by p53. ${ }^{309,330,372-376}$ Tarasov et al ${ }^{375}$ evaluated the differential regulation of 74 miRNAs by $\mathrm{p} 53$; 50 miRNAs were either positively or negatively regulated by p53, miR-34a showing the highest fold increase (33.4 fold). Although the 20 miRNAs found on chromosome $1 \mathrm{p}$ can have pleiotropic effects on cells, miR-34a is the most well studied for its role in cell cycle arrest and apoptosis in response to DNA damage. ${ }^{309,330,374,377,378}$ The miR-34 family of miRNAs is one of only 18 mammalian miRNA families ${ }^{379}$ that are present in flies and worms. ${ }^{309}$ It is probable that links between p53 and the miRNA-34 family may have arisen early in the evolution of the stress-related p53 network. ${ }^{309}$ Because of its central role in preventing carcinogenesis, miR-34a has been 
classified as a tumor suppressor. ${ }^{372,377} \mathrm{MiR}-34 \mathrm{a}$ has numerous downstream targets, including bcl-2 (major anti-apoptotic protein), NOTCH1, Delta1 (ligand for NOTCH1), NOTCH2 (found on chromosome 1p), CDK4, CDK6, Cyclin D1, Cyclin E2, c-Met, MYCN, SIRT1 and E2F3. ${ }^{319,362,374,375,377,380-384}$ The inhibition of NOTCH1 by miR-34a would enhance apoptosis since NOTCH1 is known to inhibit p53 activity ${ }^{385,386}$ and to have an anti-apoptotic role ${ }^{387,388}$ in tumorigenesis. The inhibition of SIRT1 by miR-34a contributes to p53-dependent apoptosis $^{389}$ through deacetylating and stabilizing p53 leading to an increase in p21 and PUMA. ${ }^{384}$ The E2F3 transcription factor is not known to have a role in apoptosis; however, it is a novel repressor of the ARF/p53 pathway $^{390}$ and a potent transcriptional inducer of cell-cycle progression. ${ }^{377}$ Therefore, the downregulation of E2F3 by miRNA-34a would have a growth inhibitory effect. ${ }^{362,374} \mathrm{MYCN}$ has important roles in both cell proliferation and apoptosis, and MYCN amplification is almost always associated with the loss of chromosome $1 \mathrm{p} 36 .{ }^{382}$ It is probable that the effects of miR-34a on cellular molecular pathways is widespread, since enforced expression of $34 \mathrm{~A}$ shows a dramatically altered gene expression profile with upregulation of $532 \mathrm{mRNA}$ transcripts and downregulation of 681 mRNA transcripts highly enriched for those genes that regulate cell-cycle progression, apoptosis (BCL2, BIRC3 [baculoviral IAP repeatcontaining 3], DcR3 [decoy receptor 3]), DNA repair, and angiogenesis. ${ }^{330}$ In conclusion, although p53 is a late event in colon carcinogenesis, the deletion of a major downstream target of p53, miR-34a, as a result of chromosomal 1p deletion, could have dramatic effects on colon tumorigenesis.

MiR-101 is a miRNA that, like $34 \mathrm{a}$, is pro-apoptotic ${ }^{391}$ and considered to be a tumor suppressor. ${ }^{391,392}$ The nomenclature of miR-101-1 (Table 4) and miR-101-2 is based on the fact that miR-101-1 is produced from a genomic locus on chromosome 1p31 and miR-101-2 from a genomic locus on chromosome 9p24. ${ }^{392}$ Loss of heterozygosity at both $1 \mathrm{p}$ and $9 \mathrm{p}$ are known to be associated with cancer. ${ }^{392}$ The mechanism by which miR-101 induces apoptosis is by targeting and decreasing the expression of the multifaceted anti-apoptotic protein Mcl-1 (myeloid cell leukemia sequence 1). ${ }^{391} \mathrm{Mcl}-1$ undergoes rapid turnover which may serve as a convergence point for signals that affect global translation, thereby coupling translation to cell survival and the apoptotic machinery. ${ }^{393}$ (The DNA damage response can also result in Mcl-1 destruction and the initiation of apoptosis. ${ }^{394,395}$ ) Mcl-1 specifically inhibits apoptosis, in part, by sequestering the pro-apoptotic Bim, Bak, $\mathrm{tBid}$, and Noxa, in an inactive state. Since Mcl-1 can interact with tBid and inhibit its induction of cytochrome $c$ release, it plays an important role in resistance to TRAIL and TNF $\alpha$-induced apoptosis. ${ }^{396,397}$ Therefore, Mcl-1 can inhibit apoptosis induced by both the death receptor (extrinsic) and mitochondrial (intrinsic) pathways. Mcl-1 is targeted for proteasome-mediated degradation by the $\mathrm{E} 3$ ubiquitin ligase $\mathrm{MULE}^{398}$ and is rapidly degraded with a half-life of 30 minutes to 3 hours. ${ }^{393}$ Its short half-life relates to the presence of a long proline-, glutamic acid-, serine-, and threonine-rich (PEST) region upstream of the Bcl-2 homology domains. ${ }^{398}$ The inhibition of translation with cycloheximide can cause the rapid degradation of Mcl-1 within 30 minutes, thereby triggering the apoptotic machinery through the release of Bim and the activation of Bak and Bax. ${ }^{393}$ Although full-length Mcl-1 does not interact with Bax, the caspase-mediated cleavage of Mcl-1 at Asp127 generates a fragment that induces apoptosis through direct interaction with Bax. ${ }^{399}$ Phosphorylation of Mcl-1 can affect its function and degradation. ${ }^{400}$ The phosphorylation of Mcl-1 is prominent in cells that accumulate in the $\mathrm{G} 2 / \mathrm{M}$ phase of the cell cycle as a result of exposure to microtubule disrupting agents, and in synchronized cells passing through this phase. ${ }^{401}$ This phosphorylation, especially at serine 64, enhances the anti-apoptotic function of $\mathrm{Mcl}-1,{ }^{400}$ thereby allowing cells to properly align their chromosomes prior to anaphase. In colorectal mucosa, the Mcl-1 protein is found in the apical cells of the crypt, ${ }^{402,403}$ whereas the distribution is more diffuse in the malignant cells. ${ }^{403}$

In addition to the development of apoptosis resistance, the loss of miR-101 also leads to cancer progression through the overexpression of histone methytransferase EZH2 (enhancer of zeste homolog 2), a polycomb group member, with concomitant dysregulation of epigenetic pathways. ${ }^{392,404} \mathrm{MiR}-101$ also represses the expression of FOS (v-fos FBJ murine osteosarcoma viral oncogene homolog) oncogene, a key component of the AP-1 (activator protein-1) transcription factor, MYCN (a gene amplified in many tumors), and COX-2, an enzyme involved in the production of prostaglandins from the metabolism of arachidonic acid. ${ }^{405}$ Enhanced expression of miRNA-101 also has an effect on the late stages of cancer, since it inhibits invasion and migration.

The $\mathrm{p} 53 / \mathrm{p} 63 / \mathrm{p} 73$ family of tumor suppressors are known to regulate the major components of the miRNA processing complex, ${ }^{164,406}$ which include Drosha-DGCR8, Dicer-TRBP2, and Argonaute proteins. Drosha (RNASEN) is an RNAse III endonuclease; DGCR8 is a double stranded RNA binding protein; DICER contains an RNA helicase motif required for the formation of RISC (RNA induced silencing complex); 
TRBP2 (trans-activation-responsive RNA binding protein 2) is a component of the miRNA loading complex (composed of DICER1, AGO2, and TRBP2) required for the formation of RISC. Argonaute proteins are endonucleases that aid in the maturation of pre-miRNAs of 60 to 70 nucleotides to mature miRNAs of 21 to 24 nucleotides; the tethering to mRNA mimics the miRNA-mediated repression of protein synthesis. ${ }^{164,407,408}$ There are 8 members of the Argonaute family in the human genome; 4094 belong to the PIWI subfamily and are expressed mainly in the testis, whereas the other 4 belong to the elF2C/AGO subfamily and are expressed in a variety of adult tissues. Ago1 and Ago2 (catalytic engine of RISC) reside in 3 complexes with distinct DICER and RNA-induced proteins involved in RNA metabolism. ${ }^{410}$ Three of the 4 members of the elF2C/AGO subfamily are found in a tandem cluster of closely related Argonaute non-nucleolytic proteins, ${ }^{411}$ Ago1, Ag3, and Ago4 on chromosome 1p (Table 4). Therefore, loss of chromosome $1 \mathrm{p}$ should have a major impact on the process of miRNA processing in the affected cells.

A family of miRNAs on chromosome $1 \mathrm{p}$ of particular interest to colon carcinogenesis is the miR-200 family, which includes miR-200a, -200b, and -429 (Table 4). These 3 family members are all encoded on a $7.5-\mathrm{kb}$ polycistronic primary miRNA transcript and help determine the epithelial phenotype of cancer cells through the regulation of the Wnt/ $\beta$-catenin signaling pathway. ${ }^{412,413} \mathrm{Wnt}$ growth factors activate a cascade of intracellular events, known as the canonical Wnt pathway, which ultimately leads to a coordinated proliferation, differentiation, and sorting of the epithelial cell population that forms the colonic crypts. ${ }^{414}$ In colorectal cancer, epithelial cells that acquire mutations in the $\mathrm{Wnt} / \beta$-catenin signaling pathway gain inappropriate proliferative capabilities mimicking the effect of a permanent Wnt stimulation. ${ }^{414}$ Beta-catenin is a transcription factor that translocates to the nucleus and activates target genes involved in stimulation of the cell cycle and inhibition of apoptosis. E-cadherin binds directly to $\beta$-catenin in the cytoplasm, which restricts the movement of $\beta$-catenin to the nucleus. ZEB1 and ZEB2 are proteins that repress the transcription of E-cadherin. Members of the miR-200 family were found to directly target the mRNA of ZEB1 and ZEB2, ${ }^{412,415-418}$ upregulate E-cadherin expression in cancer cell lines, and reduce cellular motility. ${ }^{412}$ Conversely, downregulation of one miR-200 family member that was tested, miR-200a, was shown to promote tumor growth by reducing E-cadherin and activating the $\mathrm{Wnt} / \beta$-catenin signaling pathway. ${ }^{413}$ Cancer progression has some similarities with embryonic development and wound healing, in which a process of epithelial-to-mesenchymal transition (EMT) occurs. ${ }^{419}$ Although the EMT normally occurs as a process of stem cell differentiation, the EMT that occurs during carcinogenesis involves a change from a differentiated tumor to a more invasive dedifferentiated tumor. ${ }^{412,419,420}$

The loss of the miR-200 family of miRNAs, coupled with the loss of 4 proteins associated with the Wnt/ $\beta$-catenin signaling pathway (Table 5 below), and the loss of the proapoptotic miR-34a and the miRNA transcriptional protein, $\mathrm{p} 73$, should have a significant impact on the initiation and progression of colon cancer.

\section{Wnt/ $\beta$-catenin signaling pathway (Table 5)}

The Wnt signaling pathway is critical for the differentiation and sorting of the epithelial cell population necessary for the organization of the colonic crypts and for the regulation of crypt cell renewal and homeostasis. ${ }^{414,421}$ Wnt signaling is initiated by the binding of extracellular Wnt factors to receptors on the cell surface, which triggers a signaling cascade that leads to the accumulation of $\beta$-catenin. ${ }^{414,422}$ In the absence of Wnt signals, $\beta$-catenin is degraded by a multicomplex complex composed, in part, of APC (adenomatous polyposis coli), GSK3 $\beta$ (glycogen synthase kinase-3-beta), and the scaffold proteins Axin1 and Axin2/ conductin, ${ }^{423-425}$ forming the $\beta$-catenin destruction box. This destruction box is responsible for the GSK3 $\beta$-mediated phosphorylation of $\beta$-catenin and its subsequent degradation by the ubiquitin-proteasome pathway. The Wnt signals block this phosphorylation and degradation, resulting in the accumulation of $\beta$-catenin. Cytoplasmic $\beta$-catenin accumulation and translocation to the nucleus allows $\beta$-catenin to associate with TCF/LEF (T cell factor/lymphocyte enhancer factor) transcription factors which target genes that enhance cell survival and proliferation (ie, c-myc, cyclin D1). ${ }^{426-428}$ Mutations in APC, $\beta$-catenin, Axin1, or ICAT (inhibitor of beta-catenin and Tcf-interacting protein) result in the deregulated accumulation of $\beta$-catenin and the constitutive activation of Wnt signaling, ${ }^{429-431}$ a major cause of cancer, including colorectal cancer. ${ }^{418,424,425,432}$

There are 4 genes located on chromosome $1 p$ that are directly involved in the Wnt signaling pathway (CTNNBIP1, DVL1, WNT2B, and WNT4) (Table 5). WNT2B and WNT4 are secreted signaling factors and Dvl1 is a cytoplasmic molecule that associates with Frat-1 to activate the Wnt signaling pathway. The loss of these positive regulators of the Wnt signaling pathway as a result of a chromosomal $1 \mathrm{p}$ deletion may contribute to the dysregulation of crypt 
organization that could initiate the carcinogenic process. ${ }^{433}$ CTNNBIP1/ICAT (Table 5), on the other hand, is a negative protein regulator of the Wnt signaling pathway. ICAT disrupts $\beta$-catenin-TCF interactions, ${ }^{434-436}$ thereby downregulating gene expression associated with proliferation and cell survival. The crystallographic structure of ICAT indicates the mechanism by which ICAT interferes with $\beta$-catenin function. The $\mathrm{NH}_{2}$-terminal domain of ICAT binds to armadillo repeats $10-12$ of $\beta$-catenin, whereas the $\mathrm{COOH}$-terminal domain of ICAT binds to the groove formed by armadillo repeats $5-9 .^{435,437}$ The armadillo repeats $5-9$ are crucial for the binding of $\beta$-catenin to both TCF and E-cadherin. ${ }^{438}$ The importance of ICAT in the prevention of carcinogenesis is underscored by the fact that ICAT is a multipotent inhibitor of $\beta$-catenin ${ }^{438}$ by interfering with the binding of $\beta$-catenin to TCF, cadherins, and APC, with consequences for transcription, cell adhesion, and cytoskeletal function. ${ }^{438-440}$ The cytoplasmic and nuclear location of ICAT, using an immunohistochemical approach, is consistent with a broader role for ICAT than previously reported. ${ }^{440}$

In addition to the effects on transcription and cell adhesion, ICAT can function as a pro-cell death molecule in certain situations. Overexpression of ICAT in colorectal tumor cells results in growth arrest and cell death, and serves to eliminate cells with a constitutively activated Wnt signaling pathway. ${ }^{441}$ Using flow cytometry, the cell death was evidenced by a sub-G1 peak of the cell cycle, and the forced entry of cells into an illegitimate DNA synthetic phase without having undergone a prior mitosis (enhanced trypan exclusion of $>4 \mathrm{~N}$ cells). ${ }^{441}$ Transgenic mice expressing ICAT also make activated $\mathrm{T}$ cells (dependent on $\beta$-catenin-TCF signaling for survival ${ }^{442,443}$ ) highly susceptible to apoptosis (using annexin $\mathrm{V}$ staining), by reducing the expression of $\mathrm{Bcl}_{\mathrm{xL}}$ below a critical threshold. ${ }^{436}$ The mechanism by which ICAT reduces $\mathrm{Bcl}_{\mathrm{xL}}$ expression is not known at the present time.

Since chromosomal instability is a major feature of colon carcinogenesis, it is appropriate to consider the role of the Wnt signaling pathway in mitotic control and aberrant Wnt signaling in the generation of chromosomal aberrations. A precedent for exploring the role of aberrant Wnt signaling in chromosomal instability are the findings that 1) multiple signaling pathways converge to orient the mitotic spindle in Caenorhabditis elegans embryos; ${ }^{444}$ 2) APC and EB1 (a microtubule-associated protein) have the ability to maintain proper spindle positioning in the developing nervous system of Drosophila ${ }^{445,446} 3$ ) binding of APC protein to microtubules increases microtubule stability and is regulated by GSK3 $\beta ;^{447} 4$ ) APC has a role in chromosome segregation; ${ }^{448} 5$ ) $\beta$-catenin is a component of the mammalian mitotic spindle and functions to ensure proper centrosome separation and subsequent establishment of a bipolar spindle; ${ }^{449}$ 6) GSK3 $\beta$ has a role in mitotic spindle dynamics and chromosome alignment, ${ }^{450}$ and localizes to the centrosome and specialized cytoskeletal structures; ${ }^{451}$ 7) dishevelled genes are involved in mitotic progression in cooperation with polo-like kinase 1;452 and 8) conductin/axin2 and Wnt signaling regulates centrosome cohesion. ${ }^{453} \mathrm{It}$ is now well established that aberrant $\mathrm{Wnt} / \beta$-catenin signaling can induce chromosomal instability in cancer, including colon cancer. ${ }^{454-458}$ An understanding of the mechanisms by which specific components of the Wnt signaling pathway affect mitosis, mitotic slippage and other aspects of the cell cycle, including interaction with spindle checkpoint proteins, needs to be experimentally determined.

\section{Tumor suppressors (Table 6)}

Experiments involving somatic cell fusion and chromosome segregation established the concept that certain genes are capable of suppressing tumorigenesis. ${ }^{459,460}$ Tumor suppressors are genes whose miRNA or protein products reduce the formation of tumors and prevent malignant progression by decreasing proliferation, regulating the cell cycle, maintaining chromosome integrity, enhancing DNA repair, inducing apoptosis, and, by reducing angiogenesis, invasion, migration, and cell adhesion. Classic tumor suppressor genes that, when deleted or mutated, contribute to tumorigenesis in many types of tumors include p53, RB, INK4a (p16), and ARF. ${ }^{461}$ In colorectal cancer, mutations and $\mathrm{LOH}$ of the tumor suppressor, APC, can affect both the initiation and progression of cancer, whereas the loss of p53 is a late event. Therefore, when the loss of chromosome $1 \mathrm{p}$ became associated with many types of cancer, including colon cancer, several groups began the quest to identify the specific tumor suppressor gene or genes located on $1 p{ }^{462-467}$ Several genomic loci were identified as "hot spots" for tumor suppressor genes, which included $1 \mathrm{p} 36$ and $1 \mathrm{p} 34$. It became evident that many genes, both inside and outside of these "hot spots", could be classified as tumor suppressors; 26 tumor suppressor genes, their genomic loci, and the function of their gene products are listed in Table 6. (Note: 11 genes classified as tumor suppressors in Table 6 are not listed in other tables [Tables 1-5 and 7]).

Several tumor suppressors are haploinsufficient, ${ }^{468}$ and cell cycle regulatory tumor suppressor genes seem especially dosage-sensitive. ${ }^{469}$ These findings indicate that the loss of 
only one copy of a gene in a diploid cell could have a biologic effect. ${ }^{469}$ Such a loss could contribute to cellular transformation, with the process of selection driving clonal expansion of pre-neoplastic cells. ${ }^{8}$

Certain tumor suppressors play a more prominent role in tumorigenesis than others in particular tissue types. However, it is probable that the loss of numerous tumor suppressor genes as a result of a chromosomal deletion probably plays a prominent role in the initiation and progression of cancer through a "combination" of different and/or complementary adverse cellular and molecular events. ${ }^{461,467}$

\section{Antioxidants (Table 7)}

Four genes on chromosome $1 \mathrm{p}$ are associated with defense against oxidative stress (Table 7). Two of these (peroxiredoxin 1 [PRDX1] and endoplasmic reticulum protein ERP19 [TXNDC12]) utilize reducing equivalents provided through the thioredoxin system, and 2 (glutamate-cysteine ligase [modifier subunit] or GCLM and glutathione peroxidase 7 [GPX7]) utilize glutathione. One of the most important genes associated with oxidative stress is glutamate-cysteine ligase (GCL) (also called gamma-glutamylcysteine synthetase), the first rate limiting enzyme of glutathione synthesis. ${ }^{470,471}$ This enzyme requires coupled ATP hydrolysis to form an amide bond between the $\gamma$-carboxyl group of glutamate and the amino group of cysteine to form $\gamma$-glutamylcysteine. The enzyme consists of a heavy catalytic subunit $(73 \mathrm{kDa})$ and a light $(31 \mathrm{kDa})$ regulatory subunit (GCLM); the light chain or modifier subunit is found on chromosome $1 \mathrm{p}$. It has been known for the past 2 decades that the ultimate formation of glutathione is required for intestinal function. ${ }^{472}$ The long-term ingestion of reduced glutathione has recently been shown to suppress the accelerating effect of a beef tallow diet on colon carcinogenesis in rats. ${ }^{473}$ The specific importance of GCLM to protection against oxidative stress is underscored in GCLM (-/-) knock-out mice, which are severely compromised in the oxidative stress response. ${ }^{474}$

GCL can be increased by oxidative stress or glutathione depletion $^{475,476}$ through the inhibition of SHP- $1^{477}$ and the activation of jun N-terminal kinase (JNK). ${ }^{477,478}$ The increase in GCL can protect against mitochondrial injury and numerous cellular processes that are depend on the generation of glutathione, such as cell cycle progression, inhibition of caspases (protection against apoptosis), activity of detoxification enzymes (see GSTM genes in Table 8; discussed below), and DNA repair. ${ }^{479-482}$ Recent studies indicate that a reduced state of proteins in the nucleus is an important environment that induces heterochromatin formation $^{482}$ and the regulation of histones and PARP activities. $^{483}$

\section{Defense against environmental and metabolic toxicity (Table 8)}

Chromosome $1 \mathrm{p}$ contains 19 genes associated with protection against toxins/carcinogens derived from the environment, dietary/cooking-derived components, and metabolism (Table 8). These genes consist of 2 arylacetamide deacetylase-like enzymes, 4 members of the aldo-keto reductase family, 6 members of the cytochrome P450 family of polypeptides, all 5 members of the mu class of glutathione-S-transferases (GSTs), and 2 metal response element binding transcription factors. A compilation of the 10 most significant transcripton factors capable of targeting the $5^{\prime}$-upstream promoter regions of these 19 genes (GeneCards [SABiosciences' database; UCSC Genome Browser]) indicates the possible involvement of 95 distinct transcription factors that control their expression. In addition, the Wnt/beta-catenin signaling pathway has been shown to activate various P450 family and GST mu class enzymes in mouse models. ${ }^{484}$ Since transcription factors respond to different cellular demands and stresses, the presence of these genes on chromosome $1 p$ indicates that the loss of this chromosome arm could compromise the cell's ability to respond to a variety of environmental toxins/carcinogens that could damage DNA.

It is of interest that all 5 genes of the mu class of GSTs are located on chromosome $1 \mathrm{p}$. The 5 genes are arranged in tandem in the physical order 5'-M4-M2-M1-M5-M3-3' ${ }^{485,486}$ The M4-M2-M1-M5 sequence in the gene cluster is oriented in a head-to-tail orientation, whereas the M3 gene is oriented tail-to-tail with respect to the adjacent M5 gene, and is therefore transcribed in the reverse orientation relevant to the other 4 GST mu genes. ${ }^{485}$ This GST mu gene cluster functions in the detoxification of electrophilic compounds by conjugating glutathione to a wide number of endogenous and exogenous toxins/carcinogens. ${ }^{487}$ Genetic polymorphisms in GSTM1 increase susceptibility to gastric and colorectal adenocarcinomas. ${ }^{488}$ In addition, about $70 \%$ of human loci is deleted for GSTM1 and 50\% of the human population is homozygous deleted for GSTM1. ${ }^{485}$ This deletion is a result of unequal crossing-over between the two $2.3 \mathrm{~kb}$ repeated regions in the intergenic regions that flank the GSTM1 gene. Homozygous deletion of GSTM1 results in increased baseline chromosomal aberrations in lymphocytes among smokers, indicating the role of epoxides and other reactive metabolites of polycyclic aromatic hydrocarbons in inducing 
genomic instability in these compromised cells. ${ }^{489}$ All 5 GSTM genes have distinct promoter regions that respond to a different array of transcription factors. Therefore, the loss of chromosome $1 \mathrm{p}$ would compromise cellular defenses against toxins/carcinogens, especially in individuals harboring the GSTM1 deletion or other specific polymorphisms.

\section{Development of resistance to cell death and the propagation of cells with DNA damage and chromosomal defects (summary)}

We have described in this review how the combination of the persistent damage to a cell's genome with the inability of that cell to adequately repair the damage or die in response to the excessive damage, is a dangerous situation which can result in clonal selection and the development of colon carcinogenesis. The molecular and cellular mechanisms that are associated with the death of cells are most complex, and include both caspase-dependent and caspase-independent processes. Listed in Tables 1-7 are 27 pro-apoptotic/pro-cell death genes found on chromosome $1 \mathrm{p}$, whose simultaneous loss caused by a chromosome $1 \mathrm{p}$ deletion could have a major impact on the development of resistance to cell death. In Table 9, we extract from those tables the specific genes whose products contribute to cell death. Caspase- 9 and both subunits of DNA fragmentation factor are on the downstream execution phase of apoptosis, and the consequences of their loss are obvious. However, the loss of other gene products (eg, TP73, miR-34a) can have pleiotropic effects on cell death pathways because of multiple transcriptional or translational targets. In addition, TP73, KIF1B, and E2F2 are classified as haploinsufficient genes, with loss of function implied with the presence of only 1 allele. ${ }^{490}$ Some gene products have dual DNA repair/pro-cell death functions (eg, MUTYH) and dual mitosis/pro-cell death functions (KIF1B). One can see (Table 9) that, in addition to classic pro-apoptotic genes, there are dual role cell survival/ pro-cell death genes, DNA damage-response genes, various tumor suppressor genes, genes associated with mitosis, miRNAs, Wnt signaling, and protection against the generation of peroxides. The mechanism of action of these 27 genes in the control of cell fate is an active area of investigation and beyond the scope of this review. This detailed study of the implications of the loss of chromosome $1 \mathrm{p}$ serve as an example of how specific chromosomal deletions can have a major impact on carcinogenesis.

\section{Role of dietary factors in colon carcinogenesis (Table 10491-538)}

In this section we first address what alteration in specific dietary factors can lead to the loss of chromosome segments or entire chromosome arms in general to produce loss of heterozygosity. Second, we will consider how the consequences of the loss of genes located on chromosome $1 \mathrm{p}$ might be affected by pro-carcinogenic and anti-carcinogenic dietary factors. Our approach is to show how specific dietary factors may influence the molecular and cellular processes affected by chromosome $1 \mathrm{p}$ loss that were described in previous sections. Links of diet to any of the specific genes lost by the 1p deletion (see Tables 1-8) are listed in Table 10.

Diets high in fat, ${ }^{43,539-547}$ but low in fiber, ${ }^{540,548-551}$ low in vegetable intake, ${ }^{552-555}$ and micronutrient deficient ${ }^{556-560}$ induce oxidative stress and DNA damage and adversely affect many molecular pathways that prevent genomic instability and apoptosis resistance, 2 major processes that, together, enhance the development of sporadic colon cancer.

Table 9 Summary of pro-cell death genes on chromosome IP

\begin{tabular}{ll}
\hline Pro-cell death genes & Reference tables \\
\hline GADD54 $\alpha$, MUTYH, TP73 & Table I DNA repair and DNA damage response genes \\
APITDI, CCNL2, CDC2L2, CDC42, E2F2, KIFIB, PLK3 & Table 2 Mitosis-related and spindle checkpoint genes \\
BCL2LI5, BCLI0, CASP9, DFFA, DFFB, THAP3, TNFRSF25 & Table 3 Apoptosis-related genes \\
miR-34a, miR-I0I-I, miR-320b-I & Table 4 MicroRNAs (miRNAs) and components of the miRNA processing complex \\
CTNNBIPI (ICAT) & Table 5 Genes associated with the Wnt signaling pathway \\
CHD5, DEARI, PRDM2, NBLI, PLA2S-II & Table 6 Tumor suppressor genes \\
PRDXI & Table 7 Genes associated with antioxidant function \\
\hline
\end{tabular}

Abbreviations: APITDI, Apoptosis-inducing, TAF9-like domain I; CL2LI5, B-Cell Lymphoma-2-like protein I5; BCLI0, B-Cell Lymphoma I0; CASP9, cysteine-aspartic acid protease, family member 9; CCNL2, Cyclin L2; CDC2L2, Cell Division Cycle 2-like 2; CDC42, Cell Division Cycle 42; CHD5, Chromodomain Helicase DNA Binding Protein 5; CTNNBIPI (ICAT), Catenin, beta interacting protein I (Inhibitor of beta-catenin-interacting protein I); DEARI, Ductal Epithelium-Associated RING Chromosome I; DFFA, DNA Fragmentation Factor A; DFFB, DNA Fragmentation Factor B; E2F2, E2F transcription factor 2; GADD45 $\alpha$, Growth Arrest and DNA-Damage-inducible 45

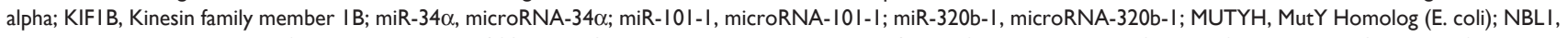
Neuroblastoma, suppression of tumorigenicity I; PLA2S-II, The Secretory Type II Phospholipase A 2 ; PLK3, Polo-like Kinase 3; PRDM2, PR Domain Containing 2; PRDXI, Peroxiredoxin I; THAP3, THAP domain containing; TNFRSF25, Tumor Necrosis Factor Receptor Superfamily, Member 25; TP73, Tumor Protein 73. 
Table 10 Preventive effects of dietary factors on processes and signaling pathways associated with genes located on chromosome IP

\begin{tabular}{|c|c|}
\hline Process & Dietary factor(s) and food sources \\
\hline \multirow[t]{2}{*}{$\begin{array}{l}\text { DNA repair and } \\
\text { DNA repair proteins }\end{array}$} & $\begin{array}{l}\text { I) Polyphenols occur in fruits and vegetables, } \\
\text { wine, tea, coffee, herbs, extra virgin olive oil, } \\
\text { chocolate, and other cocoa products }\end{array}$ \\
\hline & 2) Vitamins \\
\hline \multirow[t]{6}{*}{ MicroRNA expression } & I) Folate \\
\hline & 2) Retinoids \\
\hline & $\begin{array}{l}\text { 3) Curcumin (component of the Indian spice, } \\
\text { turmeric) }\end{array}$ \\
\hline & 4) Polyphenols \\
\hline & 5) Fish oil \\
\hline & 6) Vitamins \\
\hline
\end{tabular}

Wnt signaling pathway
Antioxidant

gene

expression
I) Polyphenols (eg, red wine, black tea)

\section{2) Curcumin}

3) Diterpenes (eg, kahweol, cafestol)

I) Polyphenols and orto-phenols

metabolic

toxicity genes

2) Diallyl disulfide (DADS)

3) Butyrate

4) Diterpenes (eg, kahweol, cafestol)

Oxidative DNA damage
Effect(s) of dietary factors and references

I) Stimulates DNA repair ${ }^{491,492}$ and increases levels of DNA repair proteins (eg, PARP-I and PMS2) by chlorogenic acid and metabolites ${ }^{493}$ and GADD45 by dihydroxyphenylethanol ${ }^{494}$ and quercetin. ${ }^{495}$

2) Ascorbate upregulates $\mathrm{MLHI}$ and $\mathrm{p} 73 .{ }^{496}$

I) Exerts cancer-protective effects through modulation of miRNA expression; ${ }^{497}$ rats fed a methyl-deficient diet exhibited decreased expression of miRNA-34a with the concomitant increase in $\mathrm{E} 2 \mathrm{~F} 3{ }^{498}$

2) Exert cancer-protective effects through modulation of miRNA expression. ${ }^{497,499}$

3) Exerts cancer-protective effects through modulation of miRNA expression. ${ }^{497,500}$

4) Quercetin and metabolites modulate inflammatory miRNA gene expression. ${ }^{501}$

5) n-3 polyunstaurated fatty acids modulate carcinogen-directed non-coding miRNA signatures in rat colon. ${ }^{502}$

6) Differences in dietary vitamin $E$ affect hepatic miRNA concentrations in vivo. ${ }^{503}$

I) Reduced nuclear and cytoplasmic immunostaining of $\beta$-catenin in the AOM rat model of colon carcinogenesis. ${ }^{504}$

2) Curcumin has an inhibitory effect on Wnt signaling ${ }^{505,506}$ through a) suppression of $\beta$-catenin response transcription activated by Wnt3a, ${ }^{507}$ b) induction of caspase-3-mediated degradation of $\beta$-catenin, ${ }^{508} \mathrm{c}$ ) downregulation of $\mathrm{p} 300$, a positive regulator of the $\mathrm{Wnt} / \beta$-catenin pathway, ${ }^{507} \mathrm{~d}$ ) reduction of expression of the Frizzled-I Wnt receptor. ${ }^{509}$

3) Lupeol treatment resulted in a) an increase of apoptosis, b) a decrease in $\beta$-catenin transcriptional activity, c) a restriction of the translocation of $\beta$-catenin from the cytoplasm to the nucleus, d) a decrease in expression of the Wnt target genes, c-myc, cyclin $D I$, e) a decrease in expression of the proliferation markers, PCNA, Ki-67, and $f$ ) a decrease in expression of the invasion marker, osteopontin. ${ }^{510}$

I) Activate endogenous antioxidant defense systems, which include the glutathione peroxidases; ${ }^{51,512}$ enhancement of glutathione and $\gamma$-glutamylcysteine synthetase. ${ }^{513-517}$

2) Curcumin alters EpRE and AP-I binding complexes and elevates glutamate-cysteine ligase expression. ${ }^{518}$

3) The coffee-derived diterpenes (eg, kahweol, cafestol) can induce $\gamma$-glutamylcysteine synthetase and glutathione levels in the liver, kidney, lung, and colon of the rat. ${ }^{519}$

I) Activate endogenous detoxification defense systems, ${ }^{51,520}$ including GSTM2; $;^{513}$ p-coumaric acid, a coffee compound..$^{521}$ can increase the mRNA levels of GSTM2. ${ }^{522}$

2) DADS increases tissue activities of quinone reductase and glutathione transferase in the gastrointestinal tract of the rat. ${ }^{523}$

3) Butyrate can induce GSTM2 expression in human colon cells. ${ }^{524}$

4) The coffee-derived diterpenes (eg, kahweol, cafestol) ${ }^{521}$ can enhance glutathione S-transferase activities. ${ }^{519,525}$

I) Polyphenols have the capacity to act as antioxidants (chain breakers or free radical scavengers, ${ }^{526}$ thereby preventing the induction of oxidative DNA lesions, ${ }^{527-530}$ and stimulating DNA repair; ${ }^{492}$ black tea complex polyphenols inhibit I,2-dimethylhydrazine-induced oxidative DNA damage in rat colonic mucosa; ${ }^{531}$ 4-coumaric acid, a coffee component, can reduce oxidative DNA damage in rat colonic mucosa. ${ }^{522}$ 
Table 10 (Continued)

\begin{tabular}{|c|c|c|}
\hline Process & Dietary factor(s) and food sources & Effect(s) of dietary factors and references \\
\hline & $\begin{array}{l}\text { 2) Fish oils, such as docosahexaenoic acid } \\
\text { (DHA), eicosapentaenoic acid (EPA) }\end{array}$ & 2) Fish oils reduce oxidative DNA damage in rat colonocytes. ${ }^{532}$ \\
\hline & $\begin{array}{l}\text { 3) Monounsaturated fatty acid (eg, oleic acid) } \\
\text { obtained from olive oil. }\end{array}$ & $\begin{array}{l}\text { 3) In a study of the effect of olive oils on biomarkers of oxidative DNA } \\
\text { stress in Northern and Southern Europeans, } 25 \mathrm{~mL} \text { of } 3 \text { olive oils } \\
\text { with low, medium, and high phenolic content were administered to } \\
\text { I } 82 \text { males daily for } 3 \text { weeks, resulting in a significant reduction of } \\
\text { DNA oxidation by } 13 \%{ }^{533} \text { The olive oil intake led to marked increase } \\
\text { in monounsaturated fatty acid intake independent of the phenolic } \\
\text { compounds; lifelong feeding of monounsaturated fatty acid-rich olive oi } \\
\text { led to a lower level of oxidative DNA damage and DNA double strand } \\
\text { breaks compared with polyunsaturated fatty acid-sunflower oil. } .^{34}\end{array}$ \\
\hline & 4) Short-chain fatty acids (eg, butyrate) & $\begin{array}{l}\text { 4) Pre-incubation of normal human colonocytes ex vivo and HT-29 } \\
\text { colon cancer cells in vitro with physiological concentrations of } \\
\text { butyrate reduced } \mathrm{H}_{2} \mathrm{O}_{2} \text {-induced DNA damage using the comet } \\
\text { assay; }{ }^{535} \text { butyrate protects human colon cells from genetic damage } \\
\text { by } 4 \text {-hydroxynonenal. }{ }^{536}\end{array}$ \\
\hline & $\begin{array}{l}\text { 5) Garlic organosulfur compounds (OSC), } \\
\text { such as allicin, diallyl sulfide, diallyl disulfide, } \\
\text { S-allyl cysteine, allyl mercaptan, are derived } \\
\text { from garlic }\end{array}$ & $\begin{array}{l}\text { 5) OSC decreased the genotoxicity of hydrogen peroxide and } \\
\text { methanesulfonate, assessed using the comet assay. }{ }^{537}\end{array}$ \\
\hline & 6) Vitamins & $\begin{array}{l}\text { 6) Ascorbic acid (vitamin C) protects against endogenous oxidative } \\
\text { DNA damage. }{ }^{538}\end{array}$ \\
\hline
\end{tabular}

Abbreviations: AOM, azoxymethane; AP-I, activator protein I; c-myc, avian myelocytomatosis viral oncogene homolog; DADS, diallyl disulfide; DHA, docosahexaenoic acid; E2F3, E2F transcription factor 3; EPA, eicosapentaenoic acid; EpRE, electrophile response element; GADD45, Growth Arrest and DNA-Damage-inducible 45; GSTM2, Glutathione S-Transferase Mu 2; Ki-67, antigen identified by monoclonal antibody Ki-67; miRNA-34a, microRNA-34a; MLHI, mutL homolog I; mRNA, messenger ribonucleic acid; OSC, organosulfur compounds; P73, Tumor Protein 73; PARP-I, poly(ADP-ribose) polymerase-I; PCNA, proliferating cell nuclear antigen; PMS2, postmeiotic segregation increased 2; Wnt, wingless-type.

The effects of diet likely occur early in the carcinogenesis process, since an altered vegetable intake is known to affect pivotal carcinogenesis pathways in the colonic mucosa from adenoma patients and controls. ${ }^{561}$ Although 2 alleles are associated with each gene, and the loss of 1 allele may be compensated for by the other, many genes are reported to be haploinsufficient, including those associated with the mitotic checkpoint. ${ }^{562}$ It is relevant that TP73, KIF1B, and E2F2, found on chromosome 1p, have also been reported to be haploinsufficient, ${ }^{490,563,564}$ and could have dramatic consequences for colon tumorigenesis if only 1 allele is expressed in colonic epithelial cells. It is possible that many other genes may be found to be haploinsufficient in the future, since a map of 1079 probable haploinsufficient genes has been compiled by systematic identification of genes unambiguously and repeatedly compromised by copy number variation among 8458 apparently healthy individuals. ${ }^{565}$ Those genes with a high probability of exhibiting haploinsufficiency were enriched among genes implicated in human dominant diseases and among genes causing abnormal phenotypes in heterozygous knockout mice. ${ }^{565}$ In addition, the loss of several genes on the same chromosome arm that affect a particular molecular pathway (see Tables 1-8) may together have a significant effect on that pathway, although the loss of a single gene may have little effect. Specific dietary factors may decrease the protein levels of certain genes through post-translational mechanisms (eg, proteasomal degradation), thereby inducing a functional pseudo-biallelic loss of a gene, one through a physical loss of the chromosomal segment harboring that gene, and the other an actual degradation of the gene product.

Although dietary factors may affect many processes associated with carcinogenesis, we will evaluate specific factors associated with oxidative stress/inflammation, since these genotoxic processes are known to have major effects on the initiation and progression of cancer, including colon cancer. ${ }^{566-578}$ Direct damage to DNA, assessed by immunohistochemical staining of 8-oxoG, correlates with poor survival in colorectal cancer. ${ }^{579}$ ROS can cause excessive DNA double strand breaks, resulting in the loss of chromosome segments or entire arms, depending on the location of the break. In addition, several DNA repair proteins are degraded through an oxidative mechanism, ${ }^{580,581}$ thereby affecting DNA repair and increasing susceptibility to cancer. ${ }^{582}$ Oxidative stress can affect spindle organization, induce centrosome amplification, cause proteolysis of components of the anaphase-promoting complex, and override the spindle checkpoint, thereby affecting chro- 
mosomal stability. Therefore, oxidative stress can induce a mutator phenotype in affected cells. ${ }^{583}$ The big question is what dietary factors contribute directly to oxidative DNA damage and aneuploidy (alteration in the number of whole chromosomes or chromosomal segments). We now address several dietary factors that may be associated with these forms of genomic instability. Although the literature on dietary factors associated with genomic instability is substantial, we have chosen to discuss the effects of a highfat diet, folate deficiency, and niacin deficiency, since the molecular and cellular mechanisms associated with the overabundance or deficiency of these factors have been especially well studied.

A high-fat diet derived from beef tallow or corn oil (eg, linoleic acid, palmitic acid) is one of the major causes of sporadic colon cancer. Long-chain nonesterified ("free") fatty acids (FFA) and some of their derivatives and metabolites can modify the intracellular production of ROS, in particular superoxide anions and hydrogen peroxide, in part, through their interference with the mitochondrial electron transport chain. ${ }^{584}$ FFA can also interfere with the glutathione system and stimulate the generation of superoxide anions from phagocytic NADPH oxidases. ${ }^{584}$ Chronic exposure of cells to FFA (eg, palmitic acid) can also alter miRNA expression (eg, miR-34a, miR-146). ${ }^{585}$

The genotoxicity associated with a high-fat diet is also caused, in part, by high concentrations of hydrophobic bile acids released into the gastrointestinal tract in response to high-fat meals where they act as detergents to aid in the digestion of fats. Our research group showed that deoxycholic acid (a major hydrophobic bile acid in the human colon) induces $\operatorname{ROS}^{586-589}$ in vitro, and oxidative DNA damage, ${ }^{590}$ sessile adenomas, ${ }^{591}$ and colon cancer ${ }^{592}$ in dietary-related mouse models. In addition to the bile acid-induced formation of 8-oxoG in guanine bases of DNA and the induction of DNA strand breaks (activation of $\gamma-\mathrm{H}_{2} \mathrm{AX}^{593}$ and PARP ${ }^{594}$ ), we have shown that deoxycholic acid affects genomic instability at the chromosomal level. ${ }^{595}$ Evidence indicating the induction of chromosomal damage by deoxycholic acid include the formation of micronuclei and aberrant mitoses, attenuation of activation of the nocodazole-induced spindle checkpoint, and decrease in protein expression of major spindle checkpoint proteins (eg, Mad2, BubR1, securin). The dramatic effect of deoxycholic acid on the process of mitosis is underscored by the finding that deoxycholic acid modulates 71 mitosis-related genes at the mRNA and/or protein levels in vitro and in vivo using mouse models. ${ }^{8}$ The induction by hydrophobic bile acids of both DNA and chromosomal damage indicates that hydrophobic bile acids are endogenous carcinogens that, at high pathophysiologic concentrations, are capable of contributing to the initiation and progression of colon cancer. ${ }^{8,189,595-597}$ In addition to causing genomic instability, deoxycholic acid can activate survival pathways (eg, NF- $\mathrm{B}^{594}$ and autophagy ${ }^{598}$ ), which allow for the survival and selection of cells with genomic instability. ${ }^{8,599}$

Coffee drinkers have a lower incidence of cancer, including that of the colon and rectum. ${ }^{600-603}$ One coffee compound that we found to prevent the formation of bile acid-induced proximal colon cancer in a mouse model is chlorogenic acid (CGA), the ester of caffeic acid with quinic acid. ${ }^{592} \mathrm{CGA}$ is one of the most abundant polyphenols in the human diet, with coffee, fruits (eg, blueberry, strawberry, raspberry, apple), and vegetables (eg, eggplants, potato, carrot, tomato) as its major sources. ${ }^{493,604}$ CGA and its metabolites are likely responsible, in part, for the lower risk of rectal cancer associated with the consumption of decaffeinated coffee in 2 large prospective cohort studies. ${ }^{603}$ One possible mechanism by which polyphenols can reduce colon cancer in this model is through the reduction in deoxycholic acid levels. ${ }^{605}$ In this study, Han et al ${ }^{605}$ report that when rats on a high-fat diet ( $30 \%$ beef tallow) received dietary curcumin (component of the Indian spice turmeric) or caffeic acid (metabolite of CGA), the fecal concentration of deoxycholic acid was substantially reduced. In addition, dietary supplementation of this high-fat diet with caffeic acid, catechin (plant polyphenol), rutin (citrus flavonoid glycoside), and ellagic acid (plant polyphenol) significantly reduced the levels of fecal lithocholic acid, a second major hydrophobic bile acid and risk factor for colon cancer. ${ }^{605}$

The induction of double-strand breaks is a major cause of the production of chromosomal fragments and the deletion of hundreds to thousands of genes. An important DNA repair protein in preventing large chromosomal deletions is Parp- $1^{606}$ (Figure 5). DNA strand breakage is directly caused by ROS (which would be enhanced due to the loss of genes encoding antioxidant proteins in the chromosome 1p deletion [Table 7]) or as a result of the activity of base excision repair enzymes (see Figure 5). Strand breakage activates Parp-1, which is involved with opening up chromatin and allowing DNA repair processes to occur, including base excision repair, singlestrand and double-strand repair (Figure 5). Shibata et al ${ }^{606}$ carried out mutation analysis using Parp-1 knockout $\left(\right.$ Parp $\left.^{-/-}\right)$ mice, and found that PARP deficiency enhanced deletion mutations, especially $>1 \mathrm{kbp}$. A dietary micronutrient whose deficiency has a major effect on PARP activity is niacin (vitamin $\mathrm{B}_{3}$ ) obtained from meat and corn. The term niacin 
refers to nicotinic acid and nicotinamide, which are both used by humans to form NAD ${ }^{+}$. PARP-1 utilizes $\mathrm{NAD}^{+}$to make poly(ADP-ribose) needed for poly(ADP-ribosyl)ation of proteins. In keeping with the protective effect of PARP, we determined that pre-treatment of cells in vitro with nicotinic acid and nicotinamide protected against bile acid-induced apoptosis, ${ }^{607}$ presumably by enhancing PARP-mediated DNA repair of bile acid-induced DNA damage and replenishing the $\mathrm{NAD}^{+}$levels in mitochondria. In addition, we showed that pre-treatment of cells with nicotinic acid and nicotinamide upregulated the mRNA levels of the glycolytic enzymes, glyceraldehyde-3-phosphate dehydrogenase (GAPDH) and glucose-6-phosphate dehydrogenase (G6PD). ${ }^{608}$ GAPDH and G6PD may protect against oxidative stress, in part through the generation of the reduced pyridine nucleotides, $\mathrm{NADH}$ and NADPH, respectively, from NAD ${ }^{+}{ }^{608}$ Niacin supplementation was even reported to improve pellagra (severe niacin deficiency) in a patient with Crohn's disease, ${ }^{609}$ a pre-cancerous inflammatory condition ${ }^{610}$ associated with oxidative DNA damage. ${ }^{611}$ Pellagra most probably developed in these Crohn's disease patients through a combination of intestinal malabsorption of niacin/nicotinic acid ${ }^{612,613}$ and the high demand for $\mathrm{NAD}^{+}$that accompanies DNA damageinduced PARP-1 activity (see Figure 5). Work from our laboratory indicated that CGA and its metabolites, caffeic acid, $m$-coumaric acid, and 3-( $m$-hydroxyphenyl) propionic acid, increased PARP-1 protein expression. ${ }^{493}$ The modulation of PARP-1 protein levels by CGA may explain, in part, the colon cancer preventive properties of CGA when added as a supplement to the bile acid-induced colon cancer mouse model. ${ }^{592}$

The mechanisms by which chromosome segments are deleted and translocated can be most complex. Deletions and translocations can arise from centromeric instability and telomeric instability. ${ }^{7,614}$ and have been proposed as possible mechanisms for chromosomal aberrations associated with chromosome $1 .^{615-617}$ Centromeric instability can result from hypomethylation or acetylation of pericentromeric heterochromatin, resulting in decondensation/uncoiling/ disruption of the centromere ${ }^{618-620}$ and loss of the affected chromosome arms. Telomeric instability is characterized by telomeric fusions, formation of anaphase bridges during mitosis, broken chromosomes upon the stress of cell division, and fusion of chromosomal fragments to chromosome ends. This cycle of chromosomal abberations is referred to as breakage-fusion-bridge cycles. ${ }^{107-114,621}$ Six genes found on chromosome 1p (APITD1, CCDC28B, CDCA8, $\mathrm{HDAC} 1, \mathrm{KIF} 2 \mathrm{C}, \mathrm{RCC} 2$ ) are associated with centomeres (see
Table 2), and whose loss would affect centromeric instability. A deficiency of HDAC1, for example, has been reported to disrupt pericentromeric heterochromatin. ${ }^{622}$ In addition to its role in the repair of interstrand cross-links, ${ }^{623}$ APOLLO (aka DCLRE1B [DNA cross-link repair $1 \mathrm{~B}$ ]) is also involved in the protection of telomeres (see Table 1). APOLLO is stabilized when bound to the telomere-binding protein TRF2, and protects human telomeres in S phase ${ }^{624}$ (Figure 4). A reduced level of APOLLO results in an increased number of telomere-induced DNA damage foci and telomeric fusions in S-phase, ${ }^{624}$ suggesting that APOLLO contributes to a processing step associated with the replication of chromosome ends. Hydrophobic bile acids, probably through the generation of oxidative stress, can modulate 71 genes associated with mitosis ${ }^{8}$ and decrease the protein expression of 3 major spindle checkpoint proteins (eg, Mad2, BubR1, securin). ${ }^{8}$ These alterations in gene expression, coupled with direct oxidative damage to components of the mitotic apparatus, may be responsible, in part, for the observed bile acid-induced mitotic aberrations. ${ }^{595}$ It is, therefore, possible that bile acids may contribute to the loss of chromosome $1 \mathrm{p}$ through its effects on centromere instability and telomeric fusions.

Another mechanism by which large chromosomal deletions can occur is through folic acid deficiency. ${ }^{625,626}$ Folic acid can attenuate the loss of heterozygosity of the DCC tumor suppressor gene in the colonic mucosa of patients with colorectal adenomas, ${ }^{625}$ indicating that folic acid deficiency can affect allelic deletion and associated micronuclei formation. ${ }^{627,628}$ Folates are a group of watersoluble B vitamins (obtained from leafy, green vegetables, the whole grain quinoa, and lentils) whose deficiency contributes to colon cancer. ${ }^{629-633}$ Folates maintain DNA stability through their ability to donate one-carbon units for cellular metabolism and particularly for DNA biosynthesis, repair, and methylation. ${ }^{629,633}$ Methylenetetrahydrofolate reductase (MTHFR) is a key enzyme in one-carbon metabolism. MTHFR catalyzes a unidirectional reaction that determines the balance between cellular availability of 5,10-methylenetetrahydrofolate, used for thymidylate and purine synthesis, and methyltetrahydrofolate used for biological methylation. ${ }^{629}$ Folate deficiency, therefore, enhances carcinogenesis by impairing normal methylation and nucleotide synthesis, and creates an imbalance between the partitioning of cellular folates into these two pathways. Inhibition of folate metabolism results in excessive uracil misincorporation into DNA ${ }^{633,634}$ with approximately 4 million uracil bases/cell. ${ }^{559}$ The repair of 2 adjacent uracil residues on opposite strands of DNA can result in a double-strand break, 
leading to chromosomal breakage and aneuploidy. ${ }^{558,629,634}$ Folate deficiency also induces hypomethylation and inhibits DNA excision repair in immortalized normal human colon epithelial cells ${ }^{633}$ and in the rat colon. ${ }^{635}$

Recent studies have implicated folate deficiency in the modulation of miRNA expression. ${ }^{497,636}$ Using microarrays of 385 known human miRNAs, it was determined that folate deficiency in vitro in cultured cells induced a statistically significant fold-change in 24 miRNAs. ${ }^{636}$ One of these miRNAs was miR-34a, which is found on chromosome $1 p$ and involved in p53-mediated signaling (see Table 4 and the section on MiRNA and MiRNA Processing). MiRNAs were also determined to be altered in patients on a folate-deficient diet. ${ }^{636}$ In addition to folate deficiency, polymorphisms of MTHFR and altered folate levels are associated with colon cancer risk. ${ }^{637-640}$ The fact that MTHFR is located on chromosome $1 \mathrm{p}$ at $1 \mathrm{p} 36.22$ indicates that the loss of this chromosome arm, coupled with folate deficiency, can have major effects on genomic instability.

In this section we have considered how dietary factors such as niacin, folic acid, and a low-fat diet associated with low bile acid levels, together with antioxidants that protect against oxidative DNA damage (Table 10), might affect the processes relevant to carcinogenesis that are altered by chromosome $1 \mathrm{p}$ loss. In addition to a deficiency in dietary factors that prevent oxidative DNA damage, a deficiency of certain dietary factors that modulate DNA repair proteins, miRNA expression, antioxidant enzymes, defenses against environmental toxicity, and the Wnt signaling pathway (Table 10) can exacerbate the effects of the loss of chromosome 1p. An understanding of the complex molecular and cellular pathways that are affected by dietary factors is an enormous undertaking, but one that has become a focus of colon cancer prevention.

\section{Acknowledgments}

This work was supported in part by NIH 5 R01 CA119087, Arizona Biomedical Research Commission Grant \#0803, VA Merit Review Grant 0142 of the Southern Arizona Veterans Affairs Health Care System and Biomedical Diagnostics and Research, Inc., Tucson, Arizona.

\section{Disclosure}

The authors declare no conflicts of interest.

\section{References}

1. Steinbeck RG. Chromosome division figures reveal genomic instability in tumorigenesis of human colon mucosa. Br J Cancer. 1998;77: 1027-1033.

2. Hermsen M, Postma C, Baak J, et al. Colorectal adenoma to carcinoma progression follows multiple pathways of chromosomal instability. Gastroenterology. 2002;123:1109-1119.
3. Ribas M, Masramon L, Aiza G, Capella G, Miro R, Peinado MA. The structural nature of chromosomal instability in colon cancer cells. FASEB J. 2003;17:289-291.

4. Richter H, Slezak P, Walch A, et al. Distinct chromosomal imbalances in nonpolypoid and polypoid colorectal adenomas indicate different genetic pathways in the development of colorectal neoplasms. Am J Pathol. 2003;163:287-294.

5. Rajagopalan H, Nowak MA, Vogelstein B, Lengauer C. The significance of unstable chromosomes in colorectal cancer. Nat Rev Cancer. 2003;3:695-701.

6. Postma C, Hermsen MA, Coffa J, et al. Chromosomal instability in flat adenomas and carcinomas of the colon. J Pathol. 2005;205:514-521.

7. Stewenius Y, Gorunova L, Jonson T, et al. Structural and numerical chromosome changes in colon cancer develop through telomere-mediated anaphase bridges, not through mitotic multipolarity. Proc Natl Acad Sci US A. 2005;102:5541-5546.

8. Payne CM, Bernstein C, Dvorak K, Bernstein H. Hydrophobic bile acids, genomic instability, Darwinian selection, and colon carcinogenesis. Clin Exp Gastroenterol. 2008;1:19-47.

9. Ashktorab H, Schaffer AA, Daremipouran M, Smoot DT, Lee E, Brim H. Distinct genetic alterations in colorectal cancer. PloS One. 2010;5:e8879

10. Pino MS, Chung DC. The chromosomal instability pathway in colon cancer. Gastroenterology. 2010;138:2059-2072.

11. Bacolod MD, Barany F. Gene dysregulations driven by somatic copy number aberrations-biological and clinical implications in colon tumors: A paper from the 2009 William Beaumont Hospital Symposium on Molecular Pathology. J Mol Diagn. 12:552-561.

12. Reichmann A, Martin P, Levin B. Chromosomes in human large bowel tumors. A study of chromosome 1. Cancer Genet Cytogenet. 1984;12: 295-301.

13. Muleris M, Salmon RJ, Dutrillaux B, et al. Characteristic chromosomal imbalances in 18 near-diploid colorectal tumors. Cancer Genet Cytogenet. 1987;29:289-301.

14. Muleris M, Salmon RJ, Dutrillaux B. Existence of two distinct processes of chromosomal evolution in near-diploid colorectal tumors. Cancer Genet Cytogenet. 1988;32:43-50.

15. Leister I, Weith A, Bruderlein S, et al. Human colorectal cancer: High frequency of deletions at chromosome 1p35. Cancer Res. 1990;50: 7232-7235.

16. Bravard A, Luccioni C, Muleris M, Lefrancois D, Dutrillaux B. Relationships between UMPK and PGD activities and deletions of chromosome 1p in colorectal cancers. Cancer Genet Cytogenet. 1991; 56:45-56.

17. Couturier-Turpin MH, Esnous C, Louvel A, Poirier Y, Couturier D. Chromosome 1 in human colorectal tumors. Cytogenetic research on structural changes and their significance. Hum Genet. 1992;88: 431-438.

18. Bardi G, Johansson B, Pandis N, et al. Cytogenetic aberrations in colorectal adenocarcinomas and their correlation with clinicopathologic features. Cancer. 1993;71:306-314.

19. Bardi G, Pandis N, Fenger C, Kronborg O, Bomme L, Heim S. Deletion of $1 \mathrm{p} 36$ as a primary chromosomal aberration in intestinal tumorigenesis. Cancer Res. 1993;53:1895-189.

20. Bardi G, Johansson B, Pandis N, et al. Cytogenetic analysis of 52 colorectal carcinomas - non-random aberration pattern and correlation with pathologic parameters. Int J Cancer. 1993;55:422-428.

21. Bomme L, Bardi G, Pandis N, Fenger C, Kronborg O, Heim S. Clonal karyotypic abnormalities in colorectal adenomas: Clues to the early genetic events in the adenoma-carcinoma sequence. Genes Chromosomes Cancer. 1994;10:190-196.

22. Bardi G, Sukhikh T, Pandis N, Fenger C, Kronborg O, Heim S. Karyotypic characterization of colorectal adenocarcinomas. Genes Chromosomes Cancer. 1995;12:97-109.

23. Gerdes H, Chen Q, Elahi AH, et al. Recurrent deletions involving chromosomes 1, 5, 17, and 18 in colorectal carcinoma: Possible role in biological and clinical behavior of tumors. Anticancer Res. 1995;15: $13-24$. 
24. Lothe RA, Andersen SN, Hofstad B, et al. Deletion of 1p loci and microsatellite instability in colorectal polyps. Genes Chromosomes Cancer. 1995;14:182-188.

25. Praml C, Finke LH, Herfarth C, Schlag P, Schwab M, Amler L. Deletion mapping defines different regions in 1p34.2-pter that may harbor genetic information related to human colorectal cancer. Oncogene. 1995; 11:1357-1362.

26. Di Vinci A, Infusini E, Peveri C, Risio M, Rossini FP, Giaretti W. Deletions at chromosome $1 \mathrm{p}$ by fluorescence in situ hybridization are an early event in human colorectal tumorigenesis. Gastroenterol. 1996; 111:102-107.

27. Bomme L, Bardi G, Pandis N, Fenger C, Kronborg O, Heim S Chromosome abnormalities in colorectal adenomas: Two cytogenetic subgroups characterized by deletion of $1 \mathrm{p}$ and numerical aberrations. Hum Pathol. 1996;27:1192-1197.

28. Bardi G, Parada LA, Bomme L, et al. Cytogenetic findings in metastases from colorectal cancer. Int J Cancer. 1997;72:604-607.

29. Ogunbiyi OA, Goodfellow PJ, Gagliardi G, et al. Prognostic value of chromosome 1p allelic loss in colon cancer. Gastroenterology. 1997; 113:761-766.

30. Di Vinci A, Infusini E, Peveri C, et al. Correlation between 1p deletions and aneusomy in human colorectal adenomas. Int J Cancer. 1998;75: 45-50.

31. Di Vinci A, Infusini E, Nigro S, Monaco R, Giaretti W. Intratumor distribution of $1 \mathrm{p}$ deletions in human colorectal adenocarcinoma is commonly homogeneous. Indirect evidence of early involvement in colorectal tumorigenesis. Cancer. 1998;83:415-422.

32. Tomlinson I, Ilyas M, Johnson V, et al. A comparison of the genetic pathways involved in the pathogenesis of three types of colorectal cancer. J Pathol. 1998;184:148-152.

33. Bomme L, Heim S, Bardi G, et al. Allelic imbalance and cytogenetic deletion of $1 \mathrm{p}$ in colorectal adenomas: A target region identified between D1S199 and D1S234. Genes Chromosomes Cancer. 1998; 21:185-194.

34. Di Vinci A, Infusini $\mathrm{E}$, Peveri $\mathrm{C}$, et al. Intratumor heterogeneity of chromosome 1, 7, 17, and 18 aneusomies obtained by FISH and association with flow cytometric DNA index in human colorectal adenocarcinomas. Cytometry. 1999;35:369-375.

35. Parada LA, Maranon A, Hallen M, et al. Cytogenetic analyses of secondary liver tumors reveal significant differences in genomic imbalances between primary and metastatic colon carcinomas. Clin Exp Metastasis. 1999;17:471-479.

36. Ragnarsson G, Eiriksdottir G, Johannsdottir JT, Jonasson JG, Egilsson V, Ingvarsson $\mathrm{S}$. Loss of heterozygosity at chromosome 1p in different solid human tumours: association with survival. $\mathrm{Br} J$ Cancer. 1999;79:1468-1474.

37. Rashid A, Houlihan PS, Booker S, Petersen GM, Giardiello FM, Hamilton SR. Phenotypic and molecular characteristics of hyperplastic polyposis. Gastroenterology. 2000;119:323-332.

38. Thorstensen L, Qvist H, Heim S, et al. Evaluation of 1p losses in primary carcinomas, local recurrences and peripheral metastases from colorectal cancer patients. Neoplasia. 2000;2:514-522.

39. Couterier-Turpin MH, Bertrand V, Couturier D. Distal deletion of $1 \mathrm{p}$ in colorectal tumors: An initial event and/or a step in carcinogenesis? Study by fluorescence in situ hybridization interphase cytogenetics. Cancer Genet Cytogenet. 2001;124:47-55.

40. Thiagalingam S, Laken S, Willson JK, et al. Mechanisms underlying losses of heterozygosity in human colorectal cancers. Proc Natl Acad Sci USA. 2001;98:2698-2702.

41. Shih IM, Zhou W, Goodman SN, Lengauer C, Kinzler KW, Vogelstein B. Evidence that genetic instability occurs at an early stage of colorectal tumorigenesis. Cancer Res. 2001;61:818-822.

42. Nowak MA, Komarova NL, Sengupta A, et al. The role of chromosomal instability in tumor initiation. Proc Natl Acad Sci U S A. 2002;99: 16226-16231.

43. Hoglund M, Gisselssonm D, Hansen GB, Sall T, Mitelman F, Nilbert M. Dissecting karyotypic patterns in colorectal tumors: Two distinct but overlapping pathways in the adenoma-carcinoma transition. Cancer Res. 2002;62:5939-5946.
44. Cianciulli A, Cosimelli M, Marzano R, et al. Genetic and pathologic significance of $1 p, 17 p$, and $18 \mathrm{q}$ aneusomy and the ERBB2 gene in colorectal cancer and related normal colonic mucosa. Cancer Genet Cytogenet. 2004;151:52-59.

45. Giaretti W, Molinu S, Ceccarelli J, Prevosto C. Chromosomal instability, aneuploidy, and gene mutations in human sporadic colorectal adenomas. Cell Oncol. 2004;26:301-305.

46. Zhou CZ, Qiu GQ, Zhang F, He L, Peng ZH. Loss of heterozygosity on chromosome 1 in sporadic colorectal carcinoma. World J Gastroenterol. 2004;10:1431-1435.

47. Tsafrir D, Bacolod M, Selvanayagam Z, et al. Relationship of gene expression and chromosomal abnormalities in colorectal cancer. Cancer Res. 2006;66:2129-2137.

48. Fijneman RJ, Carvalho B, Postma C, Mongera S, van Hinsbergh VW, Meijer GA. Loss of 1p36, gain of 8q24, and loss of 9q34 are associated with stroma percentage of colorectal cancer. Cancer Lett. 2007;258: 223-229.

49. Brosens RP, Haan JC, Carvalho B, et al. Candidate driver genes in focal chromosomal aberrations of stage II colon cancer. J Pathol. 2010;221: 411-424.

50. Sandforth F, Witzel L, Balzer T, Gutschmidt S, Janicke I, Riecken EO. Identification of patients at high risk for colorectal carcinoma from biopsy studies of the apparently normal colorectal mucosa. A multivariate analysis. Eur J Clin Invest. 1991;21:295-302.

51. Chhatwal VJ, Ngoi SS, Chan ST, Chia YW, Moochhala SM. Aberrant expression of nitric oxide synthase in human polyps, neoplastic colonic mucosa and surrounding peritumoral normal mucosa. Carcinogenesis. 1994;15:2081-2085.

52. Bernstein C, Bernstein H, Garewal H, et al. A bile acid-induced apoptosis assay for colon cancer risk, and associated quality control studies. Cancer Res. 1999;59:2353-2357.

53. Bernstein C, Bernstein H, Payne CM, Garewal H. Field defects in progression to adenocarcinoma of the colon and esophagus. Electronic J Biotechnol. 2000;3:1-17. Available on the Web: http://www.ejb.org/ content/vol3/issue3/full/1.

54. Bernstein H, Holubec H, Warneke JA, et al. Patchy field defects of apoptosis resistance and dedifferentiation in flat mucosa of colon resections from colon cancer patients. Ann Surg Oncol. 2002;9: 505-517.

55. Suter CM, Martin DI, Ward RL. Hypomethylation of L1 retrotransposons in colorectal cancer and adjacent normal tissue. Int J Colorectal Dis. 2004;19:95-101

56. Roy HK, Liu Y, Wali RK, et al. Four-dimensional elastic lightscattering fingerprints as preneoplastic markers in the rat model of colon carcinogenesis. Gastroenterology. 2004;126:1071-1081.

57. Roy HK, Kim YL, Liu Y, et al. Risk stratification of colon carcinogenesis through enhanced backscattering spectroscopy analysis of the uninvolved colonic mucosa. Clin Cancer Res. 2006;12:961-968.

58. Hao CY, Moore DH, Wong P, Bennington JL, Lee NM, Chen LC. Alteration of gene expression in macroscopically normal colonic mucosa from individuals with a family history of sporadic colon cancer. Clin Cancer Res. 2005;11:1400-1407.

59. Payne CM, Holubec H, Bernstein C, et al. Crypt-restricted loss and decreased protein expression of cytochrome c oxidase subunit I as potential hypothesis-driven biomarkers of colon cancer risk. Cancer Epidemiol Biomarkers Prev. 2005;14:2066-2075.

60. Badvie S, Hanna-Morris A, Anreyev HJ, Cohen P, Saini S, AllenMersh TG. A "field change" of inhibited apoptosis occurs in colorectal mucosa adjacent to colorectal adenocarcinoma. J Clin Pathol. 2006;59: 942-946.

61. Bernstein H, Prasad A, Holubec H, et al. Reduced Pms2 in non-neoplastic flat mucosa from patients with colon cancer correlates with reduced apoptosis competence. Appl Immunohistochem $\mathrm{Mol}$ Morphol. 2006;14:166-172.

62. Kawakami K, Ruszkiewicz A, Bennett G, et al. DNA hypermethylation in the normal colonic mucosa of patients with colon cancer. Br J Cancer. 2006;94:593-598. 
63. Alberts DS, Einspahr JG, Krouse RS, et al. Karyometry of the colonic mucosa. Cancer Epidemiol Biomarkers Prev. 2007;16:2704-2716.

64. Payne CM, Bernstein C, Bernstein H. Field change of apoptosis resistance in colonic mucosa of patients with colorectal carcinoma. J Clin Path. 2007. [electronic letter published February 5, 2007].

65. Bernstein C, Bernstein H, Payne CM, Dvorak K, Garewal H. Field defects in progression to gastrointestinal tract cancers. Cancer Lett. 2008;260:1-10.

66. Belshaw NJ, Elliott GO, Foxall RJ, et al. Profiling $\mathrm{CpG}$ island field methylation in both morphologically normal and neoplastic human colonic mucosa. Br J Cancer. 2008;99:136-142.

67. Chao H, Brown RE. Field effect in cancer - an update. Ann Clin Lab Sci. 2009;39:331-337.

68. Daniel CR, Bostick RM, Flanders WD, et al. TGF- $\alpha$ expression as a potential biomarker of risk within the normal-appearing colorectal mucosa of patients with and without incident sporadic adenoma. Cancer Epidemiol Biomarkers Prev. 2009;18:65-73.

69. Belshaw NJ, Pal N, Tapp HS, et al. Patterns of DNA methylation in individual colonic crypts reveal aging and cancer-related field defects in the morphologically normal mucosa. Carcinogenesis. 2010;31: $1158-1163$.

70. Nguyen H, Loustaunau C, Facista A, et al. Deficient Pms2, ERCC1, $\mathrm{Ku} 86, \mathrm{CcOI}$ in field defects during progression to colon cancer. $J$ Vis Exp. 2010 Jul 28:41. Pii:1931. doi: 10.3791/1931.

71. Paraskeva C, Buckle BG, Sheer D, Wigley CB. The isolation and characterization of colorectal epithelial cell lines at different stages in malignant transformation from familial polyposis coli patients. Int $J$ Cancer. 1984;34:49-56.

72. Paraskeva C, Finerty S, Powell S. Immortalization of a human colorectal adenoma cell line by continuous in vitro passage: Possible involvement of chromosome 1 in tumour progression. Int $J$ Cancer. 1988;41:908-912.

73. Paraskeva C, Finerty S, Mountford RA, Powell SC. Specific cytogenetic abnormalities in two new human colorectal adenoma-derived epithelial cell lines. Cancer Res. 1989;49:1282-1286.

74. Paraskeva C, Harvey A, Finerty S, Powell S. Possible involvement of chromosome 1 in in vitro immortalization: Evidence from progression of a human adenoma-derived cell line in vitro. Int $J$ Cancer. 1989b;43:743-746.

75. Williams AC, Harper SJ, Paraskeva C. Neoplastic transformation of a human colonic epithelial cell line: In vitro evidence for the adenoma to carcinoma sequence. Cancer Res. 1990;50:4724-4730.

76. Tanaka K, Yanoshita R, Konishi M, et al. Suppression of tumourigenicity in human colon carcinoma cells by introduction of normal chromosome 1p36 region. Oncogene. 1993;8:2253-2258.

77. Roschke AV, Glebov OK, Lababidi S, Gehlhaus KS, Weinstein JN, Kirsch IR. Chromosomal instability is associated with higher expression expression of genes implicated in epithelial-mesenchymal transition, cancer invasiveness, and metastasis and with lower expression of genes involved in cell cycle checkpoints, DNA repair, and chromatin maintenance. Neoplasia. 2008;10:1222-1230.

78. Negrini S, Gorgoulis VG, Halazonetis TD. Genetic instability - an evolving hallmark of cancer. Nat Rev Mol Cell Biol. 2010;11:220-228.

79. Sawyer JR, Husain M, Lukacs JL, Stangeby C, Binz RL, Al-Mefty O. Telomeric fusion as a mechanism for the loss of $1 \mathrm{p}$ in meningioma. Cancer Genetics Cytogenet. 2003;145:38-48.

80. Gregory SG, Barlow KF, McLay KE, et al. The DNA sequence and biological annotation of human chromosome 1. Nature. 2006;44: 315-321.

81. Bartek J, Bartkova J, Lukas J. DNA damage signalling guards against activated oncogenes and tumour progression. Oncogene. 2007;26: 7773-7779.

82. Harper JW, Elledge. The DNA damage response: Ten years after. $M o l$ Cell. 2007;28:739-745.

83. Jackson SP, Bartek. The DNA-damage response in human biology and disease. Nature. 2009;461:1071-1078.

84. Ciccia A, Elledge SJ. The DNA damage response: Making it safe to play with knives. Mol Cell. 2010;40:179-204.
85. Nigg EA. Mitotic kinases as regulators of cell division and its checkpoints. Nat Rev Mol Cell Biol. 2001;2:21-32.

86. Nyberg KA, Michelson RJ, Putnam CW, Weinert TA. Toward maintaining the genome: DNA damage and replication checkpoints. Annu Rev Genet. 2002;36:617-656.

87. Sancar A, Lindsey-Boltz LA, Unsal-Kacmaz K, Linn S. Molecular mechanisms of mammalian DNA repair and the DNA damage checkpoints. Annu Rev Biochem. 2004;73:39-85.

88. Su TT. Cellular responses to DNA damage: One signal, multiple choices. Аnnu Rev Genet. 2006;40:187-208.

89. Hakem R. DNA-damage repair; the good, the bad, and the ugly. EMBO J. 2008;27:589-605.

90. Wood JL, Chen J. DNA-damage checkpoints: Location, location, location. Trends Cell Biol. 2008;18:451-455.

91. Reinhardt HC, Yaffe MB. Kinases that control the cell cycle in response to DNA damage: Chk1, Chk2, and MK2. Curr Opin Cell Biol. 2009; 21:245-255.

92. Decordier I, Cundari E, Kirsch-Volders M. Mitotic checkpoints and the maintenance of the chromosome karyotype. Mutat Res. 2008;651:3-13.

93. Gimenez-Abian JF, Diaz-Martinez LA, Wirth KG, Andrews CA, Gimenez-Martin G, Clarke, DJ. Regulated separation of sister centromeres depends on the spindle assembly checkpoint but not on the anaphase promoting complex/cyclosome. Cell Cycle. 2005;4: 1561-1575.

94. Kops GJPL, Weaver BAA, Cleveland DW. On the road to cancer: Aneuploidy and the mitotic checkpoint. Nat Rev Cancer. 2005;5: 773-785.

95. May KM, Hardwick KG. The spindle checkpoint. J Cell Sci. 2006;119: 4139-4142.

96. Musacchio A, Salmon ED. The spindle-assembly checkpoint in space and time. Nat Rev Mol Cell Biol. 2007;8:379-393.

97. Suijkerbuijk SJE, Kops GJPL. Preventing aneuploidy: The contribution of mitotic checkpoint proteins. Biochim Biophys Acta. 2008;1786: 24-31.

98. Thirthagiri E, Robinson CM, Huntley S, et al. Spindle assembly checkpoint and centrosome abnormalities in oral cancer. Cancer Lett. 2007;258:276-285.

99. Mikhailov A, Cole RW, Rieder CL. DNA damage during mitosis in human cells delays the metaphase/anaphase transition via the spindleassembly checkpoint. Curr Biol. 2002;12:1797-1806.

100. D'Adda di Fagagna F, Reaper PM, Clay-Farrace, et al. A DNA damage checkpoint response in telomere-initiated senescence. Nature. 2003; 426:194-198.

101. Longhese MP. DNA damage response at functional and dysfunctional telomeres. Genes Develop. 2008;22:125-140.

102. Maser RS, DePinho RA. Telomeres and the DNA damage response: Why the fox is guarding the henhouse. DNA Repair. 2004;3: 979-988.

103. Meier A, Fiegler H, Munoz P, et al. Spreading of mammalian DNAdamage response factors studied by ChIP-chip at damaged telomeres. EMBO J. 2007;26:2707-2718.

104. Pantic M, Zimmermann S, El Daly H, et al. Telomere dysfunction and loss of p53 cooperate in defective mitotic segregation of chromosomes in cancer cells. Oncogene. 2006;25:4413-4420.

105. Takai H, Smogorzewska A, de Lange T. DNA damage foci at dysfunctional telomeres. Curr Biol. 2003;13:1549-1556.

106. Viscardi V, Clerici M, Cartagena-Lirola H, Longhese MP. Telomeres and DNA damage checkpoints. Biochimie. 2005;87:613-624.

107. Gisselsson D, Pettersson L, Hoglund M, et al. Chromosomal breakagefusion-bridge events cause genetic intratumor heterogeneity. Proc Natl Acad Sci U SA. 2000;97:5357-5362.

108. Hoffelder DR, Luo L, Burke NA, Watkins SC, Gollin SM, Saunders WS. Resolution of anaphase bridges in cancer cells. Chromosoma. 2004;112:389-397.

109. Kitada K, Yamasaki T. The complicated copy number alterations in chromosome 7 of a lung cancer cell line is explained by a model based on repeated breakage-fusion-bridge cycles. Cancer Genet Cytogenet. 2008;185:11-19. 
110. Lo AWI, Sabatier L, Fouladi B, Pottier G, Ricoul M, Murnane JP. DNA amplification by breakage/fusion/bridge cycles initiated by spontaneous telomere loss in a human cancer cell line. Neoplasia. 2002;4:531-538.

111. McClintock B. The behavior in successive nuclear divisions of a chromosome broken at meiosis. Proc Natl Acad Sci U S A. 1939;25: 405-416.

112. McClintock B. The fusion of broken ends of chromosomes following nuclear fusion. Proc Natl Acad Sci U S A. 1942;28:458-463.

113. Selvarajah S, Yoshimoto M, Park PC, et al. The breakage-fusion-bridge (BFB) cycle as a mechanism for generating genetic heterogeneity in osteosarcoma. Chromosoma. 2006;115:459-467.

114. Shimizu N, Shingaki K, Kaneko-Sasaguri Y, Hashizume T, Kanda T. When, where and how the bridge breaks: Anaphase bridge breakage plays a crucial role in gene amplification and HSR generation. Exp Cell Res. 2005;302:233-243.

115. Bree RT, Neary C, Samali A, Lowndes NF. The switch from survival responses to apoptosis after chromosomal breaks. DNA Repair. 2004; 3:989-995.

116. Brodsky MH, Weinert BT, Tsang G, et al. Drosophila melanogaster $\mathrm{MNK} / \mathrm{Chk} 2$ and $\mathrm{p} 53$ regulate multiple DNA repair and apoptotic pathways following DNA damage. Mol Cell Biol. 2004;24: 1219-1231.

117. Kastan MB. DNA damage responses: Mechanisms and roles in human disease. Mol Cancer Res. 2008;6:517-524.

118. Kohn KW, Pommier Y. Molecular interaction map of the p53 and Mdm2 logic elements, which control the Off-On switch of p53 in response to DNA damage. Biochem Biophys Res Comm. 2005;331: 816-827.

119. Lee MW, Kim W-J, Beardsley DI, Brown KD. $N$-Methyl- $N$ '-Nitro- $N$ Nitrosoguanidine activates multiple cell death mechanisms in human fibroblasts. DNA Cell Biol. 2007;26:683-694.

120. Liontos M, Niforou K, Velimezi G, et al. Modulation of the E2F1driven cancer cell fate by the DNA damage response machinery and potential novel E2F1 targets in osteosarcomas. Am J Pathol. 2009; 175:376-391.

121. Michalak E, Villunger A, Erlacher M, Strasser A. Death squads enlisted by the tumour suppressor p53. Biochem Biophys Res Comm. 2005; 331:786-798.

122. Morrison C, Rieder CL. Chromosome damage and progression into and through mitosis in vertebrates. DNA Repair. 2004;3:1133-1139.

123. Kops GJPL, Foltz DR, Cleveland DW. Lethality to human cancer cells through massive chromosome loss by inhibition of the mitotic checkpoint. Proc Natl Acad Sci U S A. 2004;101:68704.

124. Bekier ME, Fischbach R, Lee J, Taylor WR. Length of mitotic arrest induced by microtubule-stabilizing drugs determines cell death after mitotic exit. Mol Cancer Ther. 2009;8:1646-1654.

125. Nitta M, Kobayashi O, Honda S, et al. Spindle checkpoint function is required for mitotic catastrophe induced by DNA-damaging agents Oncogene. 2004;23:6548-6558.

126. Rieder CL, Maiato H. Stuck in division or passing through: What happens when cells cannot satisfy the spindle assembly checkpoint. Dev Cell. 2004;7:637-651.

127. Weaver BAA, Cleveland DW. Decoding the links between mitosis, cancer, and chemotherapy: The mitotic checkpoint, adaptation, and cell death. Cancer Cell. 2005;8:7-12.

128. Ahmad K, Golic KG. Telomere loss in somatic cells of Drosophila causes cell cycle arrest and apoptosis. Genetics. 1999;151:1041-1051.

129. Aoki H, Iwado E, Eller MS, et al. Telomere 3' overhang-specific DNA oligonucleotides induce autophagy in malignant glioma cells. FASEBJ. 2007;21:2918-2930.

130. Arkus N. A mathematical model of cellular apoptosis and senescence through the dynamics of telomere loss. J Theoret Biol. 2005;235: 13-32.

131. Artandi SE, Attardi LD. Pathways connecting telomeres and p53 in senescence, apoptosis, and cancer. Biochem Biophys Res Comm. 2005; 331:881-890
132. Eller MS, Puri N, Hadshiew IM, Venna SS, Gilchrest BA. Induction of apoptosis by telomere 3- overhang-specific DNA. Exp Cell Res. 2002;276:185-193.

133. Espejel S, Franco S, Rodriquez-Perales, Bouffler SD, Cigudosa JC, Blasco MA. Mammalian Ku86 mediates chromosomal fusions and apoptosis caused by critically short telomeres. EMBO J. 2002;21: 2207-2219

134. Hemann MT, Strong MA, Hao L-Y, Greider CW. The shortest telomere, not average telomere length, is critical for cell viability and chromosomal stability. Cell. 2001;107:67-77.

135. Herbert B-S, Pitts AE, Baker SI, et al. Inhibition of human telomerase in immortal human cell cells leads to progressive telomere shortening and cell death. Proc Natl Acad Sci U S A. 1999;96: 14276-14281.

136. Kaminker PG, Kim S-H, Taylor RD, et al. TANK2, a new TRF1associated poly(ADP-ribose) polymerase, causes rapid induction of cell death upon overexpression. J Biol Chem. 2001;276:35891-35899.

137. Karlseder J, Broccoli D, Dai Y, Hardy S, de Lange T. p53- and ATMdependent apoptosis induced by telomeres lacking TRF2. Science. 1999;283:1321-1325.

138. Ramirez R, Carracedo J, Jimenez R, Canela A, Herrera E. Massive telomere loss is an early event of DNA damage-induced apoptosis. $J$ Biol Chem. 2003;278:836-842.

139. Titen SWA, Golic KG. Telomere loss provokes multiple pathways to apoptosis and produces genomic instability in Drosophila melanogaster. Genetics. 2008;180:1821-1832.

140. Zhang X, Mar V, Zhou W, Harrington L, Robinson MO. Telomere shortening and apoptosis in telomerase-inhibited human tumor cells Genes Dev. 1999;13:2388-2399.

141. Plesca D, Mazumder S, Almasan A. DNA damage response and apoptosis. Methods Enzymol. 2008;446:107-122.

142. Roos WP, Kaina B. DNA damage-induced cell death by apoptosis. Trends Mol Med. 2006;12:440-450.

143. Yu J, Zhang L. The transcriptional targets of p53 in apoptosis control. Biochem Biophys Res Comm. 2005;331:851-858.

144. Kitagawa K, Niikura Y. Caspase-independent mitotic death (CIMD) Cell Cycle. 2008;7:1001-1005.

145. Castedo M, Perfettini J-L, Roumier T, et al. Mitotic catastrophe constitutes a special case of apoptosis whose suppression entails aneuploidy. Oncogene. 2004;23:4362-4370.

146. Castedo M, Perfettini JL, Roumier T, Andreau K, Medema R, Kroemer G. Cell death by mitotic catastrophe: A molecular definition. Oncogene. 23:2825-2837.

147. Mansilla S, Priebe W, Portugal J. Mitotic catastrophe results in cell death by caspase-dependent and caspase-independent mechanisms. Cell Cycle. 2006;5:53-60.

148. Vakifahmetoglu H, Olsson M, Zhivotovsky B. Death through a tragedy: mitotic catastrophe. Cell Death Differ. 2008;15:1153-1162.

149. Borges HL, Linden R, Wang JYJ. DNA damage-induced cell death: Lessons from the central nervous system. Cell Res. 2008;18: $17-26$.

150. Wang JY, Cho SK. Coordination of repair, checkpoint and cell death responses to DNA damage. Adv Protein Chem. 2004;69:101-135.

151. Fearon ER, Vogelstein B. A genetic model for colorectal tumorigenesis. Cell. 1990;61:759-767.

152. Murray-Zmijewski F, Lane DP, Bourdon JC. p53/p63/p73 isoforms: an orchestra of isoforms to harmonise cell differentiation and response to stress. Cell Death Differ. 2006;13:962-972.

153. Bourdon J-C. p53 and its isoforms in cancer. Br J Cancer. 2007;97: 277-282.

154. Marabese M, Vikhanskaya F, Broggini M. p73: a chiaroscuro gene in cancer. Eur J Cancer. 2007;43:1361-1372.

155. Oswald C, Stiewe T. In good times and bad: 73 in cancer. Cell Cycle. 2008;7:1726-1731.

156. Scian MJ, Carchman EH, Mohanraj L, et al. Wild-type p53 and p73 negatively regulate expression of proliferation related genes. Oncogene. 2008;27:2583-2593. 
157. Tomkova K, Tomka M, Zajac V. Contributions of p53, p63, and p73 to the developmental diseases and cancer. Neoplasma. 2008;55: 177-181.

158. Vilgelm AE, Washington MK, Wei J, Chen H, Prassolov VS, Zaika AI. Interactions of the p53 protein family in cellular stress response in gastrointestinal tumors. Mol Cancer Ther. 2010;9:693-705.

159. Hsieh SC, Lo PK, Wang FF. Mouse DDA3 gene is a direct transcriptional target of p53 and p73. Oncogene. 2002;21:3050-3057.

160. Jang CY, Wong J, Coppinger JA, Seki A, Yates JR 3rd, Fang G. DDA3 recruits microtubule depolymerase Kif2a to spindle poles and controls spindle dynamics and mitotic chromosome movement. J Cell Biol. 2008;181:255-267.

161. Merlo P, Fulco M, Costanzo A, et al. A role of p73 in mitotic exit. J Biol Chem. 289:30354-30360.

162. Tomasini R, Mak TW, Melino G. The impact of p53 and p73 on aneuploidy and cancer. Trends Cell Biol. 2008;18:244-252.

163. Boominathan L. Some facts and thoughts: p73 as a tumor suppressor gene in the network of tumor suppressors. Mol Cancer. 2007;6:27.

164. Boominathan $\mathrm{L}$. The tumor suppressors $\mathrm{p} 53$, $\mathrm{p} 63$, and $\mathrm{p} 73$ are regulators of microRNA processing complex. PloS One. 2010;5:e10615.

165. Rosenbluth JM, Pietenpol JA. The jury is in: p73 is a tumor suppressor after all. Genes Dev. 2008;22:2591-2595.

166. Collavin L, Lunardi A, Del Sal G. p53-family proteins and their regulators: Hubs and spokes in tumor suppression. Cell Death Differ. 2010;17:901-911.

167. Zawacka-Pankau J, Kostecka A, Sznarkowska A, Hedstrom E, Kawiak A. p73 tumor suppressor protein. A close relative of p53 not only in structure but also in anti-cancer approach? Cell Cycle. 2010;9: 720-728.

168. Simonelli V, Narciso L, Dogliotti E, Fortini P. Base excision repair intermediates are mutagenic in mammalian cells. Nucleic Acids Res. 2005;33:4404-4411.

169. Neeley WL, Essigmann JM. Mechanisms of formation, genotoxicity, and mutation of guanine oxidation products. Chem Res Toxicol. 2006; 19:491-505.

170. David SS, O'Shea VL, Kundu S. Base excision repair of oxidative DNA damage. Nature. 2007;447:941-950.

171. Lindahl T, Wood RD. Quality control by DNA repair. Science. 1999;286:1897-1905.

172. Kairupan C, Scott RJ. Base excision repair and the role of MUTYH. Hered Cancer Clin Pract. 2007;5:199-209.

173. Tenesa A, Campbell H, Barnetson R, Porteous M, Dunlop M, Farrington SM. Association of MUTYH and colorectal cancer. Br J Cancer. 2006;95:239-242.

174. Sieber OM, Howarth KM, Thirlwell C, et al. Myh deficiency enhances intestinal tumorogenesis in multiple intestinal neoplasia $\left(A p c^{\mathrm{Min} /+}\right)$ mice. Cancer Res. 2004;64:8876-8881.

175. Hirano S, Tominaga Y, Ichinoe A, et al. Mutator phenotype of MUTYH-null mouse embryonic stem cells. J Biol Chem. 2003;278: 38121-38124.

176. Slupska MM, Baikalov C, Luther WM, Chiang JH, Wei YF, Miller JH. Cloning and sequencing a human homolog (hMYH) of the Escherichia coli mutY gene whose function is required for the repair of oxidative DNA damage. J Bacteriol. 1996;178:3885-3892.

177. Shinmura K, Yamaguchi S, Saitoh T, et al. Adenine excisional repair function of $\mathrm{MYH}$ protein on the adenine: 8-hydroxyguanine base pair in double-stranded DNA. Nucleic Acids Res. 2000;28: 4912-4918.

178. Bolgogh I, Milligan D, Lee MS, Bassett H, Lloyd S, McCullough AK. hMYH cell cycle-dependent expression, subcellular localization and association with replication foci: evidence suggesting replicationcoupled repair of adenine:8-oxoguanine mispairs. Nucleic Acids Res. 2001;29:2802-2809.

179. Scharer OD, Jiricny J. Recent progress in the biology, chemistry and structural biology of DNA glycosylases. Bioessays. 2001;23: $270-281$
180. Jiricny J, Mana G. DNA repair defects in colon cancer. Curr Opin Genet Develop. 2003;13:61-69.

181. De Murcia G, de Murcia JM. Poly(ADP-ribose) polymerase: A molecular nick-sensor. Trends Biol Sci. 1994;19:172-176.

182. Mortusewicz O, Ame J-C, Schreiber V, Leonhardt H. Feedbackregulated poly(ADP-ribosyl)ation by PARP-1 is required for rapid response to DNA damage in living cells. Nucleic Acids Res. 2007;35: 7665-7675.

183. Yoshihara K, Tanaigawa Y, Burzio L, Koide SS. Evidence for adenosine diphosphate ribosylation of $\mathrm{Ca}^{2+}, \mathrm{Mg}^{2+}$ - dependent endonuclease. Proc Natl Acad Sci U S A. 1975;72:289-293.

184. Wielckens K, Schmidt A, George E, Bredehorst R, Hilz H. DNA fragmentation and NAD depletion. Their relationship to the turnover of endogenous mon(ADP-ribosyl) and poly(ADP-ribosyl) proteins. J Biol Chem. 1982;257:12872-12877.

185. Ha HC, Snyder SH. Poly(ADP-ribose) polymerase is a mediator of necrotic cell death by ATP depletion. Proc Natl Acad Sci USA. 1999; 96:13978-13982.

186. Zong WX, Ditsworth D, Bauer DE, Wang ZQ, Thompson CB. Alkylating DNA damage stimulates a regulated form of necrotic cell death. Genes Dev. 2004;18:1272-1282.

187. Cipriani G, Rapizzi E, Vannacci A, Rizzuto R, Moroni F, Chiarugi A. Nuclear poly(ADP-ribose) polymerase-1 rapidly triggers mitochondrial dysfunction. J Biol Chem. 2005;280:17227-17234.

188. Liu H, Knabb JR, Spike BT, Macleod KF. Elevated poly-(ADPribose)-polymerase activity sensitizes retinoblastoma-deficient cells to DNA damage-induced necrosis. Mol Cancer Res. 2009;7: 1099-1109.

189. Bernstein H, Bernstein C, Payne CM, Dvorakova K, Garewal H. Bile acids as carcinogens in human gastrointestinal cancers. Mutat Res. 2005;589:47-65.

190. Payne CM, Bernstein C, Bernstein H. Apoptosis overview emphasizing oxidative stress, DNA damage and signal-transduction pathways. Leuk Lymphoma. 1995;19:43-93.

191. Oka S, Ohno M, Tsuchimoto D, Sakumi K, Furuichi M, Nakabeppu Y. Two distinct pathways of cell death triggered by oxidative damage to nuclear and mitochondrial DNAs. EMBO J. 2008; 27:421-432.

192. Oka S, Ohno M, Nakabeppu Y. Construction and characterization of a cell line deficient in repair of mitochondrial, but not nuclear, oxidative DNA damage. Methods Mol Biol. 2009;554:251-265.

193. Ichikawa J, Tsuchimoto D, Oka S, et al. Oxidation of mitochondrial deoxynucleotide pools by exposure to sodium nitroprusside induces cell death. DNA Repair. 2008;7:418-430.

194. Kagedal K, Johansson AC, Johansson U, et al. Lysosomal membrane permeabilization during apoptosis-involvement of Bax? Int J Exp Pathol. 2005;86:309-321.

195. Wang H, Yu SW, Koh DW, et al. Apoptosis-inducing factor substitutes for caspase executioners in NMDA-triggered excitotoxic neuronal death. J Neurosci. 2004;24:10963-10973.

196. Yu SW, Wang H, Poitras MF, et al. Mediation of poly(ADP-ribose) polymerase-1-dependent cell death by apoptosis-inducing factor. Science. 2002;297:259-263.

197. Andrabi SA, Kim NS, Yu S-W, et al. Poly(ADP-ribose) (PAR) polymer is a death signal. Proc Natl Acad Sci U S A. 2006;103:18308-18313.

198. Wang Y, Dawson VL, Dawson TM. Poly(ADP-ribose) signals to mitochondrial AIF: A key event in parthanatos. Exp Neurol. 2009; 218:193-202.

199. Yu S-W, Andrabi SA, Wang H, et al. Apoptosis-inducing factor mediates poly(ADP-ribose) (PAR) polymer-induced cell death. Proc Natl Acad Sci U S A. 2006;103:18314-18319.

200. Lipton SA, Bossy-Wetzel E. Dueling activities of AIF in cell death versus survival: DNA binding and redox activity. Cell. 2002;111: 147-150.

201. Ye H, Cande C, Stephanou NC, et al. DNA binding is required for the apoptogenic action of apoptosis inducing factor. Nat Struct Biol. 2002;9:680-684. 
202. Vahsen N, Cande C, Dupaigne P, et al. Physical interaction of apoptosis-inducing factor with DNA and RNA. Oncogene. 2006;25: 1763-1774.

203. Susin SA, Lorenzo HK, Zamzami N, et al. Molecular characterization of mitochondrial apoptosis-inducing factor. Nature. 1999;397: 441-446.

204. Modjtahedi N, Giordanetto F, Madeo F, Kroemer G. (2006) Apoptosis-inducing factor: Vital and lethal. Trends Cell Biol. 2005;16: 264-272.

205. Hong SJ, Dawson TM, Dawson VL. Nuclear and mitochondrial conversations in cell death: PARP-1 and AIF signaling. Trends Pharmacol Sci. 2004;25:259-264.

206. Van Wijk SJ, Hageman GJ. Poly(ADP-ribose) polymerase-1 mediated caspase-independent cell death after ischemia/reperfusion. Free Radic Biol Med. 2005;39:81-90.

207. Boujrad H, Gubkina O, Robert N, Krantic S, Susin SA. AIF-mediated programmed necrosis: A highly regulated way to die. Cell Cycle. 2007; 6:2611-1618

208. Krantic S, Mechawar N, Reix S, Quirion R. Apoptosis-inducing factor: A matter of neuron life and death. Prog Neurobiol. 2007;81: 179-196.

209. Li GY, Osborne NN. Oxidative-induced apoptosis to an immortalized ganglion cell line is caspase independent but involves the activation of poly(ADP-ribose) polymerase and apoptosis-inducing factor Brain Res. 2008;1188:35-43.

210. Lorenzo HK, Susin SA. Therapeutic potential of AIF-mediated caspase-independent programmed cell death. Drug Resist Updates. 2007;10:235-255.

211. Moubarak RS, Yuste VJ, Artus C, et al. Sequential activation of poly(ADP-ribose) polymerase 1, calpains, and Bax is essential in apoptosis-inducing factor-mediated programmed necrosis. Mol Cell Biol. 2007;27:4844-4862.

212. Son Y-O, Jang Y-S, Heo J-S, Chung W-T, Choi K-C, Lee J-C. Apoptosis-inducing factor plays a critical role in caspase-independent, pyknotic cell death in hydrogen peroxide-exposed cells. Apoptosis. 2009; $14: 796-808$.

213. Son YO, Kook SH, Jang YS, Shi X, Lee JC. Critical role of poly(ADPribose) polymerase- 1 in modulating the mode of cell death caused by continuous oxidative stress. J Cell Biochem. 2009;108:989-997.

214. Norberg E, Orrenius S, Zhivotovsky B. Mitochondrial regulation of cell death: Processing of apoptosis-inducing factor. Biochem Biophys Res Comm. 2010;396:95-100.

215. Otera H, Ohsakaya S, Nagaura Z, Ishihara N, Mihara K. Export of mitochondrial AIF in response to proapoptotic stimuli depends on processing at the intermembrane space. EMBO J. 2005;24:1375-1386.

216. Uren RT, Dewson G, Bonzon C, Lithgow T, Newmeyer DD, Kluck RM. Mitochondrial release of pro-apoptotic proteins: Electrostatic interactions can hold cytochrome c but not Smac/ DIABLO to mitochondrial membranes. $J$ Biol Chem. 2005;280: 2266-2274.

217. Polster BM, Basanez G, Etxebarria A, Hardwick JM, Nicholls DG. Calpain I induces cleavage and release of apoptosis-inducing factor from isolated mitochondria. J Biol Chem. 2005;280:6447-6454.

218. Yuste VJ, Moubarak RS, Delettre C, et al. Cysteine protease inhibition prevents mitochondrial apoptosis-inducing factor (AIF) release. Cell Death Differ. 2005;12:1445-1448.

219. Norberg E, Gogvadze V, Vakifahmetoglu H, Orrenius S, Zhivotovsky B. Oxidative modification sensitizes mitochondrial apoptosis-inducing factor to calpain-mediated processing. Free Radic Biol Med. 2010;48:791-797.

220. Yacoub A, Park MA, Hanna D, et al. OSU-03012 promotes caspaseindependent but PERK-, cathepsin B-, BID-, and AIF-dependent killing of transformed cells. Mol Pharmacol. 2006;70:589-603.

221. Chaitanya GV, Babu PP. Multiple apoptogenic proteins are involved in the nuclear translocation of apoptosis inducing factor during transient focal cerebral ischemia in rat. Brain Res. 2008;1246: 178-190.
222. Norberg E, Gogvadze V, Ott M, et al. An increase in intracellular $\mathrm{Ca}^{2+}$ is required for the activation of mitochondrial calpain to release AIF during cell death. Cell Death Differ. 2008;15:1857-1864.

223. Vosler PS, Sun D, Wang S, et al. Calcium dysregulation induces apoptosis-inducing factor release: Cross-talk between PARP-1 and calpain-signaling pathways. Exp Neurol. 2009;218:213-220.

224. Gagne JP, Hunter JM, Labrecque B, Chabot B, Poirier GG. A proteomic approach to the identification of heterogeneous nuclear ribonucleoproteins as a new family of poly(ADP-ribose)-binding proteins. Biochem J. 2003;371:331-340.

225. Gagne JP, Hendzel MJ, Droit A, Poirier GG. The expanding role of poly(ADP-ribose) metabolism: Current challenges and new perspectives. Curr Opin Cell Biol. 2006;18:145-151.

226. Gagne JP, Isabelle M, Lo KS, et al. Proteome-wide identification of poly(ADP-ribose) binding proteins and poly(ADP-ribose)-associated protein complexes. Nucleic Acids Res. 2008;36:6959-6976.

227. Chen M, He H, Zhan S, Krajewski S, Reed JC, Gottlieb RA. Bid is cleaved by calpain to an active fragment in vitro and during myocardial ischemia/reperfusion. J Biol Chem. 2001;276:30724-30728.

228. Deng Y, Ren X, Yang L, Lin Y, Wu X. A JNK-dependent pathway is required for TNFalpha-induced apoptosis. Cell. 2003; 115:61-70

229. Culmsee C, Zhu C, Landshamer S, et al. Apoptosis-inducing factor triggered by poly(ADP-ribose) polymerase and bid mediates neuronal cell death after oxygen-glucose deprivation and focal cerebral ischemia. J Neurosci. 2005;25:10262-10272.

230. Letai A, Bassik MC, Walensky LD, Sorcinelli MD, Weiler S, Korsmeyer SJ. Distinct BH3 domains either sensitize or activate mitochondrial apoptosis, serving as prototype cancer therapeutics. Cancer Cell. 2002;2:183-192.

231. Chen D, Zhou Q. Caspase cleavage of $\mathrm{Bim}_{\mathrm{EL}}$ triggers a psoitive feedback amplification of apoptotic signaling. Proc Natl Acad Sci U S A. 2004;101:1235-1240

232. Liou AK, Zhou Z, Pei W, Lim TM, Yin XM, Chen J. BimEL up-regulation potentiates AIF translocation and cell death in response to MPTP. FASEB J. 2005;19:1350-1352.

233. Alano CC, Swanson RA. Players in the PARP-1 cell-death pathway: JNK1 joins the cast. Trends Biochem Sci. 2006;31:309-311.

234. Xu Y, Huang S, Liu Z-G, Han J. Poly(ADP-ribose) polymerase-1 signaling to mitochondria in necrotic cell death requires RIP1/TRAF2mediated JNK activation. $J$ Biol Chem. 2006;281:8788-8795.

235. Song ZF, Ji XP, Li XX, Wang SJ, Wang SH, Zhang Y. Inhibition of the activity of poly(ADP-ribose) polymerase reduces heart ischaemia/ reperfusion injury via suppressing JNK-mediated AIF translocation. J Cell Mol Med. 2008;12:1220-1228.

236. Lei K, Davis RJ. JNK phosphorylation of Bim-related members of the Bcl2 family induces Bax-dependent apoptosis. Proc Natl Acad Sci U S A. 2003;100:2432-2437.

237. Heeres JT, Hergenrother PJ. Poly(ADP-ribose) makes a date with death. Curr Opin Chem Biol. 2007;11:644-653.

238. Burton TR, Eisenstat DD, Gibson SP. BNIP3 (Bcl-2 interacting protein) acts as transcriptional repressor of apoptosis-inducing factor expression preventing cell death in human malignant gliomas. J Neurosci. 2009;29:4189-4199.

239. Pietsch EC, Sykes SM, McMahon SB, Murphy ME. The $\mathrm{p} 53$ family and programmed cell death. Oncogene. 2008;27:6507-6521.

240. Yuan ZM, Shioya H, Ishiko T, et al. p73 is regulated by tyrosine kinase $\mathrm{c}-\mathrm{Abl}$ in the apoptotic response to DNA damage. Nature. 1999;399:814-817.

241. Stiewe T, Putzer BM. Role of the p53-homologue p73 in E2F1-induced apoptosis. Nat Genet. 2000;26:464-469.

242. Toh WH, Siddique MM, Boominathan L, Lin KW, Sabapathy K. c-Jun regulates the stability and activity of the p53 homologue, p73.J Biol Chem. 2004;279:44713-44722.

243. Melino G, Bernassola F, Ranalli M, et al. p73 induces apoptosis via PUMA transactivation and Bax mitochondrial translocation. $J$ Biol Chem. 2004;279:8076-8083. 
244. Rossi M, Sayan AE, Terrinoni A, Melino G, Knight RA. Mechanism of induction of apoptosis by $\mathrm{p} 73$ and its relevance to neuroblastoma biology. Ann N Y Acad Sci. 2004;1028:143-149.

245. Ramadan S, Terrinoni A, Catani MV, et al. p73 induces apoptosis by different mechanisms. Biochem Biophys Res Commun. 2005;331: 713-717.

246. Carter SL, Eklund AC, Kohane IS, Harris LN, Szallasi Z. A signature of chromosomal instability inferred from gene expression profiles predicts clinical outcome in multiple human cancers. Nat Genet. 2006; 38:1043-1048.

247. Perez de Castro I, de Carcer G, Marcos M. A census of mitotic cancer genes: New insights into tumor cell biology and cancer therapy. Carcinogenesis. 2007;28:899-912.

248. Tarin JJ, Vendrell FJ, Ten J, Blanes R, van Blerom J, Cano A. The oxidizing agent tertiary butyl hydroperoxide induces disturbances in spindle organization, c-meiosis, and aneuploidy in mouse oocytes. Mol Human Reproduct. 1996;2:895-901.

249. Choi WJ, Banerjee J, Falcone T, Bena J, Agarwal A, Sharma RK. Oxidative stress and tumor necrosis factor- $\alpha$-induced alterations in metaphase II mouse oocyte spindle structure. Fertl Steril. 2007; 88(4 Suppl):1220-1231.

250. D'Angiolella V, Santarpia C, Grieco D. Oxidative stress overrides the spindle checkpoint. Cell Cycle. 2007;6:576-579.

251. Chang T-S, Jeong W, Lee D-Y, Cho C-S, Rhee SG. The ring-H2-finger protein APC11 as a target of hydrogen peroxide. Free Rad Biol Med. 2004;37:521-530.

252. Blagosklonny MV. Mitotic arrest and cell fate: Why and how mitotic inhibition of transcription drives mutually exclusive events. Cell Cycle. 2007;6:70-74.

253. Delcuve GP, He S, Davie JR. Mitotic partitioning of transcription factors. J Cell Biochem. 2008;105:1-8.

254. Gascoigne KE, Taylor SS. Cancer cells display profound intra- and interline variation following prolonged exposure to antimitotic drugs. Cancer Cell. 2008;14:111-122.

255. Elhajouji A, Cunha M, Kirsch-Volders M. Spindle poisons induce polyploidy by mitotic slippage and micronucleate mononucleates in the cytokinesis-block assay. Mutagenesis. 1998;13:193-198.

256. Dai W, Wang Q, Liu T, et al. Slippage of mitotic arrest and enhanced tumor development in mice with BubR1 haploinsufficiency. Cancer Res. 2004;64:440-445.

257. Tao W, South VJ, Zhang Y, et al. Induction of apoptosis by an inhibitor of the mitotic kinesin KSP requires both activation of the spindle assembly checkpoint and mitotic slippage. Cancer Cell. 2005; 8:49-59.

258. Brito DA, Rieder CL. Mitotic checkpoint slippage in humans occurs via cyclin B destruction in the presence of an active checkpoint. Curr Biol. 2006;16:1194-1200.

259. Stevens FE, Beamish H, Warrener R, Gabrielli B. Histone deacetylase inhibitors induce mitotic slippage. Oncogene. 2008;27: 1345-1354.

260. Brito DA, Yang Z, Rieder CL. Microtubules do not promote mitotic slippage when the spindle assembly checkpoint cannot be satisfied. J Cell Biol. 2008;182:623-629.

261. Riffell JL, Zimmerman C, Khong A, McHardy LM, Roberge M. Effects of chemical manipulation of mitotic arrest and slippage on cancer cell survival and proliferation. Cell Cycle. 2009;8:3029-3042.

262. Lee J, Kim JA, Margolis RL, Fotedar R. Substrate degradation by the anaphase promoting complex occurs during mitotic slippage. Cell Cycle. 2010;9:1792-1801.

263. Xu FL, Rbaibi Y, Kiselyov K, Lazo JS, Wipf P, Saunders WS. Mitotic slippage in non-cancer cells induced by a microtubule disruptor, disorazole $\mathrm{C}_{1}$. Chem Biol. 2010;10:1.

264. Dodson H, Bourke E, Jeffers LJ, et al. Centrosome amplification induced by DNA damage occurs during a prolonged G2 phase and involves ATM. EMBO J. 2004;23:3864-3873.

265. Butler LM, Hewett PJ, Fitridge RA, Cowled PA. Deregulation of apoptosis in colorectal carcinoma: Theoretical and therapeutic implications. Aust N Z J Surg. 1999;69:88-94.
266. Payne CM, Bernstein H, Bernstein C, Garewal H. The role of apoptosis in biology and pathology: Resistance to apoptosis in colon carcinogenesis. Ultrastruct Pathol. 1995a; 19:221-248.

267. Nelson DA, Tan TT, Rabson AB, Anderson D, Degenhardt K, White E. Hypoxia and defective apoptosis drive genomic instability and tumorigenesis. Genes Develop. 2008;18:2095-2107.

268. Enari M, Sakahira H, Yokoyama H, Okawa K, Iwamatsu A, Nagata S. A caspase-activated DNase that degrades DNA during apoptosis, and its inhibitor ICAD. Nature. 1998;391:43-50.

269. Halenbeck R, MacDonald H, Roulston A, Chen TT, Conroy L, Williams LT. CPAN, a human nuclease regulated by the caspasesensitive inhibitor DFF45. Curr Biol. 1998;8:537-540.

270. Liu X, Zou H, Slaughter C, Wang X. DFF, a heterodimeric protein that functions downstream of caspase-3 to trigger DNA fragmentation during apoptosis. Cell. 1997;89:175-184.

271. Liu X, Li P, Widlak P, et al. The 40-kDa subunit of DNA fragmentation factor induces DNA fragmentation and chromatin condensation during apoptosis. Proc Natl Acad Sci U SA. 1998;95: 8461-8466.

272. Kerr JFR, Wyllie AH, Currie AR. Apoptosis: A basic biological phenomenon with wide-ranging implications in tissue kinetics. $\mathrm{Br} J$ Cancer. 1972;26:239-257.

273. Wyllie AH, Kerr JF, Currie AR. Cell death: The significance of apoptosis. Int Rev Cytol. 1980;68:251-305.

274. Searle J, Kerr JFR, Bishop CJ. Necrosis and apoptosis: Distinct modes of cell death with fundamentally different significance. Pathol Annu. 1982;17:229-259.

275. Wyllie AH, Morris RG, Smith AL, Dunlop D. Chromatin cleavage in apoptosis: Association with condensed chromatin morphology and dependence on macromolecular synthesis. J Pathol. 1984;142: $67-77$.

276. Payne CM, Bjore CG Jr, Schultz DA. Change in the frequency of apoptosis after low- and high-dose X-irradiation of human lymphocytes. J Leukocyte Biol. 1992;52:433-440.

277. Oberhammer F, Wilson JW, Dive C, et al. Apoptotic death in epithelial cells: Cleavage of DNA to $300 \mathrm{and} /$ or $50 \mathrm{~kb}$ fragments prior to or in the absence of internucleosomal fragmentation. EMBO J. 1993;12:3679-3684.

278. Widlak P. DFF40/CAD hypersensitive sites are potentially involved in high molecular weight DNA fragmentation during apoptosis. Cell Mol Biol Lett. 2000;5:373-379.

279. Mcllroy D, Sakahira H, Talanian RV, Nagata S. Involvement of caspase 3-activated DNase in internucleosomal DNA cleavage induced by diverse apoptotic stimuli. Oncogene. 1999;18: 4401-4408.

280. Widlak P, Gerrard WT. Roles of the major apoptotic nuclease-DNA fragmentation factor in biology and disease. Cell Mol Life Sci. 2009;66: 263-274.

281. Yan B, Wang H, Peng Y, et al. A unique role of the DNA fragmentation factor in maintaining genomic stability. Proc Natl Acad Sci U S A. 2006a;103:1504-1509.

282. Zhang J, Liu X, Scherer DC, van Kaer L, Wang X, Xu M. Resistance to DNA fragmentation and chromatin condensation in mice lacking the DNA fragmentation factor 45. Proc Natl Acad Sci U S A. 1998; 95:12480-12485.

283. Zhang J, Wang X, Bove KE, Xu M. DNA fragmentation factor 45-deficient cells are more resistant to apoptosis and exhibit different dying morphology than wild-type control cells. J Biol Chem. 1999; 274:37450-37454.

284. Yan B, Wang H, Wang H, et al. Apoptotic DNA fragmentation factor maintains chromosome stability in a 533 -independent manner. Oncogene. 2006b;25:5370-5376.

285. Zhang J, Guo H, Qian G, et al. MiR-145, a new regulator of the DNA fragmentation factor-45 (DFF45)-mediated apoptotic network. Mol Cancer. 2010;9:211

286. Li P, Nijhawan D, Budihardjo I, et al. Cytochrome c and dATPdependent formation of Apaf-1/caspase-9 complex initiates an apoptotic protease cascade. Cell. 1997;91:479-489. 
287. Hofmann K, Bucher P, Tschopp J. The CARD domain: A new apoptotic signaling motif. Trends Biochem Sci. 1997;22:155-156.

288. Liu X, Kim CN, Yang J, Jemmerson R, Wang X. Induction of apoptotic program in cell-free extracts: Requirement for dATP and cytochrome c. Cell. 1996;86:147-157.

289. Zou H, Li Y, Liu X, Wang X. An APAF-1 cytochrome c multimeric complex is a functional apoptosome that activates procaspase-9. J Biol Chem. 1999;274:11549-11556.

290. Zuo Y, Xiang B, Yang J, et al. Oxidative modification of caspase-9 facilitates its activation via disulfide-mediated interaction with Apaf-1. Cell Res. 2009;19:449-457.

291. Slee EA, Harte MT, Kluck RM, et al. Ordering the cytochrome c-initiated caspase cascade: hierarchical activation of caspases-2, $-3,-6,-7,-8$, and -10 in a caspase-9-dependent manner. $J$ Cell Biol. 1999;144:281-292.

292. Zhivotovsky B, Orrenius S. Caspase-2 function in response to DNA damage. Biochem Biophys Res Comm. 2005;331:859-867.

293. Samraj AK, Sohn D, Schulze-Osthoff K, Schmitz I. Loss of caspase-9 reveals its essential role for caspase-2 activation and mitochondrial membrane depolarization. Mol Biol Cell. 2007;18:84-93.

294. Guerrero AD, Chen M, Wang J. Delineation of the caspase-9 signaling cascade. Apoptosis. 2008;13:177-186.

295. Kuida K, Haydar TF, Kuan CY, et al. Reduced apoptosis and cytochrome c-mediated caspase activation in mice lacking caspase 9 Cell. 1998;94:325-337.

296. Robertson JD, Gogvadze V, Zhivotovsky B, Orrenius S. Distinct pathways for stimulation of cytochrome c release by etoposide. J Biol Chem. 2000;275:32438-32443.

297. Lassus P, Opitz-Araya X, Lazebnik Y. Requirement for caspase-2 in stress-induced apoptosis before mitochondrial permeabilization. Science. 2002;297:1352-1354.

298. Tinel A, Tschopp J. The PIDDosome, a protein complex implicated in activation of caspase-2 in response to genotoxic stress. Science. 2004;304:843-846

299. Jang TH, Bae JY, Park OK, et al. Identification and analysis of dominant negative mutants of RAIDD and PIDD. Biochim Biophys Acta. 2010;1804:1557-1563.

300. Mace PD, Riedl SJ. Molecular cell death platforms and assemblies. Curr Opin Cell Biol. 2010;22:828-836.

301. Raina D, Pandey P, Ahmad R, et al. c-Abl tyrosine kinase regulates caspase-9 autocleavage in the apoptotic response to DNA damage. J Biol Chem. 2005;280:11147-11151.

302. Morishima N, Nakanishi K, Takenouchi H, Shibata T, Yasuhiko Y. An endoplasmic reticulum stress-specific caspase cascade in apoptosis. Cytochrome $c$-independent activation of caspase- 9 by caspase- 12 . J Biol Chem. 2002;277:34287-34294.

303. Jeong W, Lee D-Y, Park S, Rhee SG. ERp16, and endoplasmic reticulum-resident thiol-disulfide oxidoreductase. Biochemical properties and role in apoptosis induced by endoplasmic reticulum stress. J Biol Chem. 2008;283:25557-25566.

304. Jimbo A, Fujita E, Kouroku Y, et al. ER stress induces caspase-8 activation, stimulating cytochrome $\mathrm{c}$ release and caspase-9 activation. Exp Cell Res. 2003;283:156-166.

305. Lagos-Quintana M, Rauhut R, Lendeckel W, Tuschi T. Identification of novel genes coding for small expressed RNAs. Science. 2001;294: $853-858$.

306. Bartel DP. MicroRNAs: Genomics, biogenesis, mechanism, and function. Cell. 2004;116:281-297.

307. Bartel DP, Chen CZ. Micromanagers of gene expression: The potentially widespread influence of metazoan microRNAs. Nat Rev Genet. 2004;5:396-400.

308. He L, Hannon GJ. MicroRNAs: Small RNAs with a big role in gene regulation. Mol Cell. 2004;26:45-752, 2007.

309. He L, He X, Lim LP, et al. A microRNA component of the p53 tumour suppressor network. Nature. 2007;447:1130-1134.

310. Kim VN. MicroRNA biogenesis: Coordinated cropping and dicing. Nat Rev Mol Cell Biol. 2005;6:376-385.
311. Farh KK, Grimson A, Jan C, et al. The widespread impact of mammalian microRNAs on mRNA repression and evolution. Science. 2005;310:1817-1821.

312. Carthew RW. Gene regulation by microRNAs. Curr Opin Genet Dev. 2006; 16:203-208.

313. Valenci-Sanchez MA, Liu J, Hannon GJ, Parker R. Control of translation and mRNA degradation by miRNAs ans siRNAs. Genes Dev. 2006;20:515-524.

314. Tsang J, Zhu J, van Oudenaarden A. MicroRNA-mediated feedback and feedforward loops are recurrent network motifs in mammals. Mol Cell. 2007;26:753-767.

315. Kim VN, Han J, Siomi MC. Biogenesis of small RNAs in animals. Nat Rev Mol Cell Biol. 2009;10:126-139.

316. Pillai RS. MicroRNA function: Multiple mechanisms for a tiny RNA? RNA. 2005;11:1753-1761.

317. Kloosterman WP, Plasterk RH. The diverse functions of microRNAs in animal development and disease. Dev Cell. 2006;11:441-450.

318. Krek A, Grun D, Poy MN, et al. Combinatorial microRNA target predictions. Nat Genet. 2005;37:495-500.

319. Lewis, et al. Prediction of mammalian microRNA targets. Cell. 2003; 115:787-798

320. Lewis BP, Burge CB, Bartel DP. Conserved seed pairing, often flanked by adenosines, indicates that thousands of human genes are microRNA targets. Cell. 2005;120:15-20.

321. Lim LP, Lau NC, Garrett-Engele P, et al. Microarray analysis shows that some microRNAs downregulate large numbers of target mRNAs. Nature. 2005;433:769-773.

322. Selbach M, Schwanhausser B, Thierfelder N, Fang Z, Khanin R, Rajewsky N. Widespread changes in protein synthesis induced by microRNAs. Nature. 2008;455:58-63.

323. Baek D, Villen J, Shin C, Camargo FD, Gygi SP, Bartel DP. The impact of microRNAs on protein output. Nature. 2008;455:64-71.

324. Cimmino A, Calin GA, Fabbri M, et al. miR-15 and miR-16 induce apoptosis by targeting BCL2. Proc Natl Acad Sci U S A. 2005;103: 3687-3692.

325. Hayashita Y, Osada H, Tatematsu Y, et al. A polycistronic microRNA cluster, mir-17-92, is overexpressed in human lung cancers and enhances cell proliferation. Cancer Res. 2005;65:9628-9632.

326. Miska EA. How microRNAs control cell division, differentiation and death. Curr Opin Genet Dev. 2005;15:563-568.

327. Calin GA, Sevignani C, Dumitru CD, et al. Human microRNA genes are frequently located at fragile sites and genomic regions involved in cancers. Proc Natl Acad Sci U S A. 2004;101:2999-3004.

328. Chen JF, Mandel EM, Thomson JM, et al. The role of microRNA-1 and microRNA-133 in skeletal muscle proliferation and differentiation. Nat Genet. 2006;38:228-233.

329. Carleton M, Cleary MA, Linsley PS. MicroRNAs and cell cycle regulation. Cell Cycle. 2007;6:2127-2132.

330. Chang TC, Wentzel EA, Kent OA, et al. Transactivation of mir-34a by p53 broadly influences gene expression and promotes apoptosis. Mol Cell. 2007;26:745-752.

331. Yi R, Poy MN, Stoffel M, Fuchs E. A skin microRNA promotes differentiation by repressing "stemness". Nature. 2008;452: 225-229.

332. Lal A, Navarro F, Maher CA, et al. miR-24 inhibits cell proliferation by targeting E2F2, MYC, and other cell-cycle genes via binding to "seedless" 3'UTR microRNA recognition elements. Mol Cell. 2009; 35:610-625.

333. Bueno MJ, Gomez de Cedron M, Laresgoiti U, Fernandez-Piqueras J, Zubiaga AM, Malumbres M. Multiple E2F-induced microRNAs prevent replicative stress in response to mitogenic signaling. Mol Cell Biol. 2010;30:2983-2995.

334. Meltzer PS. Cancer genomics: Small RNAs with big impacts. Nature. 2005;435:745-746.

335. Dalmay T, Edwards DR. MicroRNAs and the hallmarks of cancer. Oncogene. 2006;25:6170-6175.

336. Esquela-Kerscher A, Slack FJ. Oncomirs - microRNAs with a role in cancer. Nat Rev Cancer. 2006;6:259-269. 
337. Bandres E, Agirre X, Ramirez N, Zarate E, Garcia-Foncillas J. MicroRNAs as cancer players: Potential clinical and biological effects. DNA Cell Biol. 2007;26:273-282.

338. Cho WCS. OncomiRs: The discovery and progress of microRNAs in cancers. Mol Cancer. 2007;6:60; doi: 10.1186/1476-4598-6-60.

339. Ventura A, Jacks T. MicroRNAs and cancer. Short RNAs go a long way. Cell. 2009; 136:586-591.

340. Nicoloso MS, Spizzo R, Shimizu M, Rossi S, Calin GA. MicroRNAs the micro steering wheel of tumour metastases. Nat Rev Cancer. 2009;9:293-302.

341. Calin GA, Liu CG, Sevignani C, et al. MicroRNA profiling reveals distinct signatures in B cell chronic lymphocytic leukemias. Proc Natl Acad Sci U S A. 2004b;101:11755-11760.

342. Calin GA, Croce CM. MicroRNA signatures in human cancers. Nat Rev Cancer. 2006;6:857-866.

343. Lu J, Getz G, Miska EA, et al. MicroRNA expression profiles classify human cancers. Nature. 2005;435:834-838.

344. Cummins JM, He Y, Leary RJ, et al. The colorectal microRNAome. Proc Natl Acad Sci US A. 2006;103:3687-3692.

345. Volinia S, Calin GA, Liu CG, et al. A microRNA expression signature of human solid tumors defines cancer gene targets. Proc Natl Acad Sci U S A. 2006;103:2257-2261.

346. Lee EJ, Gusev Y, Jiang J, et al. Expression profiling identifies microRNA signature in pancreatic cancer. Int J Cancer. 2007;120: 1046-1054.

347. Subramanian S, Lui WO, Lee $\mathrm{CH}$, et al. MicroRNA expression signature of human sarcomas. Oncogene. 2008;27:2015-2026.

348. Rosenfeld N, Aharonov R, Meiri E, et al. MicroRNAs accurately identify cancer tissue origin. Nat Biotechnol. 2008;26: 462-469.

349. Vandenboom TG II, Li Y, Philip PA, Sarkar FH. MicroRNA and cancer: tiny molecules with major implications. Curr Genomics. 2008;9: 97-109.

350. Hu X, Schwartz JK, Lewis JS Jr, et al. A microRNA expression signature for cervical cancer prognosis. Cancer Res. 2010;70:1441-1448.

351. Kumar MS, Lu J, Mercer KL, Golub TR, Jacks T. Impaired microRNA processing enhances cellular transformation and tumorigenesis. Nat Genet. 2007;39:673-677.

352. Chang TC, Yu D, Lee YS, et al. Widespread microRNA repression by Myc contributes to tumorigenesis. Nat Genet. 2008;40:43-50.

353. Chen CZ. MicroRNAs as oncogenes and tumor suppressors. NEng J Med. 2005;353:1768-1771.

354. Kent OA, Mendell JT. A small piece in the cancer puzzle: MicroRNAs as tumor suppressors and oncogenes. Oncogene. 2006;25: 6188-6196.

355. Zhang B, Pan X, Cobb GP, Anderson TA. MicroRNAs as oncogenes and suppressors. Dev Biol. 2007;302:1-12.

356. Michael MZ, O'Connor SM, van Holst Pellekaan NG, Young GP, James RJ. Reduced accumulation of specific microRNAs in colorectal neoplasia. Mol Cancer Res. 2003;1:882-891.

357. Akao Y, Nakagawa Y, Naoe T. let-7 microRNA functions as a potential growth suppressor in human colon cancer cells. Biol Pharm Bull. 2006;29:903-906.

358. Bandres E, Cubedo E, Agirre X, et al. Identification by real-time PCR of 13 mature microRNAs differentially expressed in colorectal cancer and non-tumoral tissues. Mol Cancer. 2006;5:29.

359. Xi Y, Shalgi R, Fodstad O, Pilpel Y, Ju J. Differentially regulated micro-RNAs and actively translated messenger RNA transcripts by tumor suppressor p53 in colon cancer. Clin Cancer Res. 2006;12: 2014-2024.

360. Shi B, Sepp-Lorenzino L, Prisco M, Linsley P, deAngelis T, Baserga R. Micro RNA 145 targets the insulin receptor substrate-1 and inhibits the growth of colon cancer cells. J Biol Chem. 2007;282: 32582-32590.

361. Slaby O, Svoboda M, Fabian P, et al. Altered expression of miR-21. MiR-31, miR-143 and miR-145 is related to clinicopathologic features of colorectal cancer. Oncology. 2007;72:397-402.
362. Tazawa H, Tsuchiya N, Izumiya M, Nakagama H. Tumor-suppressive miR-34a induces senescence-like growth arrest through modulation of the E2F pathway in human colon cancer cells. Proc Natl Acad Sci US A. 2007; 104:15472-15477.

363. Schepeler T, Reinert JT, Ostenfeld MS, et al. Diagnostic and prognostic microRNAs in stage II colon cancer. Cancer Res. 2008;68: 6416-6424.

364. Schetter AJ, Leung SY, Sohn JJ, et al. MicroRNA expression profiles associated with prognosis and therapeutic outcome in colon adenocarcinoma. JAMA. 2008;299:425-436.

365. Motoyama K, Inoue H, Takatsuno Y, et al. Over- and under-expressed microRNAs in human colorectal cancer. Int J Oncol. 2009;34: 1069-1075.

366. Ng EK, Tsang WP, Ng SS, et al. MicroRNA-143 targets DNA methyltransferases 3A in colorectal cancer. Br J Cancer. 2009;101: 699-706.

367. Sarver Al, French AJ, Borralho PM, et al. Human colon cancer profiles show differential microRNA expression depending on mismatch repair status and are characteristic of undifferentiated proliferative states. BMC Cancer. 2009;9:401.

368. Yantiss RK, Goodarzi M, Zhou XK, et al. Clinical, pathologic, and molecular features of early-onset colorectal carcinoma. Am J Surg Pathol. 2009;33:572-582.

369. Wang YX, Zhang XY, Zhang BF, Yang CQ, Chen XM, Gao HJ. Initial study of microRNA expression profiles of colonic cancer without lymph node metastasis. J Dig Dis. 2010;11:50-54.

370. Lanza G, Ferracin M, Gafa R, et al. mRNA/microRNA gene expression profile in microsatellite unstable colorectal cells. Mol Cancer. 2007;6:54

371. Atkin NB. Microsatellite instability. Cytogenet Cell Genet. 2001;92: 177-181.

372. Bommer GT, Gerin I, Feng Y, et al. p53-mediated activation of miRNA34 candidate tumor-suppressor genes. Curr Biol. 2007;17: 1298-1307.

373. Hermeking H. p53 enters the microRNA world. Cancer Cell. 2007;12: 414-418.

374. Raver-Shapira N, Marciano E, Meiri E, et al. Transcriptional activation of miR-34a contributes to p53-mediated apoptosis. Mol Cell. 2007;26:731-743.

375. Tarasov V, Jung P, Verdoodt B, et al. Differential regulation of microRNAs by p53 revealed by massively parallel sequencing: miR-34a is a p53 target that induces apoptosis and G1-arrest. Cell Cycle. 2007;6:1586-1593.

376. Dijkstra MK, van Lom K, Tielemans D, et al. 17p13/TP53 deletion in B-CLL patients is associated with micoRNA-34a downregulation. Leukemia. 2009;23:625-627.

377. Welch C, Chen Y, Stallings RL. MicroRNA-34a functions as a potential tumor suppressor by inducing apoptosis in neuroblastoma. Oncogene. 2007;26:5017-5022.

378. Rokhlin OW, Scheinker VS, Taghiyev AF, Bumcrot D, Glover RA, Cohen MB. MicroRNA-34 mediates AR-dependent p53-induced apoptosis in prostate cancer. Cancer Biol Ther. 2008;7: 1288-1296.

379. Ruby JG, Jan C, Player C, et al. Large-scale sequencing reveals 21U-RNAs and additional microRNAs and endogenous siRNAs in C. elegans Cell. 2006;127:1193-1207.

380. Cole KA, Attiyeh EF, Mosse YP, et al. A functional screen identifies miR-34a as a candidate neuroblastoma tumor suppressor gene. $\mathrm{Mol}$ Cancer Res. 2008;6:735-742.

381. Sun F, Fu H, Liu Q, et al. Downregulation of CCND1 and CDK6y miR-34a induces cell cycle arrest. FEBS Lett. 2008;582:1564-1568.

382. Wei JS, Song YK, Durinck S, et al. The MYCN oncogene is a direct target of miR-34a. Oncogene. 2009;27:5204-5213.

383. Li Y, Guessous F, Zhang Y, et al. MicroRNA-34a inhibits glioblastoma growth by targeting multiple oncogenes. Cancer Res. 2009;69: 7569-7576.

384. Yamakuchi M, Lowenstein CJ. MiR-34, SIRT1 and p53: The feedback loop. Cell Cycle. 2009;8:712-715. 
385. Beverly LJ, Felsher DW, Capobianco AJ. Suppression of $\mathrm{p} 53$ by Notch in lymphomagenesis: Implications for initiation and regression. Cancer Res. 65:7159-7168.

386. Mungamuri SK, Yang X, Thor AD, Somasundaram K. Survival signaling by Notch1: Mammalian target of rapamycin (mTOR)dependent inhibition of p53. Cancer Res. 2006;66:4715-4724.

387. Leong KG, Karsan A. Recent insights into the role of Notch signaling in tumorigenesis. Blood. 2006;107:2223-2233.

388. Miele L, Golde T, Osborne B. Notch signaling in cancer. Curr Mol Med. 2006;6:905-918.

389. Yamakuchi M, Ferlito M, Lowenstein CJ. miR-34a repression of SIRT1 regulates apoptosis. Proc Natl Acad Sc U S A. 2008;105:13421-13426.

390. Ginsberg D. E2F3-a novel repressor of the ARF/p53 pathway. Dev Cell. 2004;6:742-743.

391. Su H, Yang JR, Xu T, et al. MicroRNA-101, down-regulated in hepatocellular carcinoma, promotes apoptosis and suppresses tumorigenicity. Cancer Res. 2009;69:1135-1142.

392. Friedman JM, Liang G, Jones PA. The tumor suppressor microRNA101 becomes an epigenetic player by targeting the Polycomb group protein EZH2 in cancer. Cell Cycle. 2009;8:2313-2314.

393. Adams KW, Cooper GM. Rapid turnover of MCL-1 couples translation to cell survival and apoptosis. J Biol Chem. 2007;282:6192-6200.

394. Cuconati A, Mukherjee C, Perez D, White E. DNA damage response and Mcl-1 destruction initiate apoptosis in adenovirus-infected cells Genes Dev. 2003;17:2922-2932.

395. Nijhawan D, Fang M, Traer E, et al. Elimination of Mcl-1 is required for the initiation of apoptosis following ultraviolet irradiation. Genes Dev. 2003;17:1475-1496.

396. Clohessy JG, Zhuang J, de Boer J, Gil-Gomez G, Brady HJM. Mcl-1 interacts with truncated Bid and inhibits its induction of cytochrome $c$ release and its role in receptor-mediated apoptosis. $J$ Biol Chem. 2006;281:5750-5759.

397. Han J, Goldstein LA, Gastman BR, Rabinowich H. Interrelated roles for Mcl-1 and BIM in regulation of TRAIL-mediated mitochondrial apoptosis. J Biol Chem. 2006;281:10153-10163.

398. Zhong Q, Gao W, Du F, Wang X. Mule/ARF-BP1, a BH3-only E3 ubiquitin ligase, catalyzes the polyubiquitination of Mcl-1 and regulates apoptosis. Cell. 2005;121:1085-1095.

399. Menoret E, Gomez-Bougie P, Surget S, et al. Mcl-1(127-350) fragment induces apoptosis through direct interaction with Bax. FEBS Lett. 2010;584:487-492.

400. Kobayashi S, Lee SH, Meng XW, et al. Serine 64 phosphorylation enhances the antiapoptotic function of Mcl-1.J Biol Chem. 2007;282: $18407-18417$.

401. Domina AM, Smith JH, Craig RW. Myeloid cell leukemia 1 is phosphorylated through two distinct pathways, one associated with extracellular signal-regulated kinase activation and the other with $\mathrm{G} 2 / \mathrm{M}$ accumulation or protein phosphatase $1 / 2 \mathrm{~A}$ inhibition. $J$ Biol Chem. 2000;275:21688-21694.

402. Krajewski S, Bodrug S, Krajewska M, et al. Immunohistochemical analysis of Mcl-1 protein in human tissues. Differential regulation of Mcl-1 and Bcl-2 protein production suggests a unique role for Mcl-1 in control of programmed cell death in vivo. Am J Pathol. 1995;146: 1309-1319.

403. Backus HH, Van Groeningen CJ, Vos W, et al. Differential expression of cell cycle and apoptosis related proteins in colorectal mucosa, primary colon tumours, and liver metastases. J Clin Pathol. 2002;55: 206-211.

404. Varambally S, Cao Q, Mani RS, et al. Genomic loss of microRNA-101 leads to overexpression of histone methyltransferase EZH2 in cancer. Science. 2008;322:1695-1699.

405. Li S, Fu H, Wang Y, et al. MicroRNA-101 regulates expression of the v-fos FBJ murine osteosarcoma viral omcogene homolog (FOS) oncogene in human hepatocellular carcinoma. Hepatol. 2009;49:1194-1202.

406. Suzucki HI, Yamagata K, Sugimoto K, Iwamoto T, Kato S, Miyazono K. Modulation of microRNA processing by $\mathrm{p} 53$. Nature. 2009;460:529-533.
407. Carmell MA, Xuan Z, Zhang MQ, Hannon GJ. The argoanute family: Tentacles that reach into RNAi, developmental control, stem cell maintenance, and tumorigenesis. Genes Develop. 2002;16:2733-2742.

408. Pillai RS, Artus CG, Filipowicz W. Tethering of human Ago proteins to mRNA mimics the miRNA-mediated repression of protein synthesis RNA. 2004;10:1518-1525.

409. Sasaki T, Shiohama A, Minoshima S, Shimizu N. Identification of eight members of the Argonaute family in the human genome small star, filled. Genomics. 2003;82:323-330

410. Hock J, Weinmann L, Ender C, et al. Proteomic and functional analysis of Argonaute-containing mRNA-protein complexes in human cells. EMBO Rep. 2007;8:1052-1060.

411. Wu L, Fan J, Belasco JG. Importance of translation and nonnucleolytic ago proteins for on-target RNA interference. Curr Biol. 2008;18: $1327-1332$

412. Park SM, Gaur AB, Lengyel E, Peter ME. The miR-200 family determines the epithelial phenotype of cancer cells by targeting the E-cadherin repressors ZEB1 and ZEB2. Genes Develop. 2008;22: 894-907.

413. Saydam O, Shen Y, Wurdinger T, et al. Downregulated microRNA200a in meningiomas promotes tumor growth by reducing E-cadherin and activating the Wnt $/ \beta$-catenin signaling pathway. Mol Cell Biol. 2009;29:5923-5940.

414. Schneikert J, Behrens J. The canonical WNT signaling pathway and its APC partner in colon cancer development. Gut. 2007;56:417-425.

415. Korpal M, Lee ES, Hu G, Kang Y. The miR-200 family inhibits epithelial-mesenchymal transition and cancer cell migration by direct targeting of E-cadherin transcriptional repressors ZEB1 and ZEB2. J Biol Chem. 2008;14910-14914.

416. Bendoraite A, Knouf EC, Garg KS, et al. Regulation of miR-200 family microRNAs and ZEB transcription factors in ovarian cancer: Evidence supporting a mesothelial-to-epithelial transition. Gynecol Oncol. 2010:117-125.

417. Brabletz S, Brabletz T. The ZEB/miR-200 feedback loop - a motor of cellular plasticity in development and cancer? EMBO Rep. 2010:670-677.

418. Huang K, Zhang J-X, Han L, et al. MicroRNA roles in beta-catenin pathway. Mol Cancer. 2010;9:252.

419. Savagner P. Leaving the neighborhood: Molecular mechanisms involved during epithelial-mesenchymal transition. Bioessays. 2001; 23:912-923.

420. Fuchs IB, Lichtenegger W, Buehler H, et al. The prognostic significance of epithelial-mesenchymal transition in breast cancer. Anticancer Res. 2002;22:3415-3419.

421. Clevers H. Wnt/beta-catenin signaling in development and disease Cell. 2006;127:469-480.

422. Huang H, He Xi. Wnt/-catenin signaling: New (and old) players and new insights. Curr Opin Cell Biol. 2008;20:119-125.

423. Akiyama T. Wnt/ $/$-catenin signaling. Cytokine Growth Factor Rev. 2000:273-282.

424. Bienz M, Clevers H. Linking colorectal cancer to Wnt signaling. Cell. 2000;103:311-320.

425. Peifer M, Polakis P. Wnt signaling in oncogenesis and embryogenesis a look outside the nucleus. Science. 2000;287:1606-1609.

426. He TC, Sparks AB, Rago C, et al. Identification of c-MYC as a target of the APC pathway. Science. 1998;281:1509-1512.

427. Shtutman M, Zhurinsky J, Simcha I, et al. The cyclin D1 gene is a target of the $\beta$-catenin/LEF-1 pathway. Proc Natl acad Sci U S A. 1999;96:5522-5527.

428. Tetsu O, McCormick F. $\beta$-catenin regulates expression of cyclin D1 in colon carcinoma cells. Nature. 1999;398:422-426.

429. Morin PJ, Sparks AB, Korinek V, et al. Activation of $\beta$-catenin-Tcf signaling in colon cancer by mutations in $\beta$-catenin or APC. Science. 1997;275:1787-1790.

430. Satoh S, Daigo Y, Furukawa Y, et al. AXIN1 mutations in hepatocellular carcinomas and growth suppression in cancer cells by virusmediated transfer of AXIN1. Nat Genet. 2000;24:245-250. 
431. Koyama T, Tago K-I, Nakamura T, et al. Mutation and expression of the $\beta$-catenin-interacting protein ICAT in human colorectal tumors. Jpn J Clin Oncol. 2002;32:358-362.

432. Giles RH, van Es JH, Clevers H. Caught up in a Wnt storm: Wnt signaling in cancer. Biochim Biophys Acta. 2003;1653:1-24.

433. Humphries A, Wright NA. Colonic crypt organization and tumorigenesis. Nat Rev Cancer. 2008;8:415-424.

434. Tago K, Nakamura $T$, Nishita $M$, et al. Inhibition of Wnt signaling by ICAT, a novel $\beta$-catenin-interacting protein. Genes Dev. 2000;14: 1741-1749.

435. Daniels DL, Weis WI. ICAT inhibits beta-catenin binding to Tcf/Lef-family transcription factors and the general coactivator p300 using independent structural modules. Mol Cell. 2002;10: 573-584.

436. Hossain MZ, Yu Q, Xu M, Sen JM. ICAT expression disrupts $\beta$-catenin-TCF interactions and impairs survival of thymocytes and activated mature T cells. Int Immunol. 2008;20:925-935.

437. Graham TA, Clements WK, Kimelman D, Xu W. The crystal structure of the $\beta$-catenin/ICAT complex reveals the inhibitory mechanism of ICAT. Mol Cell. 2002;10:1674-1687.

438. Stow JL. ICAT is a multipotent inhibitor of $\beta$-catenin. Focus on "Role for ICAT in $\beta$-catenin-dependent nuclear signaling and cadherin functions". Am J Physiol Cell Physiol. 2004;286:C745-C746.

439. Hulsken J, Birchmeier W, Behrens J. E-cadherin and APC compete for the interaction with $\beta$-catenin and the cytoskeleton. J Cell Biol. 1994:2061-2069.

440. Gottardi CJ, Gumbiner BM. Role for ICAT in $\beta$-catenin-dependent nuclear signaling and cadherin functions. Am J Physiol Cell Physiol. 2004;286:C747-C756

441. Sekiya T, Nakamura T, Kazuki Y, et al. Overexpression of Icat induces G2 arrest and cell death in tumor cell mutants for adenomatous polyposis coli, $\beta$-catenin, or axin. Cancer Res. 2002;62:3322-3326.

442. Ioannidis V, Beermann F, Clevers H, Held W. The beta-catenin-TCF-1 pathway ensures CD4(+)CD8(+) thymocyte survival. Nat Immunol. 2001;2:691-697.

443. Xie H, Huang Z, Sadim MS, Sun Z. Stabilized beta-catenin extends thymocyte survival by up-regulating Bcl-xL. J Immunol. 2005;175: 7981-7988.

444. Walston T, Tuskey C, Edgar L, et al. Multiple Wnt signaling pathways converge to orient the mitotic spindle in early $C$. elegans embryos. Dev Cell. 2004;7:831-841.

445. McCartney BM, McEwen DG, Grevengoed E, Maddox P, Bejsovec A, Peifer M. Drosophila APC2 and Armadillo participate in tethering mitotic spindles to cortical actin. Nat Cell Biol. 2001;3: 933-938.

446. Rogers SL, Rogers GC, Sharp DJ, Vale RD. Drosophila EB1 is important for proper assembly, dynamics, and positioning of the mitotic spindle. J Cell Biol. 2002;158:873-884.

447. Zumbrunn J, Kinoshita K, Hyman AA, Nathke IS. Binding of the adenomatous polyposis coli protein to microtubules increases microtubule stability and is regulated by GSK3 beta phosphorylation. Curr Biol. 2001;11:44-49.

448. Kaplan KB, Burds AA, Swedlow JR, Bekir SS, Sorger PK, Nathke IS. A role for the Adenomatous Polyposis Coli protein in chromosome segregation. Nat Cell Biol. 2001;3:429-432.

449. Kaplan DD, Meigs TE, Kelly P, Casey PJ. Identification of a role for $\beta$-catenin in the establishment of a bipolar mitotic spindle. $J$ Biol Chem. 2004;279:10829-10832.

450. Wakefield JG, Stephens DJ, Tavare JM. A role for glycogen synthase kinase-3 in mitotic spindle dynamics and chromosome alignment. J Cell Sci. 2003;116:637-646.

451. Bobinnec Y, Morin X, Debec A. Shaggy/GSK-3 $\beta$ kinase localizes to the centrosome and to specialized cytoskeletal structures in Drosophila. Cell Motil Cytoskel. 2006;63:313-320.

452. Kikuchi K, Niikura Y, Kitagawa K, Kikuchi A. Dishevelled, a Wnt signalling component, is involved in mitotic progression in cooperation with Plk1. EMBO J. 2010;29:3470-3483.
453. Hadjihannas MV, Bruckner M, Behrens J. Conductin/axin2 and Wnt signalling regulates centrosome cohesion. EMBO Rep. 2010;11: 317-324.

454. Fodde R, Kuiper J, Rosenberg C, et al. Mutations in the APC tumour suppressor gene cause chromosomal instability. Nat Cell Biol. 2001;3: 433-438.

455. Green RA, Kaplan KB. Chromosome instability in colorectal tumor cells is associated with defects in microtubule plus-end attachments caused by a dominant mutation in APC attachments caused by a dominant mutation in APC. J Cell Biol. 2003;163: 949-961.

456. Hadjihannas MV, Bruckner M, Jerchow B, Birchmeier W, Dietmaier W, Behrens J. Aberrant Wnt/ $\beta$-catenin signaling can induce chromosomal instability in colon cancer. Proc Natl Acad Sci USA. 2006;103:10747-10752.

457. Hadjihannas MV, Behrens J. CIN by WNT. Growth pathways, mitotic control and chromosomal instability in cancer. Cell Cycle. 2006;5: 2077-2081.

458. Aoki K, Aoki M, Sugai M, et al. Chromosomal instability by $\beta$-catenin/ TCF transcription in APC or $\beta$-catenin mutant cells. Oncogene. 2007;26:3511-3520.

459. Harris H, Miller OJ, Klein G, Worst P, Tachibana T. Suppression of malignancy by cell fusion. Nature. 1969;223:363-368.

460. Stanbridge EJ. Suppression of malignancy in human cells. Nature. 1976;260:17-20.

461. Sherr CJ. Principles of tumor suppression. Cell. 2004;116: 235-246, 976.

462. Carling T, Imanishi Y, Gaz RD, Arnold A. Analysis of the RAD54 gene on chromosome $1 p$ as a potential tumor-suppressive gene in parathyroid adenomas. Int J Cancer. 1999;83:80-82.

463. Sulman EP, Whit PS, Brodeur GM. Genomic annotation of the meningioma tumor suppressor locus on chromosome p34. Oncogene. 2004;2:1014-1020.

464. Bagchi A, Papazoglu C, Wu, et al. CHD5 is a tumor suppressor at human 1p36. Cell. 2007;128:459-475.

465. Fugita T, Igarashi J, Okawa ER, et al. $C D H 5$, a tumor suppressor gene deleted from 1p36.31 in neuroblastomas. J Natl Cancer Inst. 2008;100:940-949.

466. Okawa ER, Gotoh T, Manne J, et al. Expression and sequence analysis of candidates for the $1 \mathrm{p} 36.31$ tumor suppressor gene deleted in neuroblastomas. Oncogene. 2008;27:803-810.

467. Bagchi A, Mills AA. The quest for the 1 p 36 tumor suppressor. Cancer Res. 2008;68:2551-2556.

468. Cook WD, McCaw BJ. Accommodating haploinsufficient tumor suppressor genes in Knudson's model. Oncogene. 2000;19: 3434-3438.

469. Santarosa M, Ashworth A. Haploinsufficiency for tumour suppressor genes: When you don't need to go all the way. Biochim Biophys Acta. 2004;1654:105-122.

470. Forman HJ, Zhang H, Rinna A. Glutathione: Overview of its protective roles, measurement, and biosynthesis. Mol Aspects Med. 2009;30:1-12.

471. Franklin CC, Backos DS, Mohar I, White CC, Forman HJ, Kavanagh TJ. Structure, function, and post-translational regulation of the catalytic and modifier subunits of glutamate cysteine ligase. Mol Aspects Med. 2009;30:86-98.

472. Martensson J, Jain A, Meister A. Glutathione is required for intestinal function. Proc Natl Acad Sci U S A. 1990;87:1715-1719.

473. Shiraishi R, Fujise T, Kuroki T, et al. Long-term ingestion of reduced glutathione suppressed an accelerating effect of beef tallow diet on colon carcinogenesis in rats. J Gastroenterol. 2009;44: 1026-1035.

474. Yang Y, Dieter MZ, Chen Y, Shertzer HG, Nebert DW, Dalton TP. Initial characterization of the glutamate-cysteine ligase modifier subunit Gclm (-/-) knockout mouse. Novel model system for a severely compromised oxidative stress response. J Biol Chem. 2002;277: 49446-49452. 
475. Ochi T. Hydrogen peroxide increases the activity of $\gamma$-glutamylcysteine synthetase in cultured Chinese hamster V79 cells. Arch Toxicol. 1995; 70:96-103.

476. Tian L, Shi MM, Forman HJ. Increased transcription of the regulatory subunit of $\gamma$-glutamylcysteine synthetase in rat lung epithelial L2 cells exposed to oxidative stress or glutathione depletion. Arch Biochem Biophys. 1997;342:126-133.

477. Rinna A, Forman HJ. SHP-1 inhibition by 4-hydroxynonenol activates jun N-terminal kinase and glutamate cysteine ligase. Am J Respir Cell Mol Biol. 2008;39:97-104.

478. Dickinson DA, Iies KE, Watanabe N, et al. 4-hydroxynonenal induces glutamate cysteine ligase through JNK in HBE1 cells. Free Radic Biol Med. 2002;33:974-987.

479. Siitonen T, Alaruikka P, Mantymaa P, et al. Protection of acute myeloblastic leukemia cells against apoptotic cell death by high glutathione and G-glutamylcysteine synthetase levels during etoposide-induced oxidative stress. Ann Oncol. 1999;10:1361-1367.

480. Botta D, Franklin CC, White CC, et al. Glutamate-cysteine ligase attenuates TNF-induced mitochondrial injury and apoptosis. Free Radic Biol Med. 2004;37:632-642.

481. Lu SC. Regulation of glutathione synthesis. Mol Aspects Med. 2009;30:42-59

482. Markovic J, Garcia-Gimenez JL, Gimeno A, Vina J, Pallardo FV. Role of glutathione in cell nucleus. Free Radic Res. 2010;44: 721-733.

483. Diaz Vivancos P, Wolff T, Markovic J, Pallardo FV, Foyer CH. A nuclear glutathione cycle within the cell cycle. Biochem J. 2010;431: 169-178.

484. Giera S, Braeuning A, Kohle C, et al. Wnt/beta-catenin signaling activates and determines hepatic zonal expression of glutathione S-transferases in mouse liver. Toxicol Sci. 2010;115:22-33.

485. Patskovsky YV, Huang MQ, Takayama T, Listowsky I, Pearson WR. Distinctive structure of the human GSTM3 gene - inverted orientation relative to the mu class glutathione transferase gene cluster. Arch Biochem Biophys. 1999;361:85-93.

486. Yu KD, Fan L, Di GH, et al. Genetic variants in GSTM3 gene within GSTM4-GSTM2-GSTM1-GSTM5-GSTM3 cluster influence breast cancer susceptibility depending on GSTM1. Breast Cancer Res Treat. 2010;121:485-496.

487. Pool-Zobel B, Veeriah S, Bohmer F-D. Modulation of xenobiotic metabolising enzymes by anticarcinogens-focus on glutathione S-transferases and their role as targets of dietary chemoprevention in colorectal carcinogenesis. Mutat Res. 2005;591:74-92.

488. Katoh T, Nagata N, Kuroda Y, et al. Glutathione S-transferase M1 (GSTM1) and T1 (GSTT1) genetic polymorphism and susceptibility to gastric and colorectal adenocarcinoma. Carcinogenesis. 1996;17: $1855-1859$

489. Scarpato N, Hirvonen A, Migliore L, Falck G, Norppa H. Influence of GSTM1 and GSTT1 polymorphisms on the frequency of chromosome aberrations in lymphocytes of smokers and pesticide-exposed greenhouse workers. Mutat Res. 1997;389:227-235.

490. Griesmann H, Schlereth K, Krause M, Samans B, Stiewe T. p53 and p73 in suppression of Myc-driven lymphomagenesis. Int $J$ Cancer. 2009;124:502-506

491. Gao K, Henning SM, Niu Y, et al. The citrus flavonoid naringenin stimulates DNA repair in prostate cancer cells. J Nutr Biochem. 2006;17:89-95.

492. Morel I, Abalea V, Cillard P, Cillard J. Repair of oxidized DNA by the flavonoid myricetin. Methods Enzymol. 2001;335:308-316.

493. Bernstein H, Crowley-Skillicorn C, Bernstein C, Payne CM, Dvorak K, Garewal H. In: Lanseer BR, eds. Dietary compounds that enhance DNA repair and their relevance to cancer and aging. New Research on DNA Repair. Hauppauge, NY: Nova Science Publishers, Inc; 2007:99-113.

494. Della Ragione F, Cucciolla V, Criniti V, Indaco S, Borriello A, Zappia V. Antioxidants induce different phenotypes by a distinct modulation of signal transduction. FEBS Lett. 2002;532:289-294.
495. Yoshida T, Maeda A, Horinaka M, et al. Quercetin induces gadd45 expression through a p53-independent pathway. Oncol Rep. 2005;14: 1299-1303.

496. Catani MV, Costanzo A, Savini I, et al. Ascorbate up-regulates MLH1 (Mut L homologue-1) and p73: Implications for the cellular response to DNA damage. Biochem J. 2002;364:441-447.

497. Davis CD, Ross SA. Evidence for dietary regulation of microRNA expression in cancer cells. Nutr Rev. 2008;66:477-482.

498. Pogribny IP, Tryndyak VP, Ross SA, Beland FA. Differential expression of microRNAs during hepatocarcinogenesis induced by methyl deficiency in rats. Nutr Rev. 2008;66(Suppl 1):S33-S35.

499. Garzon R, Pichiorri F, Palumbo T, et al. MicroRNA gene expression during retinoic acid-induced differentiation of human acute promyelocytic leukemia. Oncogene. 2007;26:4148-4157.

500. Sun M, Estrov Z, Ji Y, Coombes KR, Harris DH, Kurzrock R. Curcumin (diferuloylmethane) alters the expression profiles of microRNAs in human pancreatic cancer cells. Mol Cancer Ther. 2008;7:464-473.

501. Boesch-Saadatmandi C, Loboda A, Wagner AE, et al. Effect of quercetin and its metabolites isorhamnetin and quercetin-3-glucuronide on inflammatory gene expression: Role of miR-155. J Nutr Biochem. 2010 June 23. [Epub ahead of print].

502. Davidson LA, Wang N, Shah MS, et al. n-3 polyunsaturated fatty acids modulate carcinogen-directed non-coding microRNA signatures in rat colon. Carcinogenesis. 2009;30:2077-2084.

503. Gaedicke S, Zhang X, Schmelzer C, et al. Vitamin E dependent microRNA regulation in rat liver. FEBS Lett. 2008;582:3542-3546.

504. Paul S, DeCastro AJ, Lee HJ, et al. Dietary intake of pterostilbene, a constituent of blueberries, inhibits the $\beta$-catenin/p65 downstream signaling 1 pathway and colon carcinogenesis in rats. Carcinogenesis. 2010;31:1272-1278.

505. Sarkar FH, Li Y, Wang Z, Kong D. Cellular signaling perturbation by natural products. Cell Signal. 2009;21:1541-1547.

506. Sarkar FH, Li Y, Wang Z, Kong D. The role of neutroceuticals in the regulation of Wnt and Hedgehog signaling in cancer. Cancer Metastasis Rev. 2010;29:383-394.

507. Ryu MJ, Cho M, Song JY, et al. Natural derivatives of curcumin attenuate the Wnt/beta-catenin pathway through down-regulation of the transcriptional coactivator p300. Biochem Biophys Res Commun. 2008;377:1304-1308.

508. Jaiswal AS, Marlow BP, Gupta N, Narayan S. Beta-catenin-mediated transactivation and cell-cell adhesion pathways are important in curcumin (diferuylmethane)-induced growth arrest and apoptosis in colon cancer cells. Oncogene. 2002:8414-8427.

509. Yan C, Jamaluddin MS, Aggarwal B, Myers J, Boyd DD. Gene expression profiling identifies activating transcription factor 3 as a novel contributor to the proapoptotic effect of curcumin. Mol Cancer Ther. 2005;4:233-241.

510. Tarapore RS, Siddiqui IA, Saleem M, Adhami VM, Spiegelman VS, Mukhtar H. Specific targeting of Wnt/ $\beta$-catenin signaling in human melanoma cells by a dietary triterpene lupeol. Carcinogenesis. 2010; 31:1844-1853.

511. Masella R, Di Benedetto R, Vari R, Filesi C, Giovannini C. Novel mechanisms of natural antioxidant compounds in biological systems: Involvement of glutathione and glutathione-related enzymes. $J$ Nutr Biochem. 2005;16:577-586.

512. Suzucki K, Koike H, Matsui H, et al. Genistein, a soy isoflavone, induces glutathione peroxidase in the human prostate cancer cell lines LNCAP and PC-3. Int J Cancer. 2002;99:846-852.

513. Luceri C, Caderni G, Sanna A, Dolara P. Red wine and black tea polyphenols modulate the expression of cycloxygenase-2, inducible nitric oxide synthase and glutathione-related enzymes in azoxymethaneinduced F344 rat colon tumors. J Nutr. 2002;132:1376-1379.

514. Myhrstad MC, Carlsen H, Nordstrom O, Blomhoff R, Moskaug JO. Flavonoids increases the intracellular glutathione level by transactivation of the $\gamma$-glutamylcysteine synthetase catalytic subunit promoter. Free Radic Biol Med. 2002;32:386-393. 
515. Scharf G, Prustomersky S, Knasmuller S, Schulte-Hermann R, Huber WW. Enhancement of glutathione and $\gamma$-glutamylcysteine synthetase, the rate limiting enzyme of glutathione synthesis, by chemopreventive plant-derived food and beverage components in the human hepatoma cell line HepG2. Nutr Cancer. 2003;45:74-83.

516. Moskaug JO, Carlsen H, Myhrstad MC, Blomhoff R. Polyphenols and glutathione synthesis regulation. Am J Clin Nutr. 2005; 81(1 Suppl):277S-283S

517. Na HK, Surh YJ. Modulation of Nrf2-mediated antioxidant and detoxifying enzyme induction by the green tea polyphenol EGCG. Food Chem Toxicol. 2008;46:1271-1278.

518. Dickinson DA, Iies KE, Zhang H, Blank V, Forman HJ. Curcumin alters EpRE and AP-1 binding complexes and elevates glutamate-cysteine ligase gene expression. The FASEB J. 2003;17: 473-475.

519. Huber WW, Scharf G, Rossmanith W, et al. The coffee components Kahweol and Cafestol induce $\gamma$-glutamylcysteine synthetase, the rate limiting enzyme of chemoprotective glutathione synthesis, in several organs of the rat. Arch Toxicol. 2002b;75:685-694.

520. Fiander H, Schneider H. Dietary orto-phenols that induce glutathione S-transferase and increase the resistance of cells to hydrogen peroxide are potential cancer chemopreventives that act by two mechanisms: The alleviation of oxidative stress and the detoxification of mutagenic xenobiotics. Cancer Lett. 2000;156:117-124.

521. Huber WW, Parzefall W. Modification of N-acetyltransferases and glutathione S-transferases by coffee components: Possible relevance for cancer risk. Methods Enzymol. 2005;401:307-341.

522. Guglielmi F, Luceri C, Giovannelli L, Dolara P, Lodovici M. Effect of 4-coumaric acid and 3,4-dihydroxybenzoic acid on oxidative DNA damage in rat colonic mucosa. Br J Nutr. 2003;89: 581-587.

523. Munday R, Munday CM. Low soses of diallyl disulfide, a compound derived from garlic, increase tissue activities of quinone reductase and glutathione transferase in the gastrointestinal tract of the rat. Nutr Cancer. 1999;34:42-48.

524. Ebert MN, Klinder A, Peters WH, et al. Expression of glutathione S-transferases (GST) in human colon cells and inducibility of GSTM2 by butyrate. Carcinogenesis. 2003;24:1637-1644.

525. Huber WW, Teitel CH, Coles BF, et al. Potential chemoprotective effects of the coffee components kahweol and cafestol palmitates via modification of hepatic $\mathrm{N}$-acetyltransferase and glutathione S-transferase activities. Environ Mol Mutagen. 2004;44: 265-276.

526. Rice-Evans C. Plant polyphenols: Free radical scavengers or chain-breaking antioxidants? Biochem Soc Symp. 1995;61: 103-116.

527. Kasai H, Fukada S, Yamaizumi Z, Sugie S, Mori H. Action of chlorogenic acid in vegetables and fruits as an inhibitor of 8-hydroxydeoxyguanosine formation in vitro and in a rat carcinogenesis model. Food Chem Toxicol. 2000;38:467-471.

528. Schaefer S, Baum M, Eisenbrand G, Dietrich H, Will F, Janzowski C. Polyphenolic apple juice extracts and their major constituents reduce oxidative damage in human colon cell lines. Mol Nutr Food Res. 2006; 50:24-33.

529. Fabiani R, Rosignoli P, De Bartolomeo A, et al. Oxidative DNA damage is prevented by extracts of olive oil, hydroxytyrosol, and other olive phenolic compounds in human blood mononuclear cells and HL60 cells. $J$ Nutr. 2008;138:1411-1416.

530. Shi Y, Wang W, Huang C, Jia Z, Yao S, Zheng R. Fast repair of oxidative DNA damage by phenylpropanoid glycosides and their analogues. Mutagenesis. 2008;23:19-26.

531. Lodovici M, Casalini C, De Filippo C, et al. Inhibition of 1,2dimethylhydrazine-induced oxidative DNA damage in rat colon mucosa by black tea complex polyphenols. Food Chem Toxicol. 2000;38:1085-1088.
532. Bancroft LK, Lupton JR, Davidson LA, et al. Dietary fish oil reduces oxidative DNA damage in rat colonocytes. Free Radic Biol Med.2003; 35:149-159.

533. Machowetz A, Poulsen HE, Gruendel S, et al. Effect of olive oils on biomarkers of oxidative DNA stress in Northern and Southern Europeans. FASEB J. 2007;21:45-52.

534. Quiles JL, Ochoa JJ, Ramirez-Tortosa C, et al. Dietary fat type (virgin olive vs sunflower oils) affects age-related changes in DNA double-strand-breaks, antioxidant capacity and blood lipids in rats. Exp Gerontol. 2004;39:1189-1198.

535. Rosignoli P, Fabiani R, De Bartolomeo A, et al. Protective activity of butyrate on hydrogen peroxide-induced DNA damage in isolated human colonocytes and HT29 tumour cells. Carcinogenesis. 2001;22: $1675-1680$.

536. Ebert MN, Beyer-Sehlmeyer G, Liegibel UM, Kautenburger T, Becker TW, Pool-Zobel BL. Butyrate induces glutathione S-transferase in human colon cells and protects from genetic damage by 4-hydroxynonenal. Nutr Cancer. 2001;41:156-164.

537. Belloir C, Singh V, Daurat C, Siess MH. Le Bon AM. Protective effects of garlic sulfur compounds against DNA damage induced by direct- and indirect-acting genotoxic agents in HepG2 cells. Food Chem Toxicol. 2006;44:827-834.

538. Fraga CG, Motchnik PA, Shigenaga MK, Helbock HJ, Jacob RA, Amers BN. Ascorbic acid protects against endogenous oxidative DNA damage in human sperm. Proc Natl Acad Sci U S A. 1991;88: 11003-11006.

539. Giovannucci E, Goldin B. The role of fat, fatty acids, and total energy intake in the etiology of human colon cancer. Am J Clin Nutr. 1997;66:1564S-1571S.

540. Rieger MA, Parlesak A, Pool-Zobel BL, Rechkemmer G, Bode C. A diet high in fat and meat but low in dietary fibre increases the genotoxic potential of 'faecal water'. Carcinogenesis. 1999;20: 2311-2316.

541. Fujise T, Iwakiri R, Kakimoto T, et al. Long-term feeding of various fat diets modulates azoxymethane-induced colon carcinogenesis through Wnt/beta-catenin signaling in rats. Am J Physiol Gastrointest Liver Physiol. 2007;292:G1150-G1156.

542. Endo H, Hosono K, Fujisawa T, et al. Involvement of JNK pathway in the promotion of the early stage of colorectal carcinogenesis under high-fat dietary conditions. Gut. 2009;58: $1637-1643$.

543. Pearson JR, Gill CIR, Rowland IR. Diet, fecal water, and colon cancer - development of a biomarker. Nutr Rev. 2009;67:509-526.

544. Xichun Z. Long-term exposure to various types of fat modulates acrylamide-induced preneoplastic lesions of colon mucosa through Wnt/beta-catenin signaling in rats. Toxicol Mech Methods. 2009;19: 285-291.

545. Larsson SC, Rafter J, Holmberg L, Bergkvist L, Wolk A. Red meat consumption and risk of cancers of the proximal colon, distal colon, and rectum: the Swedish Mammography Cohort. Int J Cancer. 2005; 113:829-834.

546. Glei M, Latunde-Dada GO, Klinder A, et al. Iron-overload induces oxidative DNA damage in the human colon carcinoma cell line HT29 clone 19A. Mutat Res. 2002;519:151-161.

547. Ilsley JNM, Belinsky GS, Guda K, et al. Dietary iron promotes azoxymethane-induced colon tumors in mice. Nutr Cancer. 2004;49: $162-169$.

548. Bingham SA, Day NE, Luben R, et al; European Prospective Investigation into Cancer and Nutrition. Dietary fibre in food and protection against colorectal cancer in the European Prospective Investigation into Cancer and Nutrition (EPIC): An observational study. Lancet. 2003;361:1496-1501.

549. Young GP, Hu Y, Le Leu RK, Nyskohus L. Dietary fibre and colorectal cancer: A model for environment - gene interactions. Mol Nutr Food Res. 2005;49:571-584. 
550. Toden S, Bird AR, Topping DL, Conlon MA. High red meat diets induce greater numbers of colonic DNA double-strand breaks than white meat in rats: Attenuation by high-amylose maize starch. Carcinogenesis. 2007;28:2355-2362.

551. Dahm CC, Keogh RH, Spencer EA, et al. Dietary fiber and colorectal cancer risk: A nested case-control study using food diaries. $J$ Natl Cancer Inst. 2010;102:614-626.

552. Hertog MG, Bueno-de-Mesquita HB, Fehily AM, Sweetnam PM, Elwood PC, Kromhout D. Fruit and vegetable consumption and cancer mortality in the Caerphilly study. Cancer Epidemiol Biomarkers Prev. 1996;5:673-677.

553. Millen AE, Subar AF, Graubard BI, et al. Fruit and vegetable intake and prevalance of colorectal adenoma in a cancer screening trial. $\mathrm{Am}$ J Clin Nutr. 2007;86:1754-1764

554. Rimando AM, Suh N. Biological/chemopreventive activity of stilbenes and their effect on colon cancer. Planta Med. 2008;74: 1635-1643.

555. Van Duijnhoven FJ, Bueno-De-Mesquita HB, Ferrari P, et al. Fruit, vegetables, and colorectal cancer risk: The European Prospective Investigation into Cancer and Nutrition. Am J Clin Nutr. 2009;89:1441-1452.

556. Tseng M, Murray SE, Kupper LL, Sandler RS. Micronutrients and the risk of colorectal adenomas.. Am J Epidemiol. 1996;144:1005-1014.

557. Ames BN. Micronutrient deficiencies. A major cause of DNA damage. Ann NY Acad Sci. 1999;889:87-106.

558. Ames BN. DNA damage from micronutrient deficiencies is likely to be a major cause of cancer. Mutat Res. 2001;475:7-20.

559. Fenech M. Micronutrients and genomic stability: A new paradigm for recommended dietary allowances (RDAs). Food Chem Toxicol. 2002 40:1113-1117.

560. Ames BN. Prevention of mutation, cancer, and other age-associated diseases by optimizing micronutrient intake. J Nucleic Acids. 2010;pii: 725071.

561. Van Breda SG, van Agen E, Engels LG, et al. Altered vegetable intake affects pivotal carcinogenesis pathways in colon mucosa from adenoma patients and controls. Carcinogenesis. 2004;25:2207-2216.

562. Ricke RM, van Ree JH, van Deursen JM. Whole chromosome instability and cancer: A complex relationship. Trends Genet. 2008;24: 457-466.

563. Munirajan AK, Ando K, Mukai A, et al. KIF1Bbeta functions as a haploinsufficient tumor suppressor gene mapped to chromosome 1 p36.2 by inducing apoptotic cell death. $J$ Biol Chem. 2008;283: 24426-24434.

564. Opavsky R, Tsai SY, Guimond M, et al. Specific tumor suppressor function for E2F2 in Myc-induced T cell lymphomagenesis. Proc Natl Acad Sci U S A. 2007;104:15400-15405.

565. Huang N, Lee I, Marcotte EM, Hurles ME. Characterising and predicting haploinsufficiency in the human genome. PLoS Genet. 2010;6:e1001154.

566. Emerit I, Keck M, Levy A, Feingold J, Michelson AM. Activated oxygen species as the origin of chromosome breakage and sister chromatid exchange. Mutat Res. 1982;103:165-172.

567. Blakeborough MH, Owen RW, Bilton RF. Free radical generating mechanisms in the colon: Their role in the induction and promotion of colorectal cancer? Free Radic Res Commun. 1989;6: 359-367.

568. Babbs CF. Free radicals and the etiology of colon cancer. Free Radic Biol Med. 1990;8:191-200.

569. Emerit I. Reactive oxygen species, chromosome mutation and cancer. Possible role of clastogenic factors in carcinogenesis. Free Radic Biol Med. 1994;16:99-109.

570. Poulsen HE, Prieme H, Loft S. Role of oxidative DNA damage in cancer initiation and promotion. Eur J Cancer. 1998;7:9-16.

571. Balkwill F, Mantovani A. Inflammation and cancer: Back to Virchow? Lancet. 2001;357:539-545.
572. Jackson AL, Loeb AA. The contribution of endogenous sources of DNA damage to the multiple mutations in cancer. Mutat Res. 2001; 477:7-21.

573. Gackowski D, Banaszkiewicz Z, Rozalski R, Jawien A, Olinski R. Persistent oxidative stress in colorectal carcinoma patients. Int $J$ Cancer. 2002;101:395-397.

574. Klaunig JE, Kamendulis LM. The role of oxidative stress in carcinogenesis. Ann Rev Pharmacol Toxicol. 2004;44:239-267.

575. Valko M, Izakovic M, Mazur M, Rhodes CJ, Telser J. Role of oxygen radicals in DNA damage and cancer incidence. Mol Cell Biochem. 2004;266:37-56.

576. Storz P. Reactive oxygen species in tumor progression. Front Biosci. 2005;10:1881-1896.

577. Kundu JK, Surh YJ. Inflammation: Gearing the journey to cancer. Mutat Res. 2008;659:15-30.

578. Colotta F, Allavena P, Sica A, Garlanda C, Mantovani A. Cancerrelated inflammation, the seventh hallmark of cancer: Links to genetic instability. Carcinogenesis. 2009;30:1073-1081.

579. Sheridan J, Wang LM, Tosetto M, et al. Nuclear oxidative damage correlates with poor survival in colorectal cancer. Br J Cancer. 2009; 100:381-388

580. Chang CL, Marra G, Chauhan DP, et al. Oxidative stress inactivates the human DNA mismatch repair system. Am J Physiol Cell Physiol. 2002;283:C148-C154.

581. Song JY, Lim JW, Kim H, Morio T, Kim KH. Oxidative stress induces nuclear loss of DNA repair proteins $\mathrm{Ku} 70$ and $\mathrm{Ku} 80$ and apoptosis in pancreatic acinar AR42J cells. J Biol Chem. 2003;278: 36676-36687.

582. Berwick M, Vineis P. Markers of DNA repair and susceptibility to cancer in humans: An epidemiologic review. $J$ Natl Cancer Inst. 2000;92:874-897.

583. Loeb KR, LA Loeb. Genetic instability and the mutator phenotype. Studies in ulcerative colitis. Am J Pathol. 1999;154:1621-1626.

584. Schonfeld P, Wojtczak L. Fatty acids as modulators of the cellular production of reactive species. Free Radic Biol Med. 2008;45: 231-241.

585. Lovis P, Roggli E, Laybutt DR, et al. Alterations in microRNA expression contribute to fatty acid-induced pancreatic $\beta$-cell dysfunction. Diabetes. 2008;57:2728-2736.

586. Washo-Stultz D, Crowley-Weber CL, Dvorakova K, et al. Role of mitochondrial complexes I and II, reactive oxygen species and arachidonic acid metabolism in deoxycholate-induced apoptosis. Cancer Lett. 2002;177:129-144.

587. Payne, CM, Weber C, Crowley-Skillicorn C, et al. Deoxycholate induces mitochondrial oxidative stress and activates NF-kB through multiple mechanisms in HCT-116 colon epithelial cells. Carcinogenesis. 2007;28:215-222.

588. Washo-Stultz D, Hoglen N, Bernstein H, Bernstein C, Payne CM. Role of nitric oxide and peroxynitrite in bile salt-induced apoptosis. Nutr Cancer. 1999;35:180-188.

589. Dall'Agnol M, Bernstein C, Bernstein H, Garewal H, Payne CM. Identification of S-nitrosylated proteins after chronic exposure of colonic epithelial cells to deoxycholate. Proteomics 2006;6: 1654-1662.

590. Bernstein H, Holubec H, Bernstein C, et al. Unique dietary-related mouse model of colitis. Inflamm Bowel Dis. 2006;12:278-293.

591. Payne CM, Holubec H, Bhattacharyya AK, Bernstein C, Bernstein H. Exposure of mouse colon to dietary bile acid supplement induces sessile adenomas. Inflamm Bowel Dis. 2009;16:729-730.

592. Bernstein C, Holubec H, Bhattacharyya AK, et al. Carcinogenicity of deoxycholate, a secondary bile acid. Arch Toxicol. 2011; doi 10.1007/ s00204-011-0648-7.

593. Holubec H, Payne CM, Bernstein H, et al. Assessment of apoptosis by immunohistochemical markers compared to cellular morphology in ex vivo-stressed colonic mucosa. J Histochem Cytochem. 2005; $53: 229-235$ 
594. Payne CM, Crowley C, Washo-Stultz D, et al. The stress-response proteins poly(ADP-ribose) polymerase and NF- $\mathrm{KB}$ protect against bile salt-induced apoptosis. Cell Death Differ. 1998;5:623-636.

595. Payne CM, Crowley-Skillicorn C, Bernstein C, Holubec H, Moyer MP, Bernstein H. Hydrophobic bile acid-induced micronuclei formation, mitotic perturbations, and decreases in spindle checkpoint proteins: Relevance to genomic instability in colon carcinogenesis. Nutr Cancer. 2010;62:825-840.

596. Knisely AS, Strautnieks SS, Meier Y, et al. Hepatocellular carcinoma in ten children under five years of age with bile salt export pump deficiency. Hepatol. 2006;44:478-486.

597. Jansen PLM. Endogenous bile acids as carcinogens. Rev Hepatol. 2007:47:434-435.

598. Payne CM, Crowley-Skillicorn C, Holubec H, et al. Deoxycholate, an endogenous cytotoxin/genotoxin, induces the autophagic stresssurvival pathway: Implications for colon carcinogenesis. $J$ Toxicol. 2009; article ID 785907:1-14; doi: 10.1155/2009/785907.

599. Crowley-Weber CL, Payne CM, Gleason-Guzman M, et al. Development and molecular characterization of colon cell lines resistant to the tumor promoter and multiple stress-inducer, deoxycholate. Carcinogenesis. 2002;23:2063-2080.

600. Giovannucci E. Meta-analysis of coffee consumption and risk of colorectal cancer. Am J Epidemiol. 1998;147:1043-1052.

601. Tavani A, La Vecchia C. Coffee and cancer: A review of epidemiological studies, 1990-1999. Eur J Cancer Prev. 2000;9:241-256.

602. Tavani A, La Vecchia C. Coffee, decaffeinated coffee, tea and cancer of the colon and rectum: A review of epidemiological studies, 1990-2003. Cancer Causes Control. 2004;15:743-757.

603. Michels KB, Willett WC, Fuchs CS, Giovannucci E. Coffee, tea, and caffeine consumption and incidence of colon and rectal cancer. $J$ Natl Cancer Inst. 2005;97:282-292.

604. Mattila P, Kumpulainen J. Determination of free and total phenolic acids in plant-derived foods by HPLC with diode-array detection. J Agric Food Chem. 2002;50:3660-3667.

605. Han Y, Haraguchi T, Iwanaga S, et al. Consumption of some polyphenols reduces fecal deoxycholic acid and lithocholic acid, the secondary bile acids of risk factors of colon cancer. $J$ Agric Food Chem. 2009;57:8587-8590.

606. Shibata A, Kamada N, Masumura K, et al. Parp-1 deficiency causes an increase of deletion mutations and inserions/rearrangements in vivo after treatment with an alkylating agent. Oncogene. 2005;24: 1328-1337.

607. Crowley C, Payne CM, Bernstein H, Bernstein C, Roe D. The NAD precursors, nicotinic acid and nicotinamide protect cells against apoptosis induced by a multiple stress inducer, deoxycholate. Cell Death Differ. 2000;7:314-326.

608. Yan Q, Briehl M, Crowley CL, Payne CM, Bernstein H, Bernstein C. The $\mathrm{NAD}^{+}$precursors, nicotinic acid and nicotinamide upregulate glyveraldehyde-3-phosphate dehydrogenase and glucose-6-phosphate dehydrogenase mRNA in Jurkat cells. Biochem Biophys Res Comm. 1999;255:133-136.

609. Zaki I, Millard L. Pellagra complicating Crohn's disease. Postgrad Med J. 1995;71:496-497.

610. Kiran RP, Khoury W, Church JM, Lavery IC, Fazio VW, Remzi FH. Colorectal cancer complicating inflammatory bowel disease: Similarities and differences between Crohn's and ulcerative colitis based on three decades of experiemce. Ann Surg. 2010;252:330-335.

611. D'Odorico A, Bortolan S, Cardin R, et al. Reduced plasma antioxidant concentrations and increased oxidative DNA damage in inflammatory bowel disease. Scand J Gastroenterol. 2001;36:1289-1294.

612. Pollack S, Enat R, Haim S, Zinder O, Barzilai D. Pellagra as the presenting manifestation of Crohn's disease. Gastroenterol. 1982; 82(5 Pt 1):948-952.

613. Abu-Qurshin R, Naschitz JE, Zuckermann E, Nash E, Eldar S, Yeshurun D. Crohn's disease associated with pellagra and increased excretion of 5-hydroxyindolacetic acid. Am J Med Sci. 1997;313: 111-113.
614. Martinez-A C, van Wely KH. Are aneuploidy and chromosome breakage caused by a CINgle mechanism? Cell Cycle. 2010;9: 2275-2280.

615. Sawyer JR, Swanson CM, Koller MA, North PE, Ross SW. Centromeric instability of chromosome 1 resulting in multi-branched chromosomes, telomeric fusion, and "jumping translocations" of 1q in a human immunodeficiency virus-related non-Hodgkin's lymphoma. Cancer. 1995;76:1238-1244.

616. Sawyer JR, Husain M, Pravdenkova S, Krisht A, Al-Mefty O. A role for telomeric and centromeric instability in the progression of chromosome aberrations in meningioma patients. Cancer. 2000;88:440-453.

617. Raimondi SC, Ragsdale ST, Behm F, Rivera G, Williams DL. Multiple telomeric associations of a trisomic whole $\mathrm{q}$ arm of chromosome 1 in a child with acute lymphoblastic leukemia. Cancer Genet Cytogenet. 1987;47:87-93.

618. Almeida A, Kokalj-Vokac N, Lefrancois D, et al. Hypomethylation of classical satellite DNA and chromosomal instability in lymphoblastoid cell lines. Hum Genet. 1993;91:538-546.

619. Kokalj-Vokac N, Almeida A, Viegas-Pequignot E, Jeanpierre M, Malfoy B, Dutrillaux B. Specific induction of uncoiling and recombination by azacytidine in classical satellite-containing constitutive heterochromatin. Cytogenet Cell Genet. 1993;63:11-15.

620. Sawyer JR, Tricot G, Mattox S, Jagannath S, Barlogie B. Jumping translocations of chromosome 1q in multiple myeloma: Evidence for a mechanism involving decondensation of pericentromeric heterochromatin. Blood. 1998;91:1732-1741.

621. Vukovic B, Beheshti B, Park P, et al. Correlating breakage-fusion-bridge events with the overall chromosomal instability and in vitro karyotype evolution in prostate cancer. Cytogenet Genome Res. 2007;116:1-11.

622. Robbins AR, Jablonski SA, Yen TJ, et al. Inhibitors of histone deacetylases alter kinetochore assembly by disrupting pericentromeric heterochromatin. Cell Cycle. 2005;4:717-726.

623. Demuth I, Digweed M, Concannon P. Human SNM1B is required for normal cellular response to both DNA interstrand crosslinkinducing agents and ionizing radiation. Oncogene. 2004;23: $8611-8618$

624. Ye J, Lenain C, Bauwens S, et al. TRF2 and Apollo cooperate with topoisomerase $2 \alpha$ to protect human telomeres from replicative damage. Cell. 2010;142:230-242.

625. Nagothu KK, Jaszewski R, Moragoda L, et al. Folic acid mediated attenuation of loss of heterozygosity of DCC tumor suppressor gene in the colonic mucosa of patients with colorectal adenomas. Cancer Detect Prevent. 2003;27:297-304.

626. Wang X, Thomas P, Xue J, Fenech M. Folate deficiency induces aneuploidy in human lymphocytes in vitro-evidence using cytokinesisblocked cells and probes specific for chromosomes 17 and 21. Mutat Res. 2004;551:167-180.

627. Fenech M, Crott JW. Micronuclei, nucleoplasmic bridges and nuclear buds induced in folic acid deficient human lymphocytes - evidence for breakage-fusion-bridge cycles in the cytokinesis-block micronucleus assay. Mutat Res. 2002;504:131-136.

628. Lindberg HK, Wang X, Jarventaus H, Falck GC, Norppa H, Fenech M. Origin of nuclear buds and micronuclei in normal and folate-deprived human lymphocytes. Mutat Res. 2007;617:33-45.

629. Choi S-W, Mason JB. Folate status: Effects on pathways of colorectal carcinogenesis. J Nutr. 2002;132:2413S-2418S.

630. Kim YI. Folate and colorectal cancer: An evidence-based critical review. Mol Nutr Food Res. 2007;51:267-292.

631. Majumdar AP, Kodali U, Jaszewski R. Chemopreventive role of folic acid in colorectal cancer. Front Biosci. 2004;9:2725-2732.

632. Kim J, Kim DH, Lee BH, et al. Folate intake and the risk of colorectal cancer in a Korean population. Eur J Clin Nutr. 2009;63: 1057-1064.

633. Duthie SJ. Folate and cancer: How DNA damage, repair and methylation impact on colon carcinogenesis. J Inherit Metab Dis. 2011;34:101-109. 
634. Blount BC, Mack MM, Wehr CM, et al. Folate deficiency causes uracil misincorporation into human DNA and chromosome breakage: Implications for cancer and neuronal damage. Proc Natl Acad Sci US A. 1997;94:3290-3295.

635. Choi SW, Kim YI, Weitzel JN, Mason JB. Folate depletion impairs DNA excision repair in the colon of the rat. Gut. 1998;43:93-99.

636. Marsit CJ, Eddy K, Kelsey KT. MicroRNA responses to cellular stresses. Cancer Res. 2006;66:10843-10848.

637. Levine AJ, Siegmund KD, Ervin CM, et al. The methylenetetrahydrofolate reductase $677 \mathrm{C} \rightarrow \mathrm{T}$ polymorphism and distal colorectal adenoma risk. Cancer Epidemiol Biomark Prev. 2000;9:657-663.
638. Kawakami K, Omura K, Kanehira E, Watanabe G. Methylenetetrahydrofolate reductase polymorphism is associated with folate pool in gastrointestinal cancer tissue. Anticancer Res. 2001;21: 285-289.

639. Little J, Sharp L, Duthie S, Narayanan S. Colon cancer and genetic variation in folate metabolism: the clinical bottom line. J Nutr. 2003; 133:3758S-3766S

640. Chang SC, Lin PC, Lin JK, Yang SH, Wang HS, Li AF. Role of MTHFR polymorphisms and folate levels in different phenotypes of sporadic colorectal cancers. Int J Colorectal Dis. 2007;22: 483-489.

\section{Publish your work in this journal}

Clinical and Experimental Gastroenterology is an international, peerreviewed, open access journal, publishing all aspects of gastroenterology in the clinic and laboratory, including: Pathology, pathophysiology of gastrointestinal disease; Investigation and treatment of gastointestinal disease; Pharmacology of drugs used in the alimentary tract;
Immunology/genetics/genomics related to gastrointestinal disease. This journal is indexed on CAS. The manuscript management system is completely online and includes a very quick and fair peer-review system. Visit http://www.dovepress.com/testimonials.php to read real quotes from published authors.

Submit your manuscript here: http://www.dovepress.com/clinical-and-experimental-gastroenterology-journal 